Provided for non-commercial research and educational use only. Not for reproduction, distribution or commercial use.

This chapter was originally published in the book, Handbook of the Economics of Innovation-Vol-II, published by Elsevier, and the attached copy is provided by Elsevier for the author's benefit and for the benefit of the author's institution, for noncommercial research and educational use including without limitation use in instruction at your institution, sending it to specific colleagues who know you, and providing a copy to your institution's administrator.

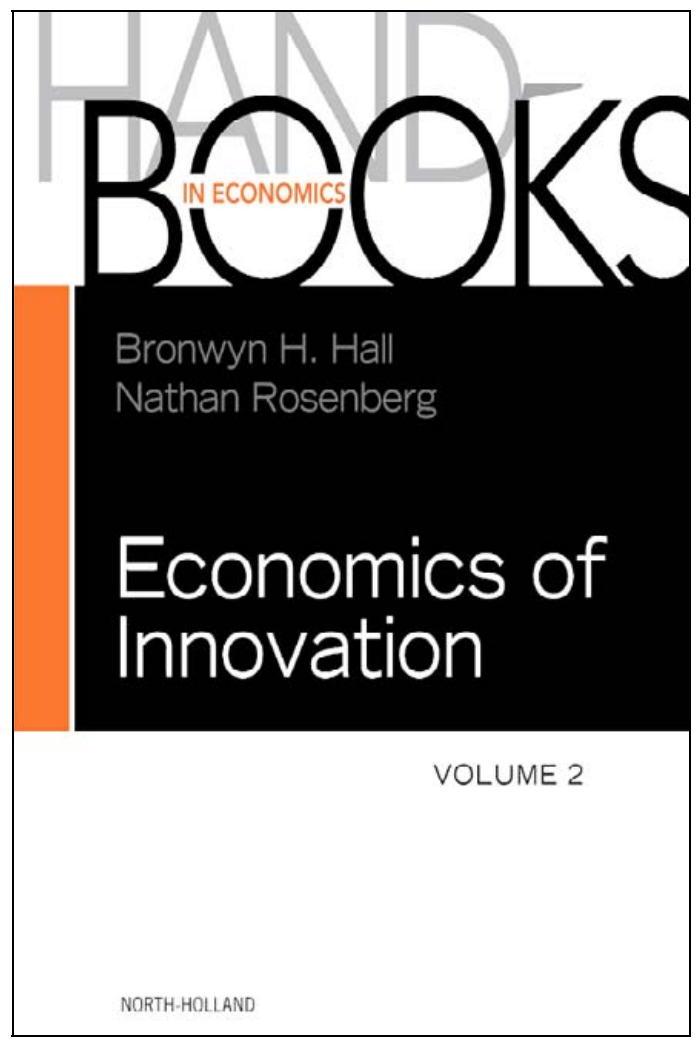

All other uses, reproduction and distribution, including without limitation commercial reprints, selling or licensing copies or access, or posting on open internet sites, your personal or institution's website or repository, are prohibited. For exceptions, permission may be sought for such use through Elsevier's permissions site at: http://www.elsevier.com/locate/permissionusematerial

From: David Popp, Richard G. Newell, and Adam B. Jaffe, Energy, the Environment, and Technological Change, In Bronwyn H. Halland and Nathan Rosenberg:

Handbook of the Economics of Innovation-Vol-II, Burlington: Academic Press, 2010, pp.873-938. ISBN: 978-0-444-53609-9,

(C) Copyright 2010 Elsevier BV, Academic Press. 
Chapter 21

\section{ENERGY, THE ENVIRONMENT, AND TECHNOLOGICAL CHANGE}

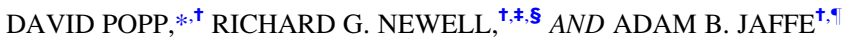

*Department of Public Administration

Center for Policy Research

The Maxwell School, Syracuse University

Syracuse New York, USA

$\mathbf{t}_{\text {National Bureau of Economic Research }}$

Cambridge, Massachusetts, USA

${ }^{\ddagger}$ Gendell Associate Professor of Energy and Environmental Economics

Nicholas School of the Environment

Duke University

Durham, North Carolina, USA

$\mathbf{\S}_{\text {Resources for the Future }}$

Washington, District of Columbia, USA

${ }^{\top}$ Fred C. Hecht Professor in Economics

College of Arts and Sciences, Brandeis University

Waltham, Massachusetts, USA

\section{Contents}

Abstract

Keywords

1. Introduction

2. Key concepts

2.1. Fundamentals of environmental economics

2.2. The economics of technological change

2.3. Implications for environmental and technology policy

3. Microeconomics: Innovation

3.1. Induced innovation

3.1.1. Empirical evidence on induced innovation in pollution abatement and energy conservation

3.1.2. Innovation and the choice of policy instrument

3.1.3. What can technological change economists contribute? 
3.2.2. Estimates of technological impact using LBD

3.2.3. Government R\&D $\quad 896$

$\begin{array}{ll}\text { 3.2.4. What can technological change economists contribute? } & 898\end{array}$

4. Microeconomics: Diffusion 899

4.1. Diffusion within countries $\quad 899$

4.1.1. Theoretical analyses $\quad 900$

4.1.2. Empirical studies $\quad 902$

4.1.3. What can technological change economists contribute? 910

4.2. Diffusion across countries 910

$\begin{array}{ll}\text { 4.2.1. What can technological change economists contribute? } & 915\end{array}$

5. Technological change in aggregate energy-environment models 915

5.1. Exogenous technological change 916

5.2. Endogenous technological change 917

$\begin{array}{ll}\text { 5.2.1. Direct price-induced technological change } & 919\end{array}$

$\begin{array}{lr}\text { 5.2.2. R\&D-induced technological change } & 920\end{array}$

$\begin{array}{ll}\text { 5.2.3. Learning-induced technological change } & 924\end{array}$

5.3. What can technological change economists contribute? 925

6. Conclusions 920

Acknowledgments 928

References $\quad 928$

\begin{abstract}
Within the field of environmental economics, the role of technological change has received much attention. The long-term nature of many environmental problems, such as climate change, makes understanding the evolution of technology an important part of projecting future impacts. Moreover, in many cases, environmental problems cannot be addressed, or can only be addressed at great cost, using existing technologies. Providing incentives to develop new environmentally friendly technologies then becomes a focus of environmental policy. This chapter reviews the literature on technological change and the environment. Our goals are to introduce technological change economists to how the lessons of the economics of technological change have been applied in the field of environmental economics, and suggest ways in which scholars of technological change could contribute to the field of environmental economics.
\end{abstract}

\title{
Keywords
}

climate change, diffusion, energy efficiency, induced innovation, pollution

JEL classification: O30, Q53, Q54, Q55 


\section{Introduction}

Within the field of environmental economics, the role of technological change has received much attention (Jaffe et al., 2003). The long-term nature of many environmental problems, such as climate change, makes understanding the evolution of technology an important part of projecting future policy impacts. Environmental technologies include technologies that reduce pollution at the end of the pipe, such as scrubbers for use on industrial smokestacks or catalytic converters for automobiles. They also include changes to the production process, such as improved energy efficiency, that lead to reduced environmental impacts. Because the benefits of environmental technologies tend to accrue to society at large, rather than the adopter of such technologies, market forces alone provide little incentive for developing environmental technologies. Instead, environmental regulation or public funding of research and development $(\mathrm{R} \& \mathrm{D})$ often provides the first impetus for developing new environmental technologies. These induced effects of environmental policy on technology may have substantial implications for the normative analysis of policy decisions. Indeed, in many cases, environmental problems cannot be addressed, or can only be addressed at great cost, using existing technologies. As a result, understanding the interactions between environmental policy and technology may have quantitatively important consequences in the context of cost-benefit or cost-effectiveness analyses of such policies.

Understanding the environmental impact of overall technological change is also important to assess the long-term sustainability of economic growth. The environmental impact of economic activity is profoundly affected by the rate and direction of technological change. Costs tend to fall, quality tends to improve, and a wider variety of technologies tend to become available as time passes. New technologies may create or facilitate increased pollution, or may mitigate or replace existing polluting activities. Further, because many environmental problems and policy responses are evaluated over time horizons of decades or centuries, the cumulative impact of technological changes is likely to be large. Indeed, uncertainty about the future rate and direction of technological change is often an important sensitivity in forecasts of the severity of environmental problems.

This is best illustrated by the example of climate change, in which different assumptions about the potential for future technological change lead to greatly different assessments about both the potential for reducing carbon emissions and the optimal rate at which such reductions should occur. For instance, in its latest report on climate change, the Intergovernmental Panel on Climate Change (IPCC) reports estimates of the costs of stabilizing global carbon concentrations from a variety of climate models. To stabilize concentrations at a level of 550 parts per million ( $\mathrm{ppm})$, the estimated costs, in terms of lost GDP in the year 2050, range from a $4 \%$ loss to a slight increase in GDP, relative to baseline growth (IPCC, 2007). Projections of future technological change are an important driver of these differences, and affect not only the cost of reducing emissions, but also predictions of what emission levels will occur in the absence of climate policy initiatives.

This chapter reviews the literature on technological change and the environment. This is a large task, inevitably requiring unfortunate but necessary omissions. In particular, we confine ourselves to the relationship between technology and problems of environmental pollution, leaving aside a large literature on technological change in agriculture and natural resources more broadly. Because of the significant environmental implications of fossil fuel combustion, we include in our review some of the relevant literature on technological change and energy use, with a focus on the environmental impacts of energy use. Our goals in this chapter are to both introduce technological change economists to how 
lessons from the study of technological change that have been applied in the field of environmental economics, and to suggest ways in which scholars of technological change might contribute to the field of environmental economics.

\section{Key concepts ${ }^{1}$}

\subsection{Fundamentals of environmental economics}

Economic analysis of environmental policy is based on the idea that the potentially harmful consequences of economic activities on the environment constitute an "externality," an economically significant effect of an activity, the consequences of which are borne (at least in part) by a party or parties other than the party that controls the externality-producing activity. A factory that pollutes the air, water, or land imposes a cost on society. The firm that owns the factory has an economic incentive to use only as much labor or steel as it can productively employ, because those inputs are costly to the firm. The cost to society of having some of its labor and steel used up in a given factory is internalized by the firm, because it has to pay for those inputs. But the firm does not have an economic incentive to minimize the external costs of pollution.

Environmental policies attempt to equalize this imbalance by raising the incentive for a firm to minimize these externalities. Policy choices accomplish this in one of two general ways-either by financially internalizing the environmental costs so polluters make their own decisions regarding their consumption of environmental inputs, or by imposing a limit on the level of environmental pollution.

The cost of environmental policies could be in the form of decreased output of desired products (e.g., a scrubber on an electric power plant reduces its electricity production from a given quantity of fuel), increased use of other variable inputs (e.g., eliminating certain gases from the waste stream in a smokestack may require more fuel to be burned and require additional labor to maintain pollutioncontrol equipment), purchase of specialized pollution-control equipment (e.g., catalytic converters on automobiles), or substitution of inferior or more expensive products or production methods to avoid pollution-causing products or methods (e.g., less effective pesticides used when DDT was banned).

In the short run, setting an efficient environmental policy requires a comparison of the marginal cost of reducing pollution with the marginal benefit of a cleaner environment. All else being equal, emissions of pollutants that are very harmful should be greatly restricted, because the pollutants otherwise produce large marginal costs to society. But, all else being equal, emissions of pollutants that are very costly to eliminate should be tolerated, because the marginal cost of reducing them is high.

When technology enters the equation, the terms of the trade-off between the marginal cost of pollution control and its marginal social benefit is altered. In particular, technology innovationssuch as new pollution-control equipment, cleaner production methods, or new substitutes for environmentally harmful products-typically reduce the marginal cost of achieving a given unit of pollution reduction. These innovations may also change the shape or the slope of these marginal costs. In most cases, technological change enables a specified level of environmental cleanup to be achieved at lower

1 This section draws considerably from Jaffe et al. (2005). 
total cost to society. New innovations also make it possible for a lower total level of pollution to be attained more efficiently than would be expected if the cost of cleanup were higher.

The ability of technology to lower environmental cleanup costs has influenced much research in environmental economics. Initially, these questions focused on the ability of environmental policy to shape the direction of technological change. In the absence of environmental policy, firms have little incentive to install cleaner technologies or develop better environmental technologies for future use. ${ }^{2}$ This can lead early, prepolicy predictions of the net benefits of environmental regulation to be lower than evaluations after the fact, as newly developed technologies lower the costs of complying with regulation (Harrington et al., 2000). More recently, environmental economists have paid increasing attention to estimating the rate at which technology improves, as well as the role of technology policy itself to supplement the effects of environmental policy.

\subsection{The economics of technological change}

As environmental economic research on technological change has grown, the importance of considering market failures for knowledge, as well as traditional environmental externalities, has been emphasized. In particular, calls for increased government support for environmentally friendly R\&D are motivated by the need to overcome such market failures. As these should be familiar to technological change scholars, we only briefly mention these here, with an emphasis on the importance of these lessons for environmental models.

The generation of knowledge through the innovative process contrasts sharply with the negative externalities from pollution. Because of the public goods nature of knowledge, a firm that invests in or implements a new technology typically creates benefits for others while incurring all the costs. The firm therefore lacks the incentive to increase those benefits by investing in technology. Pollution creates a negative externality, and so the invisible hand of the market allows too much of it. Technology creates positive externalities, and so the invisible hand of the market produces too little of it. As such, even if policies to correct the environmental externalities are in place, the level of environmental R\&D will still be suboptimal. Because they ignore the positive spillovers created by $R \& D$, firms will underinvest in research activity.

Uncertainty is also an issue for innovation. While all investment is characterized by uncertainty, the uncertainty associated with the returns to investment in innovation is often particularly large. Not only is the variance of the distribution of expected returns much larger than for other investments, but much or even most of the value may be associated with very low probability but very high value outcomes (Scherer et al., 2000). Uncertainty may prove particularly problematic for environmental policy, as the technologies needed to comply with proposed regulations may evolve in unexpected ways once policy is in place, making it difficult for regulators to anticipate the true costs of compliance.

\footnotetext{
2 The assumption here, and through much of the literature on environmental innovation, is that any resulting environmental benefits are a pure public good. Exceptions occur when the benefits are impure public goods, in which some, but not all, of the benefits of the good go to the user of technology. An example is energy efficiency improvements, for which there is an incentive even absent direct environmental policy, due to the positive price of energy. However, as reducing energy consumption also benefits the environment through lower pollution, energy prices themselves will not encourage efficient usage and development of energy efficiency technologies unless the associated environmental externalities have been fully priced.
} 
More recently, economists have come to understand additional market failures that may operate in the adoption and diffusion of new technology. For a number of reasons, the cost or value of a new technology to one user may depend on how many other users have adopted the technology. In general, users will be better off the more other people use the same technology. This benefit associated with the overall scale of technology adoption has sometimes been referred to as "dynamic increasing returns," which may be generated by learning-by-using, learning-by-doing (LBD), or network externalities. Thus, just like the creation of the technology itself, information about the performance of a technology has an important public goods component.

Finally, adoption of new technologies may be hindered by principal-agent problems, as when a builder or landlord chooses the level of investment in energy efficiency in a building, but the energy bills are paid by a later purchaser or a tenant. If the purchaser has incomplete information about the magnitude of the resulting energy savings, the builder or landlord may not be able to recover the cost of such investments, and hence might not undertake them. These market failures with respect to adoption of new technology are part of the explanation for the apparent "paradox" of underinvestment in energy-saving technologies that appear cost-effective but are not widely utilized (Gillingham et al., 2009; Jaffe and Stavins, 1994; Newell et al., 2004).

\subsection{Implications for environmental and technology policy}

The combination of environmental externalities and knowledge market failures provide two hurdles for policy makers to address when providing incentives for environmental innovation, and suggests two possible avenues through which policy can encourage the development of environmentally friendly technologies: correcting the environmental externality and/or correcting knowledge market failures. At a minimum, effective long-run environmental policies require both. Because knowledge market failures apply generally across technologies, policies addressing knowledge market failures may be general, addressing the problem in the economy as a whole, such as patent protection, $\mathrm{R} \& \mathrm{D}$ tax credits, and funding for generic basic research. Such policies focus on the overall rate of innovation-how much innovative activity takes place. In contrast, policies aimed specifically at the environment focus on the direction of innovation. While this includes policies regulating externalities, such as a carbon tax or cap-and-trade system, it also includes environmental and energy policies using more general $R \& D$ policy mechanisms with a specific focus on the environment. Technology policies specific to energy include targeted government subsidies for adoption of alternative energy, and funding for targeted basic and applied research.

Studies evaluating the effectiveness of these various policy options find that environmental and technology policies work best in tandem. While technology policy can help facilitate the creation of new environmentally friendly technologies, it provides little incentive to adopt these technologies. Fischer (2008) develops a theoretical model showing that government support for emissions control R\&D is only effective if there is at least moderate environmental policy in place to encourage adoption of the resulting technologies. Using a computable general equilibrium model to study the potential effects of energy R\&D for climate change mitigation, Schneider and Goulder (1997) show that policies to address knowledge spillovers are more effective if they address all knowledge spillovers, rather than focusing exclusively on R\&D pertaining to alternative energy. Not surprisingly, technology subsidies alone have a smaller environmental impact than policies that directly address the environmental externality. 
Popp (2006a) considers the long-run welfare gains from both an optimally designed carbon tax (one equating the marginal benefits of carbon reductions with the marginal costs of such reductions) and optimally designed R\&D subsidies. Popp finds that combining both policies yields the largest welfare gain. However, a policy using only the carbon tax achieves $95 \%$ of the welfare gains of the combined policy, while a policy using only the optimal R\&D subsidy attains just $11 \%$ of the welfare gains of the combined policy in his model. In contrast to Schneider and Goulder, R\&D policy has less effect in this study, as the subsidies only apply to the energy sector.

Given the importance of emissions policies to encourage R\&D, two recent papers ask whether initial emissions policies should be made stronger, in order to achieve lower costs through an initial burst of induced innovation. Using a growth model, Hart (2008) shows that, in general, it is not optimal to raise an emissions' tax above the level necessary to account for the environmental externality. One exception is if the shadow price of the emissions' stock is rising and the initial level of emissions-saving knowledge is low. In this case, the spillovers from emissions-savings knowledge will be more valuable than spillovers from other innovations, justifying a temporary increase in the optimal emissions tax to account for differences in the social benefits of spillovers across technologies. Presumably a targeted R\&D subsidy could also accomplish this, and perhaps with greater efficiency. Greaker and Pade (2008) find additional justification for higher emissions taxes if patent policy is weak - that is, as a second-best policy if the knowledge market spillover has not been adequately addressed.

The above studies focus on the macro level, and assume that technologies, once created, are optimally deployed. Fischer and Newell (2008) use a microapproach to study a broader set of policies, including those encouraging technology adoption, to assess policies for reducing carbon dioxide $\left(\mathrm{CO}_{2}\right)$ emissions and promoting innovation and diffusion of renewable energy. They evaluate the relative performance of policies according to incentives provided for emissions reduction and economic efficiency, and also assess how the nature of technological progress (i.e., learning vs. R\&D) and the degree of knowledge spillovers affect the desirability of different policies. Although the relative cost of individual policies in achieving emissions reductions depends on parameter values and the emissions target, in a numerical application to the US electricity sector, they find the ranking is roughly as follows: (1) emissions price, (2) emissions performance standard, (3) fossil power tax, (4) renewables share requirement, (5) renewables subsidy, and (6) R\&D subsidy. Nonetheless, an optimal portfolio of policies-including emissions pricing and $R \& D$ - achieves emission reductions at significantly lower cost than any single policy.

In a similar exercise, Gerlagh and van der Zwaan (2006) find an emissions performance standard to be cheapest policy for achieving various carbon stabilization goals. They note that, like a carbon tax, the emissions performance standard directly addresses the environmental externality. In addition, like a renewable subsidy, the emissions performance standard stimulates innovation in a sector with high spillovers. In comparing the results of these two papers, Gerlagh and van der Zwaan note that the ordering of policies depends on the assumed returns to scale of renewable energy technologies. Fischer and Newell assume greater decreasing returns to renewable energy, due to the scarcity of appropriate sites for new renewable sources. Thus, an important question raised by Gerlagh and van der Zwaan is whether the cost savings from innovation will be sufficient to overcome decreasing returns to scale for renewable energy resulting from limited space for new solar and wind installations.

An additional problem resulting from the long time frame of environmental concerns such as climate change is uncertainty over future policies. Consider, for example, a firm planning research on fuel cells for cars. Given that such technologies are not currently competitive with traditional fuel sources, and that 
sufficient policies are not in place to overcome these cost differences, what matters to the firm is not the effective price of carbon emissions today. Rather, it is the expected price of carbon emissions a decade or more in the future, when the vehicle might actually be on the market. Such long-term issues arise often when studying problems such as climate change, and raise the question of whether additional policy measures are needed that (1) enable the government to manipulate expectations of future prices or (2) perform the initial research necessary to get ground-breaking technologies close to market, thus lowering the cost (and raising political support for) future environmental policy. That is, one can look at this question as whether environmental policy should come first, and be designed in a way to encourage long-run innovation, or whether technology policy needs to accompany or precede environmental policy, so as to lower the costs of implementing environmental cleanup. A related concern is the credibility of governments to use the promise of high future emissions prices to boost current innovation, since such high prices may no longer be needed once the resulting cost reductions arrive (Kennedy and Laplante, 1999; Montgomery and Smith, 2007).

General purpose technologies (GPT) may also magnify the interaction between the two market failures. GPTs are technologies that find use in many distinct application sectors within the economy, such as the electric motor, the steam engine, the internal combustion engine, semiconductors, and the Internet (Bresnahan and Trajtenberg, 1995). The development of such technologies increases the returns to $\mathrm{R} \& \mathrm{D}$ designed to incorporate them into the different applications sectors; development of such applications in turn increases the return to improving the GPT. Because of these dynamic feedback effects, GPTs may be an important factor in economic growth (Helpman, 1998). The dynamic feedback between a GPT and its applications sectors also creates an important example of "path dependence." With respect to the environment, whether the GPTs that drive a particular era are pollution-intensive or pollution-saving may have profound implications for the long-term environmental prognosis. These phenomena can be critical to understanding the existing technological system, forecasting how that system might evolve, and predicting the potential effect of some policy or event.

\section{Microeconomics: Innovation}

Most investigations of technological change in environmental economics have been at the microeconomic level. As is typical in the field of technological change, these studies can be divided into two broad categories - those focusing on invention and innovation, and those focusing on diffusion. As described in Section 2, the externality problem in environmental economics complicates the process of environmentally friendly technological change, as market forces provide insufficient incentive for either the creation or adoption of such technologies absent environmental policies. Thus, much research has focused on how environmental policy affects the incentives for both the creation and adoption of environmental technology. This section reviews the literature linking environmental policy and innovation. We discuss the diffusion of environmental technologies in Section 4.

\subsection{Induced innovation}

Better understanding the links between environmental policy and technological change has been a major research agenda in environmental economics. Much of this literature draws its motivation from the notion of induced innovation, which recognizes that $R \& D$ is a profit-motivated investment activity and 
that the direction of innovation likely responds positively in the direction of increased relative prices. Since environmental policy implicitly or explicitly makes environmental inputs more expensive, the "induced innovation" hypothesis suggests an important pathway for the interaction of environmental policy and technology, and for the introduction of impacts on technological change as a criterion for evaluation of different policy instruments. First articulated by Hicks (1932), for further background on induced innovation theory and evidence see Jaffe et al. (2003), Binswanger and Ruttan (1978), and Thirtle and Ruttan (1987). For a recent review of empirical literature on the impacts of alternative policy instruments on technological change see Vollebergh (2007).

In the environmental literature, the relationship between innovation and policy has been explored under two broad themes. Early work focused on theoretical models to compare the effects of various environmental policy mechanisms (e.g., uniform standards, emissions taxes, or tradable permits) on environmentally friendly innovation. These papers tend to predict that market-based policies, such as a tax or tradable permit, will induce more environmentally friendly innovation than a commandand-control policy, although recent papers have shown that a precise ranking is theoretically ambiguous and dependent on a number of factors (see Fischer et al., 2003 and Section 3.1.2). Empirical studies of the links between environmental policy and innovation were initially limited by a lack of data. Recently, as measures of innovative activity such as patents have become more readily available, empirical economists have begun to estimate the effects that prices and environmental policies have on environmentally friendly innovation. We discuss each of these streams of research below.

\subsubsection{Empirical evidence on induced innovation in pollution abatement and energy conservation}

Increased availability of data pertaining to innovation, such as patent counts and R\&D expenditures, has facilitated much research on induced environmental innovation. The remaining challenge in testing the induced innovation hypothesis for environmental technologies is the difficulty of measuring the extent or intensity of inducement across firms or industries (Jaffe et al., 1995). Ideally, one would like to look at the relationship between innovation and the shadow price of pollution or environmental inputs. In practice, such shadow prices are not easily observed. Consequently, one must use proxies for this shadow price, such as characteristics of environmental regulations, expenditures on pollution abatement, or prices of polluting inputs (e.g., energy prices). Table 1 summarizes the key papers in this literature.

The first empirical studies made use of pollution abatement control expenditures (PACE) to proxy for environmental regulatory stringency. Jaffe and Palmer (1997) examine the correlation between PACE by industry and indicators of innovation more broadly. They find that there is a significant correlation within industries over time between the rate of expenditure on pollution abatement and the level of $R \& D$ spending. They do not, however, find evidence of an effect of pollution-control expenditure on overall patenting. Hamamoto (2006) finds similar effects on R\&D spending in Japan. Brunneimer and Cohen (2003) estimate the relationship between PACE and environmental patents across various US industries. They find that patents increase by just $0.04 \%$ when PACE increases by $\$ 1$ million.

One limitation of these papers is that they do not take advantage of the disaggregated nature of patent data. Each looks at innovation within specific industries. Jaffe and Palmer include all patents associated with an industry, whether or not they are environmental technologies, and Hamamoto includes all R\&D activities, not just those focused on the environment. Brunnermeier and Cohen focus specifically on 
Table 1

Empirical studies of environmental induced innovation

\begin{tabular}{|c|c|c|c|c|}
\hline Article & What is induced? & What causes innovation? & Data & Key results \\
\hline $\begin{array}{l}\text { Lanjouw and Mody } \\
\text { (1996) }\end{array}$ & Environmentally friendly patents & $\begin{array}{l}\text { Pollution abatement costs } \\
\text { and expenditures (PACE) }\end{array}$ & $\begin{array}{l}\text { US, Japan, Germany, } \\
14 \text { other countries }\end{array}$ & $\begin{array}{l}\text { PACE leads increase in } \\
\text { environmentally friendly } \\
\text { innovation }\end{array}$ \\
\hline $\begin{array}{l}\text { Jaffe and Palmer } \\
\text { (1997) }\end{array}$ & Overall R\&D spending/patents & PACE & US industry 1974-1991 & $\begin{array}{l}\text { PACE affects R\&D spending, but } \\
\text { not patenting activity }\end{array}$ \\
\hline Newell et al. (1999) & Energy-efficiency technologies & $\begin{array}{l}\text { Regulatory standards } \\
\text { energy price changes }\end{array}$ & $\begin{array}{l}\text { Appliance characteristics } \\
\text { and energy price } 1958- \\
1993\end{array}$ & $\begin{array}{l}\text { Energy prices and regulatory } \\
\text { standards affect energy-efficiency } \\
\text { innovation }\end{array}$ \\
\hline Popp (2002) & $\begin{array}{l}\text { Energy and energy-efficiency } \\
\text { technologies }\end{array}$ & $\begin{array}{l}\text { Price of fossil fuels } \\
\text { existing knowledge stock }\end{array}$ & $\begin{array}{l}\text { US energy patents } \\
1970-1994\end{array}$ & $\begin{array}{l}\text { Both energy prices and the } \\
\text { existing knowledge stock induce } \\
\text { R\&D }\end{array}$ \\
\hline $\begin{array}{l}\text { Brunneimer and } \\
\text { Cohen (2003) }\end{array}$ & Environmental patents & PACE & US industry & $\begin{array}{l}\text { PACE has small effects on } \\
\text { patents }(0.04 \% / \$ 1 \text { million })\end{array}$ \\
\hline Hamamoto (2006) & Overall R\&D spending & PACE & $\begin{array}{l}\text { Japanese industry } \\
1966-1976\end{array}$ & $\begin{array}{l}\text { PACE leads to increased R\&D } \\
\text { expenditures }\end{array}$ \\
\hline Popp (2006b) & $\begin{array}{l}\mathrm{SO}_{2} \text { and } \mathrm{NO}_{X} \text { emission reduction } \\
\text { patents }\end{array}$ & $\begin{array}{l}\text { Environmental } \\
\text { regulations }\end{array}$ & $\begin{array}{l}\text { US, Japan, Germany } \\
\text { patents, 1970-2000 }\end{array}$ & $\begin{array}{l}\text { Environmental regulations } \\
\text { significantly increase } \mathrm{SO}_{2} \text { and } \\
\mathrm{NO}_{X} \text { reduction patents }\end{array}$ \\
\hline Hascic et al. (2008) & $\begin{array}{l}\text { Patents for five environmental } \\
\text { technology: air pollution, water } \\
\text { pollution, wastes disposal, noise } \\
\text { protection, and environmental } \\
\text { monitoring }\end{array}$ & $\begin{array}{l}\text { PACE and environmental } \\
\text { stringency }\end{array}$ & $\begin{array}{l}\text { PACE expenditures } \\
\text { 1985-2004 and World } \\
\text { Economic Forum survey }\end{array}$ & $\begin{array}{l}\text { Private PACE leads to } \\
\text { environmental innovation but } \\
\text { government PACE does not. } \\
\text { However, governmental R\&D } \\
\text { promotes increase of } \\
\text { environmental patents }\end{array}$ \\
\hline
\end{tabular}


environmental technologies, but group several such technologies together for each industry. Thus, effects of innovation on specific technologies may be masked by stagnant trends in other technologies. Research focusing on specific technologies finds stronger effects. For instance, Lanjouw and Mody (1996) use the International Patent Classification (IPC) to identify several key environmental patent classes. Using patent data from the United States, Japan, Germany, and 14 low- and middle-income countries, they find that environmentally friendly innovation increases as pollution abatement cost expenditures in the country increase. Hascic et al. (2008) study the effect of environmental policy stringency on patenting activity for five different types of environmental technology-air pollution, water pollution, waste disposal, noise protection, and environmental monitoring. Using both PACE expenditures and a World Economic Forum survey of top management business executives as alternative measures of environmental stringency, they find that private expenditures on pollution control lead to greater environmental innovation, but not government expenditures on pollution control. However, higher levels of government environmental R\&D do lead to more environmental patents. Popp (2006b) finds significant increases in patents pertaining to sulfur dioxide and nitrogen oxides emissions reduction in response to the passage of environmental regulations in the United States, Japan, and Germany.

Evidence of inducement has also been sought by examining the response to changing energy prices. Similar to Lanjouw and Mody, Popp (2002) uses patent classifications to identify 11 different alternative energy and energy-efficiency technologies. Using a distributed lag model, Popp estimates the elasticity of energy patenting activity with respect to energy prices for these technologies. The distributed lag model is consistent with an adaptive expectations model of prices, in which expected future prices depend on a weighted average of past prices. The regression controls for the quality of knowledge available to an inventor as well as other factors influencing $R \& D$, such as government support for energy research and technology-specific demand shifters. ${ }^{3}$ Using this framework, Popp finds a long-run elasticity of energy patenting with respect to energy prices of 0.354 . From the distributed lag model, the mean lag occurs in 3.71 years, and the median lag in 4.86 years. The interpretation here is that over one-half of the full effect of an energy price increase on patenting will have been experienced after just 5 years. Thus, prices (or other regulations that increase the cost of using fossil fuels) can be expected to stimulate new research quickly.

Popp attributes the gradual decrease in induced innovation over time to diminishing returns. Furthermore, Popp (2002) shows that controlling for diminishing returns to research within a specific field does affect induced innovation estimates. To verify the importance of the existing knowledge stock on innovative activity, Popp uses citation data to create stocks of existing patented knowledge, where patents in the stock are weighted by their propensity to be cited. He finds that the stocks have a significant positive effect on energy patenting. Moreover, Popp $(2002,2006 \mathrm{c})$ finds evidence that the likelihood of citations to new energy patents falls over time, suggesting that the quality of knowledge available for inventors to build upon also falls. ${ }^{4}$ The intuition here is that, as more and more discoveries

\footnotetext{
${ }^{3}$ For example, for patents on using waste products as energy, the price utilities pay to purchase waste products for fuel is included in the regression. This figure captures the increased supply of waste that became available as fuel owing to concerns about declining landfill space during the 1980s.

${ }^{4}$ Note that since the probability of a patent being cited depends not only on the quality of the patent, but also on the number of patents that follow, it is important to look at probability of citation, rather than raw citation counts.
} 
are made, it gets harder to develop a new innovation that improves upon the existing technology. Since the quality of the knowledge stock is an important determinant of the level of innovative activity, decreasing quality of the knowledge stock over time means that diminishing returns to R\&D investment will result in lower levels of induced $R \& D$ over time. Moreover, because prior research affects the potential success of future inventors, the returns to research should vary along with the quality of the existing pool of research, rather than monotonically over time.

To verify the value of using patent citation data to measure the returns to research, Popp (2002) also includes regressions in which the stock of knowledge is replaced by a time trend. If diminishing returns proceed monotonically over time, a negative time trend should work as well as the weighted knowledge stocks. That, however, is not the case. These regressions prove unreliable. In fact, the elasticity of energy $R \& D$ to energy prices appears negative when a time trend is used in place of the knowledge stocks. Since diminishing returns are a bigger problem when the level of energy R\&D is highest, not controlling for this counteracts the positive effect of prices on energy R\&D. This may also explain the small effects of environmental policy on patenting activity found by Brunneimer and Cohen (2003).

Environmental economists have also studied induced innovation by decomposing changes in energy efficiency into changes due to price-based substitution and changes due to innovation. Newell et al. (1999) examine the extent to which the energy efficiency of the menu of home appliances available for sale changed in response to energy prices between 1958 and 1993, using an econometric model of induced innovation as changing characteristics of capital goods. Hicks formulated the induced innovation hypothesis in terms of factor prices. Newell et al. (1999) generalize this concept to include inducement by regulatory standards, such as labeling requirements that might increase the value of certain product characteristics by making consumers more aware of them. More generally, nonprice regulatory constraints can fit within the inducement framework if they can be modeled as changing the shadow or implicit price that firms face in emitting pollutants. In their framework, the existing technology for making a given type of equipment at a point in time is identified in terms of vectors of characteristics (including cost of manufacture) that are feasible. The process of invention makes it possible to manufacture "models" (characteristics vectors) that were previously infeasible. Innovation means the offering for commercial sale of a model that was not previously offered for sale. Induced innovation is then represented as movements in the frontier of feasible models that reduce the cost of energy efficiency in terms of other attributes.

By constructing a series of dynamic simulations, they examine the effects of energy price changes and efficiency standards on average efficiency of the menu of products over time. They find that a substantial amount of the improvement was what may be described as autonomous (i.e., associated with the passage of time), but significant amounts of innovation are also due to changes in energy prices and changes in energy-efficiency standards. They find that technological change in air conditioners was actually biased against energy efficiency in the 1960s (when real energy prices were falling), but that this bias was reversed after the two energy shocks of the 1970s. In terms of the efficiency of the average model offered, they find that energy efficiency in 1993 would have been about one-quarter to one-half lower in air conditioners and gas water heaters, if energy prices had stayed at their 1973 levels, rather than following their historical path. Most of the response to energy price changes came within less than 5 years of those changes. Illustrating the importance of information, they find that the effect of energy price increases on model substitution was strongest after product labeling requirements took effect. 


\subsubsection{Innovation and the choice of policy instrument}

The empirical studies on induced innovation provide some insight as to the pace of environmental innovation. Also important, however, is the nature of such innovation. Early theoretical work on environmental innovation focused on the incentives provided by different types of environmental policy. Environmental policies can be characterized as either uniform "command-and-control" standards or market-based approaches. Market-based instruments are mechanisms that encourage behavior through market signals rather than through explicit directives regarding pollution-control levels or methods. Such regulations allow firms flexibility to choose the least-cost solutions to improved environmental performance. In contrast, conventional approaches to regulating the environment are often referred to as "command-and-control" regulations, since they allow relatively little flexibility in the means of achieving goals. These regulations tend to force firms to take on similar magnitudes of the pollution-control burden, regardless of the cost. Command-and-control regulations do this by setting uniform standards for firms. The most commonly used types of command-and-control regulation are performance- and technology-based standards. A performance standard sets a uniform control target for firms (e.g., emissions per unit of output), while allowing some latitude in how this target is met. Technology-based standards specify the method, and sometimes the actual equipment, that firms must use to comply with a particular regulation.

Holding all firms to the same target can be expensive and, in some circumstances, counterproductive. While standards may effectively limit emissions of pollutants, they typically exact relatively high costs in the process, by forcing some firms to resort to unduly expensive means of controlling pollution. Because the costs of controlling emissions may vary greatly among firms, and even among sources within the same firm, the appropriate technology in one situation may not be cost-effective in another.

All of these forms of intervention have the potential for inducing or forcing some amount of technological change, because by their very nature they induce or require firms to do things they would not otherwise do. Performance and technology standards can be explicitly designed to be "technology forcing," mandating performance levels that are not currently viewed as technologically feasible or mandating technologies that are not fully developed. One problem with these approaches, however, is that while regulators can typically assume that some amount of improvement over existing technology will always be feasible, it is impossible to know how much. Standards must either be made unambitious, or else run the risk of being ultimately unachievable, leading to political and economic disruption (Freeman and Haveman, 1972).

Technology standards are particularly problematic, since they can freeze the development of technologies that might otherwise result in greater levels of control. Under regulations that are targeted at technologies, as opposed to emissions levels, no financial incentive exists for businesses to exceed control targets, and the adoption of new technologies is discouraged. However, there is still an incentive for equipment cost reduction. Under a "Best Available Control Technology" (BACT) standard, a business that adopts a new method of pollution abatement may be "rewarded" by being held to a higher standard of performance and thereby not benefit financially from its investment, except to the extent that its competitors have even more difficulty reaching the new standard (Hahn and Stavins, 1991). On the other hand, if third parties can invent and patent better equipment, they can-in theory-have a ready market. Under such conditions, a BACT type of standard can provide a positive incentive for technology innovation. 
In contrast with such command-and-control regulations, market-based instruments can provide powerful incentives for companies to adopt cheaper and better pollution-control technologies. This is because with market-based instruments, it always pays firms to clean up a bit more if a sufficiently lowcost method (technology or process) of doing so can be identified and adopted. The advantages of market-based policies are particularly true for flexible policies that allow the innovator to identify the best way to meet the policy goal. For instance, a carbon tax allows innovators to choose whatever technologies best reduce carbon emissions, whereas a tax credit for wind power focuses innovative efforts on wind power at the expense of other clean energy technologies.

Most papers on the effect of different environmental policy instruments on innovation are theoretical in nature. In addition, these papers pay greater attention to the supply side, focusing on incentives for firm-level decisions to incur R\&D costs in the face of uncertain outcomes. These papers are summarized in Table 2. We defer a discussion of papers analyzing the effect of policy on technology adoption and diffusion to Section 4 of this chapter.

Theory The earliest work that is directly relevant is by Magat (1978), who compares effluent taxes and CAC standards using an innovation possibilities frontier model of induced innovation, where research can be used to augment capital or labor in a standard production function. He compares the output rate, effluent rate, output-effluent ratio, and bias (in terms of labor or capital augmenting technical change), but produced ambiguous results. Subsequently, Magat (1979) compares taxes, subsidies, permits, effluent standards, and technology standards, and shows that all but technology standards would induce innovation biased toward emissions reduction. In Magat's model, if taxes and permits are set so that they lead to the same reduction in emissions as an effluent standard at all points in time, then the three instruments provide the same incentives to innovate.

Taking a somewhat broader view than most economic studies, Carraro and Siniscalaco (1994) suggest that environmental policy instruments should be viewed jointly with traditional industrial policy instruments in determining the optimal way to attain a given degree of pollution abatement. They show that innovation subsidies can be used to attain the same environmental target as other policy instruments, but without the output reductions that result from pollution taxes. Laffont and Tirole (1996) examine how a tradable permit system could - in theory-be modified to achieve desired incentive effects for technological change. They demonstrate that although spot markets for permits cannot induce the socially optimal degree of innovation, futures markets can improve the situation.

Cadot and Sinclair-Desgagne (1996) consider a potentially regulated industry that has private information on the costs of technological advances in pollution control, as is frequently the case. Since the industry has an incentive to claim that such technologies are prohibitively expensive (even if that is not the case), can the government somehow design an incentive scheme that will avoid the problems of this information asymmetry? The authors develop a solution to this game-theoretic problem involving government-issued threats of regulation (which diminish over time as the firm completes stages of technology development).

It was only recently that theoretical work followed up on Magat's attempt in the late 1970s to rank policy instruments according to their innovation-stimulating effects. Fischer et al. (2003) find that an unambiguous ranking of policy instruments was not possible. Rather, the ranking of policy instruments was shown by the authors to depend on the innovator's ability to appropriate spillover benefits of new 
Table 2

Key theoretical papers on innovation and environmental policy instruments

\begin{tabular}{|c|c|c|}
\hline Article & Policies & Key results \\
\hline Magat (1978) & Effluent taxes, uniform standards & Ranking is ambiguous \\
\hline Magat (1979) & $\begin{array}{l}\text { Taxes, subsidies, permits, effluent standards, } \\
\text { technology standards }\end{array}$ & $\begin{array}{l}\text { All except technology standards induce innovation. Taxes, permits, and } \\
\text { effluent standard have similar effects }\end{array}$ \\
\hline $\begin{array}{l}\text { Carraro and Siniscalaco } \\
\text { (1994) }\end{array}$ & $\begin{array}{l}\text { Environmental policy instruments, industrial policy } \\
\text { instruments }\end{array}$ & $\begin{array}{l}\text { Innovation subsidies have the same effects as environmental policy } \\
\text { instruments, except for emissions reduction from pollution taxes }\end{array}$ \\
\hline Laffont and Tirole (1996) & Tradable permit system & Futures markets for permits lead to innovation \\
\hline $\begin{array}{l}\text { Cadot and Sinclair- } \\
\text { Desgagne (1996) }\end{array}$ & Incentive scheme & $\begin{array}{l}\text { Government-issued threats of regulation can be a solution for } \\
\text { information asymmetry }\end{array}$ \\
\hline $\begin{array}{l}\text { Carraro and Soubeyran } \\
\text { (1996) }\end{array}$ & Emission tax and R\&D subsidy & $\begin{array}{l}\mathrm{R} \& \mathrm{D} \text { subsidies are desirable if decrease of product output is small or } \\
\text { considered negative }\end{array}$ \\
\hline $\begin{array}{l}\text { Katsoulacos and } \\
\text { Xepapadeas (1996) }\end{array}$ & Tax and environmental R\&D subsidy & Tax and subsidy together can overcome the market failure \\
\hline Ulph (1998) & Pollution taxes, uniform standards & $\begin{array}{l}\text { Stricter standards and taxes do not have significant effect on R\&D level. } \\
\text { There are two competing effects: policies increase costs (and R\&D), but } \\
\text { also lower output (which decreases R\&D) }\end{array}$ \\
\hline Montero (2002) & $\begin{array}{l}\text { Various policy instruments under noncompetitive } \\
\text { environments }\end{array}$ & $\begin{array}{l}\text { Types of market affect the level of R\&D incentives from standards and } \\
\text { taxes. Cournot competition leads to higher incentive while Bertrand } \\
\text { competition leads to lower incentive }\end{array}$ \\
\hline Innes and Bial (2002) & Environmental regulation, firm's behavior & $\begin{array}{l}\text { Technology leaders favor stricter environmental regulations, as these } \\
\text { policies raise the costs of competitors }\end{array}$ \\
\hline Fischer et al. (2003) & Market-based policies, uniform standards & $\begin{array}{l}\text { Ranking is ambiguous, and depends on ability to diffuse technologies, } \\
\text { cost, and number of polluting firms }\end{array}$ \\
\hline Requate (2005) & $\begin{array}{l}\text { Ex post regulation, interim regulation, ex ante } \\
\text { regulation (with different tax rates), ex ante } \\
\text { regulation (with a single tax rate) }\end{array}$ & $\begin{array}{l}\text { Ex ante policies with different tax rates dominate, and tax policies are } \\
\text { always preferred to permit policies }\end{array}$ \\
\hline $\begin{array}{l}\text { Baker and Adu-Bonnah } \\
(2008)\end{array}$ & $\begin{array}{l}\text { Alternative energy with no carbon emission, } \\
\text { conventional energy with efficiency improvement }\end{array}$ & $\begin{array}{l}\text { With uncertainty, stringency of policy matters. With weak } \\
\text { environmental policy, improvements in conventional energy efficiency } \\
\text { are acceptable. However, strong standards require alternative energy } \\
\text { (no carbon emissions) }\end{array}$ \\
\hline Bauman et al. (2008) & Market-based policies, uniform standards & $\begin{array}{l}\text { If command-and-control policies lead to innovation which changes the } \\
\text { slope of the marginal abatement cost curve, they may induce more } \\
\text { innovation than market-based policies }\end{array}$ \\
\hline
\end{tabular}


technologies to other firms, the costs of innovation, environmental benefit functions, and the number of firms producing emissions.

The basic model consists of three stages. First, an innovating firm decides how much to invest in R\&D by setting its marginal cost of innovation equal to the expected marginal benefits. Second, polluting firms decide whether or not to adopt the new technology, use an (inferior) imitation of it, or do nothing. Finally, firms minimize pollution-control expenditures by setting their marginal costs equal to the price of pollution. Policy instruments affect the innovation incentives primarily through three effects: (1) an abatement cost affect, reflecting the extent to which innovation reduces the costs of pollution control; (2) an imitation effect, which weakens innovation incentives due to imperfect appropriability; and (3) an emissions payment effect, which can weaken incentives if innovation reduces firms' payments for residual emissions. The relative strength of these effects will vary across policy instruments and particular applications, with no instrument clearly dominating in all applications.

In an analysis that is quite similar in its results to the study by Fischer et al. (2003), Ulph (1998) compares the effects of pollution taxes and command-and-control standards, and finds that increases in the stringency of the standard or tax had ambiguous effects on the level of R\&D, because environmental regulations have two competing effects: a direct effect of increasing costs, which increases the incentives to invest in $\mathrm{R} \& \mathrm{D}$ in order to develop cost-saving pollution-abatement methods; and an indirect effect of reducing product output, which reduces the incentive to engage in R\&D. Carraro and Soubeyran (1996) compare an emission tax and an R\&D subsidy, and found that an R\&D subsidy is desirable if the output contractions induced by the tax are small or if the government finds output contractions undesirable for other reasons. Addressing the same trade-off, Katsoulacos and Xepapadeas (1996) find that a simultaneous tax on pollution emissions and subsidy to environmental R\&D may be better suited to overcoming the joint market failure (negative externality from pollution and positive externality or spillover effects of $R \& D)$.

Montero (2002) compares instruments under noncompetitive circumstances, and finds that the results are less clear than when perfect competition is assumed. He models a two-firm oligopoly facing environmental regulation in the form of emissions standards, freely allocated permits, auctioned permits, and taxes. Firms can invest in R\&D to lower their marginal abatement costs, and they can also benefit from spillover effects from the other firm's R\&D efforts. In choosing whether and how much to invest in R\&D in order to maximize profits, a firm must consider two effects of its investment choice: (1) the increase in profits due to a decrease in its abatement costs (less the R\&D cost) and (2) the decrease in profits due to changes in the other firm's output, as a result of spillover from the first firm's $R \& D$. The result is that standards and taxes yield higher incentives for $R \& D$ when the market is characterized by Cournot competition, but the opposite holds when the market is characterized by Bertrand competition.

Addressing a policymaker's choice of the level of environmental regulation, Innes and Bial (2002) start with the observation that firms often overcomply with environmental regulation. They explain this behavior using a model of Bertrand competition. In such a model, a successful innovator may prefer stricter environmental standards so as to raise costs for rival firms. An environmental tax that is efficient ex post (e.g., after a new innovation is revealed) also provides incentives for overinvestment in $\mathrm{R} \& \mathrm{D}$, as firms hope to gain profits by being the first to invent an environmental technology that will affect regulatory levels and impose costs on other firms. Innes and Bial show that discriminatory standards for technology "winners" and "losers" can offset incentives for overinvestment. For example, regulators 
can offer noninnovating firms a lower emissions reduction target or additional time to comply with regulatory changes. If the policy levels are optimally set, technology winners still have incentive to overcomply with environmental regulation, as their profits exactly equal the social gains from their innovation.

Noting that the stringency of an optimal policy may change after new abatement technologies become available, Requate (2005) asks when policy adjustments should be made. The model considers a monopolistic provider of environmental technology that performs $R \& D$ in response to environmental regulation, and a set of competitive firms who purchase environmental equipment when required by law. The paper considers four policy options: ex post regulation after adoption of new technology, interim regulation after observing $\mathrm{R} \& \mathrm{D}$ success but before adoption, ex ante regulation with different tax rates contingent on $R \& D$ success, and ex ante regulation with a single tax rate whether or not $R \& D$ is successful. In this model, ex ante commitment with different tax rates dominates all other policies, and tax policies are always superior to permit policies.

A recent paper by Bauman et al. (2008) raises the possibility that command-and-control policies may induce more innovation under certain scenarios. They note that the results of previous models follow when innovation lowers the marginal abatement cost curve. However, these papers assume end-of-pipe solutions to pollution reduction, such as installing a scrubber on a smokestack. For end-of-pipe solutions, the marginal cost of no abatement is zero, so that a marginal abatement cost curve starts at the origin. In such cases, innovation always results in lower marginal abatement costs. However, pollution can also be reduced by changing processes, such as using cleaner fuel or using a more efficient boiler. In such cases, innovation may make the marginal abatement cost steeper. For instance, if a plant plans to reduce emissions by shutting down temporarily, it will forego more output (and profit) when it is using a more efficient boiler. In these cases, the marginal abatement cost curve after innovation will not be unambiguously below the original marginal abatement cost curve. Should that occur, commandand-control standards may provide greater incentive for innovation than market-based policies. Note, however, that their analysis is positive rather than normative in nature and does not directly address the traditional view that market-based policies are overall more efficient than command-and-control.

Finally, Baker and Adu-Bonnah (2008) show that the way in which technological change affects the shape of the marginal abatement cost curve also affects R\&D decisions made under uncertainty. Their model considers both uncertainty about future climate damages (and thus the optimal level of abatement needed) and uncertainty about the likelihood of success for various energy research projects. $R \& D$ investment affects the probability that a project will be successful. They consider two types of energy R\&D projects: alternative energy that emits no carbon and efficiency improvements for conventional fossil fuel energy sources. For alternative energy $R \& D$, technological improvements unambiguously lower the cost of reducing carbon emissions (e.g., shift marginal abatement costs down). In this case, the socially optimal investment in technologies is higher for riskier projects. However, the opposite is true for research on conventional energy technologies, for which technological change rotates the marginal abatement cost curve. For low levels of abatement, improvements to conventional technologies, such as increased fuel efficiency, lower abatement costs. However, if high levels of abatement are required, simply improving energy efficiency will not be sufficient-alternative clean energy sources will need to replace traditional fossil fuel sources of energy. In this case, improvements in the efficiency of conventional technologies raise the marginal abatement cost, as they raise the opportunity cost of eliminating fossil fuels. In such a case, optimal R\&D investment is higher for less-risky R\&D projects. 
These projects have a higher probability of success, but will only have moderate efficiency gains. However, moderate efficiency gains will have a large impact on the economy, since fossil fuels are widely used. In contrast, the payoff from risky R\&D projects with larger efficiency gains is not as high. Efficiency gains are most valuable under low climate damage scenarios. If climate damages are high, energy-efficiency gains will have little value, since fossil fuels will not be used. Thus, the need for energy-efficiency breakthroughs is not as high as the need for breakthroughs for alternative energy.

Empirical evidence Empirically, there is little work that compares innovation under different policy types. Table 3 summarizes these papers. One exception is Popp (2003), which compares innovation before and after $\mathrm{SO}_{2}$ permit trading began in the United States. This paper combines patent data with plant-level data on flue gas desulfurization (FGD) units, or "scrubbers," to compare innovation before and after passage of the 1990 Clean Air Act (CAA). Popp finds that the level of innovation, measured by the number of successful patent applications, by year, for FGD units was actually higher before tradable sulfur dioxide $\left(\mathrm{SO}_{2}\right)$ permits were introduced by the 1990 CAA. However, the nature of innovation changed after passage of the Act. Before the 1990 CAA, most new coal-fired electric utilities were required to install FGD units with a removal efficiency of $90 \%$. Since installation of FGD units was mandatory, innovation focused on reducing the operating costs of these units. However, since there were no incentives for firms to exceed the $90 \%$ limit, innovation had no effect on the removal efficiency of FGD units. In contrast, because the 1990 CAA required greater $\mathrm{SO}_{2}$ emissions reductions and gave firms' flexibility as to how to meet those goals, post-1990 innovations did have the effect of improving the removal efficiency of scrubbers. Similarly, Taylor et al. (2003) note that the scrubber requirement led to a reduction in patents on precombustion techniques for reducing $\mathrm{SO}_{2}$ emissions, such as cleaner coal. However, Taylor (2008) notes that, since most pollution-control innovators are third-party equipment vendors, rather than the regulated firms, uncertainty over how regulated firms will react to permits (and thus uncertainty over the ultimate permit price) reduces innovation incentives from permit trading vis- $a$-vis other policy instruments.

In contrast, Bellas (1998) finds no evidence of progress in scrubber technology. However, his study only includes plants from 1970 to 1991 . Thus, the analysis only considers plants under the commandand-control policy regime. In more recent work, Lange and Bellas (2005) update this research by estimating the effect of scrubber characteristics on both capital and operating costs of scrubbers installed before and after the 1990 CAA. The permit trading system of the 1990 CAA provided, for the first time, incentives for older plants to install scrubbers. This expanded the market for scrubbers, which, they argue, should increase incentives for technological change. Indeed, Lange and Bellas find that both capital and operating expenses drop for scrubbers installed after the 1990 CAA took effect. However, they find this drop to be a discrete event — costs are lower after the 1990 CAA, but the rate of change in costs does not change. While they find no evidence of cost differences between scrubbers installed under the 1970 CAA and the 1977 CAA (which mandated installation of scrubbers at plants built beginning in 1978), they do not explicitly address whether costs change over time during this period.

Addressing the value of flexible standards, Lanoie et al. (2007) use a survey of firms in seven OECD (Organization of Economic Cooperation and Development) countries to examine the effect of various environmental policy instruments on environmental R\&D. Respondents were asked to describe both the type of environmental policies faced, as well as the stringency of such policies. They find that greater stringency does induce a firm to perform more environmental R\&D. More flexible performance 
Table 3

Key empirical papers on innovation and environmental policy instruments

\begin{tabular}{|c|c|c|c|}
\hline Article & Policies & Data & Key results \\
\hline Newell et al. (1999) & $\begin{array}{l}\text { Energy price-based } \\
\text { policies, energy- } \\
\text { efficiency standards, } \\
\text { labeling }\end{array}$ & $\begin{array}{l}\text { Appliance model characteristics and energy } \\
\text { prices } 1958-1993\end{array}$ & $\begin{array}{l}\text { Energy price changes lead to the introduction of } \\
\text { new technologies in the market and removal of old } \\
\text { models, while regulation works only by eliminating } \\
\text { old models }\end{array}$ \\
\hline Popp (2003) & $\begin{array}{l}\mathrm{SO}_{2} \text { permits, direct } \\
\text { regulation }\end{array}$ & US coal-fired power plants $1985-1997$ & $\begin{array}{l}\text { CAC innovation led to cost savings. Innovation } \\
\text { with permit trading led to both cost savings and } \\
\text { emissions reductions }\end{array}$ \\
\hline Lange and Bellas (2005) & Clean air act & US coal-fired power plants $1985-2002$ & $\begin{array}{l}\text { Permit trading system lead to lower capital and } \\
\text { operating costs. Mandatory regulation alone does } \\
\text { not promote change in costs }\end{array}$ \\
\hline Lanoie et al. (2007) & $\begin{array}{l}\text { Environmental policy } \\
\text { instruments, } \\
\text { environmental R\&D }\end{array}$ & Survey of firms in seven OECD countries & $\begin{array}{l}\text { For inducing environmental } R \& D \text {, stringency of } \\
\text { policies is more important than policy type }\end{array}$ \\
\hline Johnstone et al. (2008) & $\begin{array}{l}\text { Environmental policy } \\
\text { instruments, } \\
\text { environmental R\&D }\end{array}$ & $\begin{array}{l}\text { EPO pollution-control patents to OECD } \\
\text { countries, 1978-2004 }\end{array}$ & $\begin{array}{l}\text { Flexible policies lead to higher quality innovations } \\
\text { (measured by patent family size) }\end{array}$ \\
\hline Taylor (2008) & $\begin{array}{l}\mathrm{SO}_{2} \text { permits, direct } \\
\text { regulation }\end{array}$ & US patents $1975-2004$ & $\begin{array}{l}\text { Uncertainty over future permit prices reduces } \\
\text { innovation incentives for third-party producers }\end{array}$ \\
\hline Johnstone et al. (2010) & $\begin{array}{l}\text { Price-based policies, } \\
\text { quantity-based policies }\end{array}$ & $\begin{array}{l}\text { EPO renewable energy technology patents } \\
\text { from } 25 \text { OECD countries, 1978-2003 }\end{array}$ & $\begin{array}{l}\text { Price-based policies lead to solar and waste-to- } \\
\text { energy technologies, while quantity-based policies } \\
\text { lead to wind energy (closest to current energy } \\
\text { market) }\end{array}$ \\
\hline
\end{tabular}


standards, which dictate an acceptable level of environmental performance without dictating how that level be achieved, induce more environmental $R \& D$ than technology standards, which require the use of a specific technology to meet regulatory targets. Surprisingly, being exposed to market-based environmental policies does not induce greater environmental R\&D. One explanation given for this result is that when market-based policies are used, they may be less stringent than other environmental standards. In related work, Johnstone and Hascic (2008) show that flexible environmental regulations lead to higher quality innovation. Using a World Economic Forum survey of business executives, they show that environmental patents have larger family sizes when executives in the inventor's home country perceive that there is greater freedom to choose different options in order to achieve compliance with environmental regulations.

There is a more extensive literature on the effects of alternative policy instruments on the innovation of energy-efficiency and alternative energy technologies. The innovation process can be thought of as affecting improvements in the characteristics of products on the market, and the process can be framed as the shifting inward over time of a frontier representing the trade-offs between different product characteristics for the range of models available on the market. If one axis is the cost of the product and another axis is the energy flow associated with a product, that is, its energy intensity, then innovation is represented by inward shifts of the curve-greater energy efficiency at the same cost, or lower cost for given energy efficiency. With this approach, Newell et al. (1999) assess the effects of changes in energy prices and in energy-efficiency standards in stimulating innovation. Energy price changes induced both commercialization of new models and elimination of old models. Regulations, however, worked largely through energy-inefficient models being dropped, since that is the intended effect of the energyefficiency standards (models below a certain energy-efficiency level may not be offered for sale).

Finally, Johnstone et al. (2010) use a panel of patent data on renewable energy technologies across 25 OECD countries to examine the effect of different policy instruments on innovation. They compare price-based policies such as tax credits and feed-in tariffs ${ }^{5}$ to quantity-based policies such as renewable energy mandates. They find important differences across technologies. Quantity-based policies favor development of wind energy. Of the various alternative energy technologies, wind has the lowest cost and is closest to being competitive with traditional energy sources. As such, when faced with a mandate to provide alternative energy, firms focus their innovative efforts on the technology that is closest to market. In contrast, direct investment incentives are effective in supporting innovation in solar and waste-to-energy technologies, which are further from being competitive with traditional energy technologies. These results suggest particular challenges to policy makers who wish to encourage long-run innovation for technologies that have yet to near market competitiveness.

\subsubsection{What can technological change economists contribute?}

Studying the links between environmental policy and innovation is one of the most active areas in environmental economics. Still, there are unanswered questions where technological change economists could contribute. In particular, many of the empirical studies above use aggregate data, typically at the level of an industry or a technology. More micro-oriented studies that concentrate on firm behavior would be of particular use. Such questions that might be addressed in such studies include where

${ }^{5}$ Feed-in tariffs, used in various European countries, guarantee renewable energy producers a minimum price for the electricity they produce. 
environmental R\&D comes from (e.g., does environmental policy lead firms to perform new $R \& D$, or to shift research efforts from other areas toward the environment) and which types of firms are best able to deliver environmental innovations. For instance, research on the effects of firm size and/or market structure on innovation, which has received much attention from technological change economists, has yet to enter significantly into environmental economics. This may be particularly important for energy, where market power and deregulation have both been important. For example, Sanyal (2007) finds that deregulation of electric utility markets has led to a decrease in R\&D in the industry. More research developing a better understanding of these differences across firms could help policy makers design incentives appropriate for specific industries.

The role of expectations has also not received significant attention in the literature on environmental technological change. Incentives to innovate require beliefs about the future returns to innovation. For environmental problems, those future returns depend on the policies that will be in place. To what extent can policy makers both provide current incentives for innovation and signal the future costs of pollution to inventors? Are current policy instruments sufficient to address the uncertainties and long time frames often observed with environmental problems? Understanding the ways in which policy can manipulate expectations of future energy and emissions prices and policy would be a fruitful avenue for future research.

\subsection{The impacts of technological change}

The research described in Section 3.1 focuses on the relationship between incentives (either market prices or policy) and the direction and level of technological change. In addition to these questions, another important research question is the effect of these new technologies on the environment. In the broader literature on technological change, economists consistently find that knowledge spillovers result in a wedge between private and social rates return to R\&D. Examples of such studies include Mansfield (1977, 1996), Pakes (1985), Jaffe (1986), Hall (1996), and Jones and Williams (1998). Typical results include marginal social rates of return between $30 \%$ and $50 \%$.

One would expect to find similar results in the environmental literature. However, two issues may complicate estimates of social returns on environmental R\&D. One is the twin market failure problem discussed in Section 2. The high social rates of return found in most studies of technological change occur as a result of imperfections in knowledge markets, such as spillovers. While these market failures are still an issue here, they are magnified by the externalities problem common in environmental economics. This complicates measuring the impact of environmental innovation, as the value of any resulting gains in environmental quality are difficult to quantify. For example, one could study how innovations benefit firms, either by lowering the cost of compliance with regulation (such as the paper by Bellas and Lange cited in Section 3.1.2), or, in the case of energy efficiency, by lowering the energy costs of firms or consumers. Such measures should give results analogous to those in the broader literature on technological change, but will give an incomplete measure of the social returns to environmental innovation, as they do not measure the value of environmental quality improvements that result. While there is a broad literature on measuring the benefits of environmental quality (see, e.g., Mäler and Vincent, 2005), these measures are often indirect, and have yet to be incorporated into studies on the return to environmental innovations. 


\subsubsection{Empirical evidence}

There has been exceptionally little empirical analysis of the effects that innovation has on the costs of pollution abatement, principally because of the paucity of available data. Carlson et al. (2000) look at changes in the marginal abatement costs at power plants, and find that about $20 \%$, or $\$ 50$, of the change in marginal abatement costs that have occurred from 1985 to 1995 can be attributed to technological change. Popp (2003) uses patent data to link innovative activity to lower operating costs of scrubbers for coal-fired electric power plants. Popp aggregates patents pertaining to scrubber innovations into a knowledge stock, and then regresses the operating costs of individual scrubbers on scrubber and plant characteristics, including the knowledge stock at the time the scrubber was installed. A single patent provides a present value of $\$ 6$ million in cost savings across the industry. Assuming approximately $\$ 1.5$ million of R\&D spent per patent granted, this yields a return similar to those found in the more general works cited above. However, these savings account only for the benefits to the power industry of lower environmental regulation compliance costs, as the social benefits of reduced sulfur dioxide emissions are not included in this estimate.

In contrast, the effects of innovation on energy efficiency have been studied more widely. In addition to the studies discussed in Section 3.1.2, Pakes et al. (1993) investigate the effects of gasoline prices on the fuel economy of motor vehicles offered for sale. They find that the observed increase in miles per gallon (mpg) from 1977 onward was largely due to the consequent change in the mix of vehicles on the market. Fewer low-mpg cars were marketed, and more high-mpg cars were marketed. Subsequently, Berry et al. (1996) combine plant-level cost data for the automobile industry and information on the characteristics of models that were produced at each plant to estimate a hedonic cost function-the supply-side component of the hedonic price function-finding that quality-adjusted costs generally increased over the period 1972-1982, thus coinciding with rising gasoline prices and emission standards.

One of the challenges of studying the effects of technology indirectly can be found by comparing empirical studies from different eras. Many studies use a time trend to represent technological change, so that the results are interpreted as the net effect of all technological change in a given period. For example, in a study of US industrial energy consumption from 1958 to 1974, Jorgenson and Fraumeni (1981) find that technological change was energy-using-energy use per unit output increased over time. Of course, the time period of their data would not include any of the energy-saving innovations developed after the energy crises of the 1970s. In contrast, more recent work using a time trend to capture technological change finds that technology is energy saving. Examples include Berndt et al. (1993), Mountain et al. (1989), and Sterner (1990).

As an alternative to using a time trend to represent technology, Popp (2001) uses energy patents to estimate the effect of new technology on energy consumption. Popp begins by matching energy patents with the industries that use the inventions by using the Yale Technology Concordance (Evenson et al., 1991; Kortum and Putnam, 1989, 1997). Using these patents, Popp creates stocks of energy knowledge, which are used as an explanatory variable in a system of cost functions for 13 energy-intensive industries. The knowledge stocks are defined as a cumulative function of the number of past energy patents used by each industry, adjusted for gradual decay and diffusion. Using these knowledge stocks in a cost function of energy usage, Popp finds that the median patent leads to $\$ 14.5$ million dollars in long-run energy savings. In comparison, these industries spend an average of $\$ 2.25$ million of R\&D per 
patent. In addition, using estimates of the elasticity of patenting with respect to energy prices for these technologies, Popp calculates the effect of induced innovation as the combined effect of all new patents induced by a $1 \%$ energy price increase. Interestingly, the estimated elasticities of energy use with respect to price found in that paper are lower than typically found, as they include only the effect of factor substitution, since technological change is controlled for separately. By comparison, rerunning the regressions using only a time trend to represent technological change provides energy price elasticities that are consistent with those found in other studies, as such studies include the effect of price-induced innovation in their estimates.

Similarly, Sue Wing (2008) uses patent stocks in a series of industry-level regressions to identify the effects of changing industry composition, disembodied technological change, factor substitution, and induced innovation in response to energy prices on declining US energy intensity. While Popp focuses on energy-intensive industries, Sue Wing's data includes 35 industries from 1958 to 2000. He finds changing composition and disembodied technological change to be the dominant factors. Induced innovation does have an energy-saving effect, but it is the smallest of the four factors studied.

Finally, Linn (2008) looks at the effect of energy prices on the adoption of energy-saving technology in the US manufacturing sector. Using Census of Manufacturers data to compare energy use in new and incumbent facilities, he finds that a $10 \%$ increase in the price of energy leads to technology adoption that reduces energy demand of entrants by $1 \%$. Given this, Linn concludes that technology adoption explains just a small portion of changes in energy demand during the 1970s and 1980s.

\subsubsection{Estimates of technological impact using $L B D$}

While only a few studies make a direct link between R\&D and environmental or energy impact, a more extensive literature has made use of experience curves to estimate the rates of cost decreases in energy technology. A long-recognized concept, technological learning first was quantified by Wright (1936) for the aircraft industry. In economics, the concept is often described as LBD, and generally is defined as the decrease in costs to manufacturers as a function of cumulative output, or "learning-by-using," and the decrease in costs (and/or increase in benefits) to consumers as a function of the use of a technology (Arrow, 1962; Rosenberg, 1982). ${ }^{6}$ LBD is commonly measured in the form of "learning" or "experience" curves in terms of how much unit costs decline as a function of experience or production. Among energy analysts, these estimates are often used to calibrate energy-economic models for simulating the effects of climate policy, with a particular focus on alternative energy sources. ${ }^{7}$ A typical learning curve estimation regresses costs of installation (or production) at different points in time as a function of cumulative installed capacity (or sometimes cumulative output) in $\log -\log$ fashion. The resulting elasticity coefficient on cumulative capacity in these models $(\alpha)$ is often translated into a so-called "learning rate" $\left(1-2^{-\alpha}\right)$ giving the percentage change in costs resulting from a doubling in cumulative capacity. Typically, studies on new energy technologies find faster learning for younger technologies, with estimates clustering around 15-20\% for alternative energy sources such as wind and solar energy (McDonald and Schrattenholzer, 2000).

\footnotetext{
${ }^{6}$ Note that "learning-by-searching" (based on cumulative R\&D expenditures) also has been used in the literature, but it is essentially R\&D-induced technological change (see, e.g., Bahn and Kypreos, 2003).

7 Köhler et al. (2006) includes a review of these studies.
} 
One significant caveat with estimated learning rates is that they typically focus on correlations between energy technology usage and costs, rather than causation. Recent papers by Klaassen et al. (2005), Söderholm and Sundqvist (2007), and Söderholm and Klaassen (2007) attempt to disentangle the separate contributions of R\&D and experience by estimating "two-factor" learning curves for environmental technologies. These two-factor curves model cost reductions as a function of both cumulative capacity (LBD) and R\&D (learning-by-searching, or LBS). To be comparable with the notion of cumulative capacity, in these models $R \& D$ is typically aggregated into a stock of $R \& D$ capital. Thus, endogeneity is a concern, as we would expect both investments in capacity to be a function of past $R \& D$ expenditures and $R \& D$ expenditures to be influenced by capacity, which helps determine demand for R\&D. Söderholm and Sundqvist address this endogeneity in their paper and find LBD rates around $5 \%$, and LBS rates around $15 \%$, suggesting that $\mathrm{R} \& \mathrm{D}$, rather than $\mathrm{LBD}$, contributes more to cost reductions. However, these results are very sensitive to the model specification, illustrating the difficulty of sorting through the various channels through which costs may fall over time.

To further address the problems associated with estimating and interpreting learning curves, Nemet (2006) uses simulation techniques to decompose cost reductions for PV cells into seven categories. Plant size (e.g., returns to scale), efficiency improvements, and lower silicon costs explain the majority of cost reductions. Notably, most of the major improvements in efficiency come from universities, where traditional learning by doing through production experience would not be a factor. Learning from experience (e.g., through increased yield of PV cells) plays a much smaller role, accounting for just $10 \%$ of the cost decreases in Nemet's sample.

While research on the various sources of cost reductions is limited, these results provide some guidelines for incorporating estimates of learning into environmental policy models. Most importantly, these results suggest that the relative importance of both learning by doing and R\&D must be considered when calibrating models that include both. The main lesson here is to avoid double counting. An LBD rate of just 5\%, such as found by Söderholm and Sundqvist, is lower than typically reported in the LBD literature, where learning rates of $15-20 \%$ are common. A simple one-factor LBD curve shows an association between capacity and costs, but does not address causation. A two-factor curve begins to address this problem by including a major omitted variable. As such, while the combined effect of LBD and LBS in a two-factor model may be comparable to learning rates from a one-factor model, the individual components should be smaller. Fischer and Newell (2008) show how one can jointly incorporate both R\&D-based and learning-based technological change into an analytical and numerical model, while taking care to parameterize the model based on available empirical evidence.

\subsubsection{Government $R \& D$}

Until now, we have focused primarily on the incentives faced, and activities conducted, by private firms. However, governments also play an important role in energy R\&D. The US Department of Energy (DOE) spent about $\$ 4$ billion on energy R\&D in 2007 (Newell, 2008a). ${ }^{8}$

\footnotetext{
${ }^{8}$ Note that this is not the total DOE R\&D budget, much of which goes to defense-related projects. Rather, it is DOE budget items focused on energy supply, energy efficiency, and basic energy sciences. Existing estimates place the level of US industrial energy R\&D at roughly \$2 billion per year in 2004; however, private sector R\&D investments relevant to energy technology are extremely difficult to assess and these numbers likely represent an underestimate (Newell, 2008a).
} 
This government investment plays several roles, each of which offers challenges to economists focusing on environmental innovation.

First, note that government $R \& D$ can help to compensate for underinvestment by private firms. Unlike firms, the government is in position to consider social returns when making investment decisions. In addition, government R\&D tends to have different objectives than private R\&D. Government support is particularly important for basic R\&D, as long-term payoffs, greater uncertainty, and the lack of a finished product at the end all make it difficult for private firms to appropriate the returns of basic R\&D. Thus, the nature of government $R \& D$ is important. For example, Popp (2002) finds that government energy $R \& D$ served as a substitute for private energy $R \& D$ during the 1970 s, but as a complement to private energy $R \& D$ afterwards. One explanation given for the change in impact is the changing nature of energy R\&D. During the 1970 s, much government R\&D funding went to applied projects such as the effort to produce synfuels. Beginning with the Reagan administration, government R\&D shifted toward a focus on more basic applications.

The analyses that have been conducted of US federal research relating to energy and the environment have come to mixed conclusions. Cohen and Noll (1991) documented the waste associated with the breeder reactor and synthetic fuel programs in the 1970s, but in the same volume Pegram (1991) concluded that the photovoltaics research program undertaken in the same time frame had significant benefits. More recently, the US National Research Council attempted a fairly comprehensive overview of energy efficiency and fossil energy research at DOE over the last two decades (National Research Council, 2001). Using both estimates of overall return and case studies, they concluded, as one might expect, that there were only a handful of programs that proved highly valuable. Their estimates of returns suggest, however, that the benefits of these successes justified the overall portfolio investment.

In addition to correcting for underinvestment by private firms, many government R\&D projects aim to improve commercialization of new technologies (referred to as "transfer" from basic to applied research). Such projects typically combine basic and applied research, and are often done through government/industry partnerships (National Science Board, 2006). For example, the United States passed several policies in the 1980s specifically designed to improve transfer from the more basic research done at government and university laboratories to the applied research done by industry to create marketable products. ${ }^{9}$ As such, this technology transfer can be seen as a step between the processes of invention and innovation.

A small number of papers have addressed the role that government R\&D plays facilitating transfer of energy technology. Jaffe and Lerner (2001) study the effectiveness of federally funded R\&D centers (FFRDCs) owned by the US DOE. Jaffe and Lerner supplement a detailed patent citation analysis of patents assigned either directly to the laboratories or to private contractors who collaborated on research at the DOE labs with case studies of two DOE laboratories where technology transfer efforts increased in the 1980s and 1990s. ${ }^{10}$ They find that both patenting and the number of citations received per patent increased at DOE laboratories since the policy shifts of the 1980s. That citations received also increase after the 1980 policy changes contrasts with the findings of researchers studying academic patenting,

\footnotetext{
${ }^{9}$ Examples include the Stevenson-Wylder Technology Innovation Act of 1980, the Bayh-Dole Act of 1980, and the Federal Technology Transfer Act of 1986.

10 The two laboratories are Lawrence Livermore National Laboratory and Idaho National Engineering and Environmental Laboratory.
} 
where patenting increases, but the quality of patents appears to decline. They also find that the type of research performed at a laboratory affects technology transfer. Transfer is slower when more basic research is performed, or when the research has national security implications. Interestingly, FFRDCs with greater contractor turnover appear to be more successful at commercializing new technologies.

Popp (2006c) examines citations made to patents in 11 energy technology categories, such as wind and solar energy. He finds that energy patents spawned by government R\&D are cited more frequently than other energy patents. This is consistent with the notion that these patents are more basic. More importantly, after passage of the technology transfer acts in the early 1980s, the children of these patents (i.e., privately held patents that cite government patents) are the most frequently cited patents, suggesting that transferring research results from the government to private industry produces valuable research results.

\subsubsection{What can technological change economists contribute?}

There is much for technological change economists to contribute on the topic of measuring the impact of technological change. A particular challenge for environmental and energy technologies is the measurement of research inputs and their impacts. Because of the long term, uncertain nature of the environmental problem, government R\&D funding plays an important role in the field. The mix of public and private research funding presents a challenge for estimating the effect of R\&D. In general, one would expect government R\&D to take longer to have an observable effect on outcomes than private $R \& D$, as it is further upstream from the final commercialized product. At the same time, both private and public R\&D are driven by the same demand-side influences, such as energy prices and environmental policy. This makes disentangling the effect of each difficult. However, measuring the impact of government $R \& D$ is important for modeling environmental policy. Economic theory suggests that a wedge should exist between social and private returns to R\&D. Government R\&D aims, at least in part, to close this gap. However, there is little empirical evidence specifically on the returns to government $R \& D$, nor to the extent to which government $R \& D$ effectively closes this gap. This is due, in part, to the nature of government projects, which are often more basic and long term in nature, making estimating returns difficult. Given this, estimating the gap between private and social rates of return that exist after accounting for both private and public energy R\&D spending is an important area for future research.

Economists also have much to contribute to the estimation of learning curves for energy technologies. In the economic literature, these models focus on experience within a single production process, such as the falling costs of production for Liberty ships during World War II (Rapping, 1965) or successive generations of silicon chips (Irwin and Klenow, 1994). In contrast, most of the learning curve studies using energy data make use of more aggregate industry-level data. That is, they ask how the cost of energy from new installations falls as cumulative experience in the industry increases. However, it need not be the case that users are directly learning from their own experiences. While research on learning curves suggests that energy technology costs do fall over time, only a few studies, cited in Section 3.2.2, address the sources of these cost savings. Understanding the source of these savings has important implications for policy timing. If experience itself is important-and there are spillovers to other firms - one could argue that environmental policy should encourage early adoption of technology, to take advantage of the learning effects that follow. If, instead, cost savings are the result of R\&D and other purposeful research efforts, policy should first attempt to encourage these activities, so as to lower 
the eventual costs of environmental policy. Moreover, learning is not just a matter for estimating cost savings, but also affects adoption as well, as cumulative usage lowers the cost of adoption. Disentangling the cause and effect of the relationship between experience, $R \& D$, and other factors that drive cost reductions is a fruitful topic for future research.

\section{Microeconomics: Diffusion}

Technological advances are of little use unless society ultimately makes use of the innovation through technology diffusion, that is, the process by which a new technology penetrates the relevant market. Often times, a technology that appears to surpass competing technologies in performance and cost will not immediately be chosen over existing technologies. A key question is whether this slow diffusion is a result of rational actors responding to varying incentives or due to market inefficiencies. In this section we briefly review the literature on diffusion of environmental technologies. ${ }^{11} \mathrm{We}$ focus on two key questions. One is the time lag between invention and adoption, focusing on the adoption of technologies within a single market. Second is the flow of knowledge across regions.

\subsection{Diffusion within countries}

The diffusion of a new technology is a gradual, dynamic process. New technologies are not adopted en masse. Rather, adoption usually begins with a few early adopters, followed by a more rapid period of adoption, with the rate of adoption leveling off once most potential users have adopted the technology. This process generates the well-known S-shaped diffusion curve: the rate of adoption rises slowly at first, speeds up, and then levels off as market saturation approaches. Early attempts to explain this process focused on the spread of information (epidemic models, such as Griliches, 1957) and differences among firms (probit models, such as David, 1997). More recently, researchers combine these explanations while adding potential strategic decisions of firms. These papers find that firm-specific differences explain most variation in adoption rates, suggesting that gradual diffusion is a rational process in response to varying incentives faced by individual actors.

Environmental technologies can be different, however. Incentives to adopt end-of-pipe technologies that only serve to reduce emissions must come from environmental regulation. Therefore, it is not surprising that studies addressing adoption of environmental technologies find that regulations dominate all other firm-specific factors. In contrast, energy-efficiency and fuel-saving technologies may be adopted more slowly, as it is cost savings, rather than a direct regulatory requirement, that often matters. This can be influenced by policies that raise energy prices. However, to the extent that fuel prices do not capture the external costs of energy use, such as carbon emissions, energy prices alone will not encourage a socially optimal level of adoption for energy-efficiency technologies.

Studies of the diffusion of environmental technologies within countries focus on two main questions. First, what is the theoretical and empirical potential for "induced diffusion" of lower emissions technologies? Specifically, how do environmental policy instruments that implicitly or explicitly

11 Stoneman and Battisti (2010) provide a more general review of the economics of diffusion. 
increase the economic incentive to reduce emissions affect the diffusion rate of these technologies? Second, to what extent have market failures in energy and equipment markets limited historical diffusion rates of energy efficient technologies? The observation that energy-efficient technologies that are cost-effective at current prices are diffusing only slowly dates back to the 1970s, having been identified as a "paradox" at least as far back as Shama (1983). To the extent that diffusion is limited by market failures, policy measures that simply increase the economic incentive to adopt environmentally friendly technologies will be insufficient. In addition, policies focused directly on the correction of adoption market failures can be justified.

\subsubsection{Theoretical analyses}

The predominant theoretical framework for analyses of diffusion effects has been what could be called the "discrete technology choice" model: firms contemplate the use of a certain technology which reduces marginal costs of pollution abatement and which has a known fixed cost associated with it. While some authors have presented this approach as a model of "innovation," it is more appropriately viewed as a model of adoption.

With such models, several theoretical studies have found that the incentive for the adoption of new technologies is greater under market-based instruments than under direct regulation (Downing and White, 1986; Jung et al., 1996; Milliman and Prince, 1989; Zerbe, 1970). With the exception of Downing and White (1986), all of these studies examined the gross impacts of alternative policy instruments on the quantity of technology adoption.

Theoretical comparisons among market-based instruments have produced only limited agreement. In a frequently cited article, Milliman and Prince (1989) examine firm-level incentives for technology diffusion provided by five instruments: command-and-control; emission taxes; abatement subsidies; freely allocated emission permits; and auctioned emission permits. Firm-level incentives for adoption in this representativefirm model were pictured as the consequent change in producer surplus. They found that auctioned permits would provide the largest adoption incentive of any instrument, with emissions taxes and subsidies second, and freely allocated permits and direct controls last. The Milliman and Prince (1989) study was criticized by Marin (1991) because of its assumption of identical firms, but it was subsequently shown that the results remain largely unchanged with heterogeneous abatement costs (Milliman and Prince, 1992).

Jung et al. (1996) build on Milliman and Prince's basic framework for comparing the effects of alternative policy instruments, but rather than focusing on firm-level changes in producer surplus, they considered heterogeneous firms, and modeled the "market-level incentive" created by various instruments. Their rankings echoed those of Milliman and Prince (1989): auctioned permits provided the greatest incentive, followed by taxes and subsidies, free permits, and performance standards.

Subsequent theoretical analyses (Denicolo, 1999; Fischer et al., 2003; Parry, 1998) clarify several aspects of these rankings. First, there is the question of relative firm-level incentives to adopt a new, cost-saving technology when the price of pollution (permit price or tax level) is endogenous. Milliman and Prince (1989), as well as Jung et al. (1996), argue that auctioned permits would provide greater incentives for diffusion than freely allocated permits, because technology diffusion lowers the equilibrium permit price, bringing greater aggregate benefits of adoption in a regime where all sources are permit buyers (i.e., auctions). But when technology diffusion lowers the market price for tradable permits, all firms benefit from this lower price regardless of whether or not they adopt the given 
technology (Fischer et al., 2003). Thus, if firms are price takers in the permit market, auctioned permits provide no more adoption incentive than freely allocated permits.

The overall result is that both auctioned and freely allocated permits have lesser diffusion incentives than and emission tax (but superior to command-and-control instruments). Under tradable permits, technology diffusion lowers the equilibrium permit price, thereby reducing the incentive for participating firms to adopt. Thus, a permit system provides a lower adoption incentive than a tax, assuming the two instruments are equivalent before diffusion occurs (Denicolo, 1999). See, however, the discussion of Fischer et al. (2003) in Section 3.1.2; they find that an unambiguous ranking of policy instruments with regard to innovation incentives is not possible.

More broadly, it appears that an unambiguous exhaustive ranking of instruments is not possible on the basis of theory alone. Parry (1998) finds that the welfare gain induced by an emissions tax is significantly greater than that induced by tradable permits only in the case of very major innovations. Similarly, Requate (1998) includes an explicit model of the final output market, and finds that whether (auctioned) permits or taxes provide stronger incentives to adopt an improved technology depends upon empirical values of relevant parameters.

Furthermore, complete theoretical analysis of the effects of alternative policy instruments on the rate of technological change must include modeling of the government's response to technological change, because the degree to which regulators respond to technologically induced changes in abatement costs affects the magnitude of the adoption incentive associated with alternative policy instruments. Because technology diffusion presumably lowers the aggregate marginal abatement cost function, it results in a change in the efficient level of control. Hence, following diffusion, the optimal agency response is to set a more ambitious target. Milliman and Prince (1989) examine the incentives facing private industry, under alternative policy instruments, to oppose such policy changes. They conclude that firms will oppose optimal agency adjustment of the policy under all instruments except taxes. Under an emissions tax, the optimal agency response to cost-reducing technological change is to lower the tax rate (assuming convex damages); under a subsidy, the optimal response is to lower the subsidy; under tradable permit systems, the optimal response is to decrease the number of available permits, and thereby drive up the permit price. Thus, firms have clear incentives to support the optimal agency response only under an emissions tax regime.

In a comparison of tradable permits and pollution taxes, Biglaiser et al. (1995) examine these instruments' ability to achieve the first-best outcome in a dynamic setting. They find that effluent taxes can do so, but permits cannot. With an effluent tax, the optimal tax is presumably determined by marginal damages (which the authors assume to be constant), yielding a policy which is time consistent. Whether or not firms adopt a cost-saving technology, the government has no incentive to change the tax rate. From this perspective, however, tradable permits are not time consistent, because the optimal number of permits in each period depends on both firms' costs, which are determined by all previous investments, and marginal damages. With constant marginal damages, and marginal abatement costs decreasing over time, the optimal number of permits should also be decreasing over time. Firms may internalize this, and thereby invest less than optimally in pollution-control technology.

The result of Biglaiser et al. (1995) depends, however, on the assumption of constant marginal damages. If marginal damages are not constant, then the optimal policy is determined by the interaction of marginal damages and marginal abatement costs for both taxes and permits. The result appears to be analogous to Weitzman's (1974) rule: if the marginal damage curve is relatively flat and there is 
uncertainty in marginal costs (from the regulator's perspective) due to potential innovation at the firm level, then a price instrument is more efficient.

\subsubsection{Empirical studies}

Most empirical studies of environmental technology adoption focus on one of two questions. First are studies examining the relationship between environmental policy and adoption. Many of these focus on adoption of pollution-control techniques. A common finding in this literature is that environmental regulation is necessary to encourage adoption of pollution-control techniques. Second are studies asking whether adoption eventually reaches socially efficient levels, or if market failures hinder the adoption of environmentally friendly technologies. These studies primarily focus on the adoption of energyefficiency technologies.

Environmental policy and adoption Table 4 provides a summary of empirical studies on the adoption of environmental technologies. Kerr and Newell (2003) use a duration model to analyze the influence of plant characteristics and the stringency and the form of regulation on technology adoption decisions by petroleum refineries during the leaded gasoline phasedown. They find that increased regulatory stringency (which raised the effective price of lead) encouraged greater adoption of lead-reducing technology. They also find that larger and more technically sophisticated refineries, which had lower costs of adoption, were more likely to adopt the new technology. Related to the choice of policy instruments, Kerr and Newell find that the tradable permit system provided incentives for more efficient technology adoption decisions, as evidenced by a significant divergence in the adoption behavior of refineries with low versus high compliance costs. Namely, the positive differential in the adoption propensity of expected permit sellers (i.e., low-cost refineries) relative to expected permit buyers (i.e., high-cost refineries) was significantly greater under market-based lead regulation compared to under individually binding performance standards.

Another prominent application of tradable permit systems that has provided an opportunity for empirical analysis of the effects of policy instruments on technology diffusion is the sulfur dioxide allowance trading program, initiated under the US CAA amendments of 1990. In an econometric analysis, Keohane (2007) finds evidence of the way in which the increased flexibility of a marketbased instrument can provide greater incentives for technology adoption. In particular, he finds that the choice of whether or not to adopt a "scrubber" to remove sulfur dioxide—rather than purchasing (more costly) low-sulfur coal-was more sensitive to cost differences (between scrubbing and fuel-switching) under the tradable permit system than under the earlier emissions rate standard.

In an examination of the effects of alternative policy instruments for reducing oxygen-demanding water pollutants, Kemp (1998) finds that effluent charges were a significant predictor of adoption of biological treatment by facilities. In earlier work, Purvis and Outlaw (1995) carry out a case study of EPA's permitting process for acceptable water-pollution-control technologies in the US livestock production sector. Those authors conclude that the relevant regulations encouraged the use of "time-tested" technologies that provided lower levels of environmental protection than other more innovative ones, simply because producers knew that EPA was more likely to approve a permit that employed the established approach.

Snyder et al. (2003) study the diffusion of membrane-cell technology in the chlorine manufacturing industry. Chlorine is produced using an electrolytic process. Of the three types of cells that can be used 
Table 4

Factors affecting adoption of environmental technology

\begin{tabular}{|c|c|c|c|}
\hline Article & Technology & Data & Key results \\
\hline Kerr and Newell (2003) & Lead-reducing refining technology & US oil refineries, 1971-1995 & $\begin{array}{l}\text { Increased stringency increases adoption. Larger } \\
\text { and more sophisticated refineries adopted first }\end{array}$ \\
\hline Keohane (2007) & $\mathrm{SO}_{2}$ scrubbers & $\begin{array}{l}\text { US coal-fired power plants, } \\
\text { 1995-1999 }\end{array}$ & $\begin{array}{l}\text { Adoption decision was more sensitive to cost } \\
\text { differences under tradable permits }\end{array}$ \\
\hline Kemp (1998) & Water pollution treatment facilities & $\begin{array}{l}\text { Dutch food and beverage plants } \\
\text { 1974-1991 }\end{array}$ & Effluent charges increase adoption \\
\hline Purvis and Outlaw (1995) & $\begin{array}{l}\text { Water pollution-control technologies } \\
\text { for the US livestock production }\end{array}$ & N/A & $\begin{array}{l}\text { Regulations led to adoption of "time-tested" } \\
\text { rather than innovative technologies, because } \\
\text { EPA was more likely to approve permits for } \\
\text { these }\end{array}$ \\
\hline Snyder et al. (2003) & $\begin{array}{l}\text { Membrane-cell technology for } \\
\text { chlorine production }\end{array}$ & $\begin{array}{l}\text { US chlorine manufacturers, } \\
\text { 1976-2001 }\end{array}$ & $\begin{array}{l}\text { Regulation not only encourages adoption but } \\
\text { also leads to the shutdown of plants using older } \\
\text { technologies }\end{array}$ \\
\hline Popp (2006d) & $\begin{array}{l}\text { Combustion modification and } \\
\text { postcombustion controls for } \mathrm{NO}_{X} \\
\text { emissions from coal-fired power } \\
\text { plants }\end{array}$ & $\begin{array}{l}\text { US coal-fired power plants, } \\
\text { 1990-2003 }\end{array}$ & $\begin{array}{l}\text { Regulation is the dominant factor. Technology } \\
\text { improvements lead to more adoption for } \\
\text { combustion modification, but not for more } \\
\text { expensive postcombustion controls, which are } \\
\text { only adopted when needed because of regulatory } \\
\text { pressures }\end{array}$ \\
\hline Frondel et al. (2007) & $\begin{array}{l}\text { End-of-pipe versus process } \\
\text { abatement }\end{array}$ & Survey of OECD firms & $\begin{array}{l}\text { Regulations are more likely to lead to end-of- } \\
\text { pipe solutions. Market forces influence cleaner } \\
\text { production processes }\end{array}$ \\
\hline $\begin{array}{l}\text { Wolfram and Bushnell } \\
\text { (2008) }\end{array}$ & $\begin{array}{l}\text { Modifications at coal-fired electric } \\
\text { power plants }\end{array}$ & US power plants, 1998-2004 & $\begin{array}{l}\text { Effect of new source review on capital } \\
\text { investment is small }\end{array}$ \\
\hline Fowlie (2007) & $\mathrm{NO}_{X}$ pollution-control techniques & $\begin{array}{l}702 \text { US coal-fired power plants } \\
\text { covered by the } \mathrm{NO}_{X} \text { Budget } \\
\text { Program, 2000-2004 }\end{array}$ & $\begin{array}{l}\text { Plants in restructured markets are less likely to } \\
\text { install costly abatement equipment }\end{array}$ \\
\hline $\begin{array}{l}\text { Blackman and Bannister } \\
\text { (1998) }\end{array}$ & Cleaner fuels & Traditional brick kilns in Mexico & $\begin{array}{l}\text { Community pressure and local nongovernmental } \\
\text { organizations are important }\end{array}$ \\
\hline Popp et al. (2008) & $\begin{array}{l}\text { Low-chlorine production of pulp and } \\
\text { paper }\end{array}$ & $\begin{array}{l}\text { Pulp plants in the United States, } \\
\text { Canada, Sweden, Finland, } \\
\text { Norway, and Japan, 1990-2005 }\end{array}$ & Consumer pressure spurred adoption \\
\hline
\end{tabular}


in this process, membrane cells have the least environmental impact. Usage of membrane cells have increased over time, due to three different processes: adoption of the technology at existing plants, use of membrane technology at new facilities, and the closing of plants using older cell technologies. Using a hazard model, Snyder et al. look at both the adoption and exit decisions of chlorine plants. They find that increases in the percentage of plants using membrane technology comes partially from adoption, but primarily from shutdowns of older plants. Environmental regulation does not have a statistically significant effect on adoption of membrane technology. However, the passage of more stringent regulations over time does appear to hasten the shutdown of older facilities, thus increasing the share of plants using membrane technology.

Popp (2006d) links the role of innovation and adoption in a study of $\mathrm{NO}_{X}$ pollution-control technologies. Advances (and expected advances) in a single technology should affect both its adoption rate and the adoption of substitute technologies. Popp combines plant-level data on US coal-fired electric power plants with patent data pertaining to $\mathrm{NO}_{X}$ pollution-control techniques to study this link. Plants needing to reduce $\mathrm{NO}_{X}$ emissions face two choices. They can modify the combustion process so as to produce fewer $\mathrm{NO}_{X}$ emissions, or they can install postcombustion treatment to remove $\mathrm{NO}_{X}$ from the emissions stream. Modifying the combustion process is cheaper, but postcombustion treatment reduces a greater percentage of $\mathrm{NO}_{X}$ emissions. As in other studies of environmental technologies, the effect of other explanatory variables is dominated by the effect of environmental regulations, demonstrating that the mere presence of environmental technologies is not enough to encourage its usage. Technological advances are important for the adoption of existing combustion modification technologies. However, these advances are less important for the adoption of newer postcombustion-control techniques, which are adopted only when needed to comply with the strictest emission limits. Moreover, because of the greater capital costs for postcombustion techniques, the financial strength of a plant's parent company positively influences adoption.

In general, firms can choose one of two strategies to comply with environmental regulations. End-ofthe-pipe abatement reduces emissions by using add-on technologies to clean the waste stream coming from a plant. In contrast, cleaner production methods reduce emissions by generating less pollution in the production process. Frondel et al. (2007) look at the factors influencing the choice of one strategy over the other. They find that many plants in OECD nations make use of cleaner production methods. However, environmental regulations are more likely to lead to the adoption of end-of-the-pipe techniques. In contrast, market forces such as cost savings or environmental audits lead to the adoption of cleaner production processes.

Another body of research has examined the effects on technology diffusion of command-and-control environmental standards when they are combined with "differential environmental regulations." In many situations where command-and-control standards have been used, the required level of pollution abatement has been set at a far more stringent level for new sources than for existing ones. There is empirical evidence that such differential environmental regulations have lengthened the time before plants were retired (Maloney and Brady, 1988; Nelson et al., 1993). Further, this dual system can actually worsen pollution by encouraging firms to keep older, dirtier plants in operation (Gollop and Roberts, 1983; McCubbins et al., 1989; Stewart, 1981).

Another concern with differential environmental regulation is that existing plants may forego investments that could lead to more stringent regulatory requirements. However, recent work by 
Wolfram and Bushnell (2008) suggest that the impact of this effect may be small. They analyze the effects of New Source Review (NSR) environmental regulations on coal-fired electric power plants. The 1970 CAA required new electric generating plants to install costly pollution-control equipment, but exempted existing plants with a grandfathering clause. Existing plants lost their grandfathering status if they made major modifications to their plants. Wolfram and Bushnell find some evidence that the risk of NSR enforcement reduced capital expenditures at plants. However, they find no discernable effect on the operating costs, fuel efficiency, or emissions of these plants.

The regulatory structure of markets may also affect adoption. Fowlie (2007) examines the adoption of $\mathrm{NO}_{X}$ pollution-control techniques by US power plants in response to $\mathrm{NO}_{X}$ permit trading in the eastern United States. Fowlie notes that electric utilities face different incentives depending on the regulatory structure of the industry. She considers how differences in the regulatory structure of an industry affect the response to pollution permits. State regulators typically allow firms to recoup the average costs of operating pollution controls and purchasing permits. However, the opportunity costs of using or holding permits is not reflected in regulated rates. This gives regulated firms an incentive to invest in more capital intensive abatement equipment. In contrast, utilities in restructured markets face greater uncertainty, making investments in long-term pollution abatement capital more risky. Using plant-level data on the cost of installing various $\mathrm{NO}_{X}$ abatement techniques, Fowlie finds that plants in restructured electricity markets are less likely to install capital intensive compliance options. Moreover, because the regulatory framework faced by utilities varies by state, the interaction between state utility regulation and permit markets has important environmental effects. As a result of different adoption incentives faced by deregulated utilities, a larger share of the pollution allowed by $\mathrm{NO}_{X}$ permits is emitted in states with more severe air quality problems.

In addition to economic incentives, direct regulation, and information provision, some research has emphasized the role that "informal regulation" or community pressure can play in encouraging the adoption of environmentally clean technologies. For example, in an analysis of fuel adoption decisions for traditional brick kilns in Mexico, Blackman and Bannister (1998) suggest that community pressure applied by competing firms and local nongovernmental organizations was associated with increased adoption of cleaner fuels, even when those fuels had relatively high variable costs. Popp et al. (2008) find that consumer concerns over dioxin found in the wastewater of pulp manufacturers helped spur the adoption of low-chlorine and chlorine-free bleaching techniques at pulp plants, even before regulations requiring such techniques took effect. An important difference between the technological choice here is that chlorine use not only has negative environmental impacts near the production site, but also affects the quality of the final product. Consumer concerns are more likely to be an issue when environmental choices affect product quality, such as chlorine in paper products or lead paint in children's toys.

Not surprisingly, prices also serve as an incentive for adoption. This is particularly important for technologies that improve energy efficiency, as individual users can appropriate some of the benefits of these technologies through lower energy bills, even if no other regulatory incentives exist. Rose and Joskow (1990) find a positive effect of fuel price increases on the adoption of a new fuel-saving technology in the US electricity-generation sector, with the statistical significance of the effect depending on the year of the fuel price. In a Tobit analysis of steel plant adoption of different furnace technologies, Boyd and Karlson (1993) find a significant positive effect of increases in a fuel's price on the adoption of technology that saves that fuel, although the magnitude of the effect was modest. For a 
sample of industrial plants in four heavily polluting sectors (petroleum refining, plastics, pulp and paper, and steel), Pizer et al. (2001) find that both energy prices and financial health were positively related to the adoption of energy-saving technologies.

Finally, the energy crises of the 1970s gave rise to several studies addressing automotive energy efficiency. Most relevant for our purposes is the study of Greene (1990). He uses data on fuel prices and fuel economy of automobiles from 1978 to 1989 to test the relative effectiveness of Corporate Average Fuel Economy (CAFE) standards and gasoline prices in increasing fuel economy. He finds that the big three US firms faced a binding CAFE constraint, and for these firms compliance with CAFE standards had roughly twice the impact on fuel economy as did fuel prices. Japanese firms, however, did not face a binding CAFE constraint, and fuel prices had only a small effect. Luxury European manufactures seemed to base their fuel efficiency largely on market demand and often exceeded CAFE requirements. For these firms, neither the standards nor prices seemed to have much effect. Similarly, Goldberg (1998) combines a demand-side model of discrete vehicle choice and utilization with a supply-side model of oligopoly and product differentiation to estimate the effects of CAFE standards on the fuel economy of the new car fleet. She finds that automobile fuel operating costs have had a significant effect, although a gasoline tax of a magnitude that could match the effect of CAFE on fuel economy would have to be very large.

Are there adoption market failures? Whereas environmental policy is generally a prerequisite for adoption of pollution-control techniques, there are private benefits to adopting energy efficient technology, such as lower energy bills. Nonetheless, there is a large literature documenting that such technologies are adopted at seemingly slow rates, even when the upfront capital costs of technology would be paid back in a few years. Assessing the reasons for this slow diffusion process has been an important research question, as has the evaluation of policies that seek to increase energy efficiency. In a retrospective review of past energy-efficiency programs in the United States, Gillingham et al. (2006) found that the programs reviewed (e.g., appliance standards, utility programs) cumulatively reduced total US energy use by at most $4 \%$, or $12 \%$ as a percent of energy use in buildings. The costeffectiveness of these programs has been the subject of considerable debate. Table 5 provides a summary of research in this area.

Jaffe and Stavins (1995) carry out econometric analyses of the factors affecting the adoption of thermal insulation technologies in new residential construction in the United States between 1979 and 1988. They examine the dynamic effects of energy prices and technology adoption costs on average residential energyefficiency technologies in new home construction, finding the response of mean energy efficiency to energy price changes to be positive and significant, both statistically and economically. Interestingly, they also find that equivalent percentage adoption cost changes were about three times as effective as energy price changes in encouraging adoption, although standard financial analysis would suggest that they ought to be about equal in percentage terms. This finding offers confirmation for the conventional wisdom that technology adoption decisions are more sensitive to up-front cost considerations than to longer term operating expenses. One interpretation of this finding is that energy price changes are simply not expected to persist, so that a given percentage change in today's energy price has a relatively small effect on the expected "average" energy price over the life of the investment. This possibility has implications for the challenge of devising effective policy to encourage innovation where the returns to the innovation depend on future prices. Jaffe and Stavins (1995) also examine the effects of more conventional regulations on technology diffusion, in the form of state building codes. They find no discernable effects. It is unclear to 
Table 5

Barriers to adoption of environmentally friendly technologies

\begin{tabular}{|c|c|c|c|c|}
\hline Article & Technology & Barrier(s) to adoption & Data & Key results \\
\hline $\begin{array}{l}\text { Jaffe and Stavins } \\
\text { (1995) }\end{array}$ & Thermal insulation & Up-front costs matter more & $\begin{array}{l}\text { US residential } \\
\text { construction 1979-1988 }\end{array}$ & $\begin{array}{l}\text { Lower adoption costs three times more } \\
\text { likely to encourage adoption than } \\
\text { increased energy costs }\end{array}$ \\
\hline $\begin{array}{l}\text { Hassett and Metcalf } \\
\text { (1995) }\end{array}$ & $\begin{array}{l}\text { Residential energy } \\
\text { conservation }\end{array}$ & Up-front costs matter more & $\begin{array}{l}\text { US households } \\
1979-1981\end{array}$ & $\begin{array}{l}\text { Installation cost savings via tax credits } \\
\text { encourage adoption }\end{array}$ \\
\hline Kemp (1997) & Thermal home insulation & Inadequate information & Netherlands households & $\begin{array}{l}\text { Government subsidies do not lead to } \\
\text { adoption. Epidemic model fits data } \\
\text { better than rational choice model }\end{array}$ \\
\hline $\begin{array}{l}\text { Metcalf and Hassett } \\
\text { (1999) }\end{array}$ & Attic insulation & Inadequate information & $\begin{array}{l}\text { US Residential Energy } \\
\text { Consumption Survey, } \\
\text { 1984, 1987, and } 1990\end{array}$ & $\begin{array}{l}\text { Actual energy savings are less than } \\
\text { promised }\end{array}$ \\
\hline Reppelin-Hill (1999) & Clean steal technologies & Import barriers & $\begin{array}{l}\text { Adoption of electric arc } \\
\text { furnace in } 30 \text { countries, } \\
1970-1994\end{array}$ & $\begin{array}{l}\text { Import barriers restrain the adoption } \\
\text { of foreign-produced goods }\end{array}$ \\
\hline Howarth et al. (2000) & $\begin{array}{l}\text { Energy-saving } \\
\text { technology (efficient } \\
\text { lighting equipment) }\end{array}$ & $\begin{array}{l}\text { Agency decision-making } \\
\text { problems inadequate } \\
\text { information }\end{array}$ & $\begin{array}{l}\text { Green lights and energy } \\
\text { star programs }\end{array}$ & $\begin{array}{l}\text { Voluntary programs lead to wider } \\
\text { adoption in private firms. Inadequate } \\
\text { information inhibits adoption }\end{array}$ \\
\hline Nijkamp et al. (2001) & $\begin{array}{l}\text { Energy-efficient } \\
\text { technology }\end{array}$ & $\begin{array}{l}\text { Economic barriers: } \\
\text { - Alternative investment } \\
\text { - Low energy costs } \\
\text { - Capital replacement }\end{array}$ & Survey of Dutch firms & $\begin{array}{l}\text { Economic barriers affect adoption } \\
\text { more than financial and uncertainty } \\
\text { barriers }\end{array}$ \\
\hline Mulder et al. (2003) & $\begin{array}{l}\text { Energy-efficiency } \\
\text { technologies }\end{array}$ & $\begin{array}{l}\text { Complementarities among } \\
\text { technologies }\end{array}$ & N/A & $\begin{array}{l}\text { Complementarities and learning-by- } \\
\text { doing process impede adoption }\end{array}$ \\
\hline $\begin{array}{l}\text { Anderson and Newell } \\
\text { (2004) }\end{array}$ & $\begin{array}{l}\text { Firm-level adoption of } \\
\text { energy-saving projects } \\
\text { recommended by energy } \\
\text { audits }\end{array}$ & $\begin{array}{l}\text { Inadequate information on } \\
\text { technologies Initial costs and } \\
\text { payback years of adoption }\end{array}$ & $\begin{array}{l}\text { US Department of } \\
\text { Energy's industrial } \\
\text { assessment centers } \\
\text { database, 1981-2000 }\end{array}$ & $\begin{array}{l}\text { Firms adopt additional projects with } \\
\text { improved information. Up-front costs } \\
\text { have } 40 \% \text { greater effect than energy } \\
\text { costs }\end{array}$ \\
\hline
\end{tabular}


what extent this is due to inability to measure the true variation across states in the effectiveness of codes, or to codes that were in many cases not binding relative to typical practice. This is a reminder, however, that although price-based policies will always have some effect, standards may have little effect if they are set below existing standards of practice.

Hassett and Metcalf (1995) find an even larger discrepancy between the effect of changes in installation cost (here coming through tax credits) and changes in energy prices. Anderson and Newell (2004) also find a divergence in their investigation of industrial energy-efficiency audits (discussed below) —albeit a much lesser one-with costs have a $40 \%$ greater percentage effect relative to future energy savings. There are three interrelated possible explanations for these findings. One possibility is a behavioral bias that causes purchasers to focus more on up-front cost than they do on the lifetime operating costs of an investment. As discussed above, an alternative (but probably indistinguishable) view is that purchasers focus equally on both, but uncertainty about future energy prices makes them give less weight to the current energy price (which is only an indicator of future prices) than they do to the capital cost, which is known. A final interpretation might be that consumers actually have reasonably accurate expectations about future energy prices, and their decisions reflect those expectations, but our empirical proxies for their expectations are not correct.

In a separate analysis of thermal home insulation, this one in the Netherlands, Kemp (1997) finds that a threshold model of diffusion (based on a rational choice approach) could not explain observed diffusion patterns. Instead, epidemic models provided a better fit to the data. Kemp also finds that there was no significant effect of government subsidies on the adoption of thermal insulation by households.

Attention has also been given to the effects on energy-efficiency technology diffusion of voluntary environmental programs. Howarth et al. (2000) examine two voluntary programs of the US Environmental Protection Agency - the Green Lights and Energy Star programs-both of which are intended to encourage greater private industry use of energy-saving technologies. A natural question from economics is why would firms carry out additional technology investments as part of a voluntary agreement? The authors respond that there are a set of agency problems that inhibit economically wise adoption of some technologies. For example, most energy-saving investments are small, and senior staff may rationally choose to restrict funds for small projects that cannot be perfectly monitored. The Green Lights program may be said to attempt to address this type of agency problem by providing information on savings opportunities at the level of the firm where decisions are made.

For households and small firms, adoption of new technologies with significant capital costs may be constrained by inadequate access to financing. And in some countries, import barriers may inhibit the adoption of technology embodied in foreign-produced goods (Reppelin-Hill, 1999). On the other hand, Nijkamp et al. (2001) present the qualitative results of a survey of Dutch firms regarding their decisions on how much to invest in energy-efficient technologies. They found that standard economic "barriers" to energy-efficient technology adoption-including the existence of alternative investments, low energy costs, and a desire to replace capital only when it is fully depreciated-are more important than financial barriers and uncertainty about future technologies and prices.

Information plays an important role in the technology diffusion process. There are two reasons why the importance of information may result in market failure. First, information is a public good that may be expected in general to be underprovided by markets. Second, to the extent that the adoption of the technology by some users is itself an important mode of information transfer to other parties, adoption creates a positive externality and is therefore likely to proceed at a socially suboptimal rate. Howarth 
et al. (2000) explore the significance of inadequate information in inhibiting the diffusion of more efficient lighting equipment. Metcalf and Hassett (1999) compare available estimates of energy savings from new equipment to actual savings realized by users who have installed the equipment. They find that actual savings, while significant, were less than those promised by engineers and product manufacturers. Their estimate of the median realized rate of return is about $12 \%$, which they found to be close to a discount rate for this investment implied by a CAPM analysis.

Anderson and Newell (2004) examine the role of information by asking how firms respond to energy audits offered through the US DOE's Industrial Assessment Centers (IAC). This program has offered energy assessments at no cost to small and medium-sized manufacturers since 1976. Data on both the recommendations made and projects implemented within 2 years of the evaluation are kept by the IAC. Using these data, Anderson and Newell note that firms adopted only 53\% of recommended projects, even though the average payback time for these projects was just 1.29 years. Using fixed effect logit estimation, they find that adoption rates are higher for projects with shorter paybacks, lower costs, greater annual savings, higher energy prices, and greater energy conservation. As discussed above, plants are $40 \%$ more responsive to initial costs than annual energy savings. Using multiple decisions for a given firms, they estimate a "payback threshold" for a typical firm, below which all projects are adopted and above which all projects are rejected. They find that over $98 \%$ of firms have payback thresholds of less than 5 years, with a median payback threshold of just 1.2 years. As in previous studies, these firms demand quick paybacks of 1-2 years (implicit hurdle rates of 50-100\%) for project adoption. These results are consistent with the investment criteria that small and medium-sized firms typically state that they intend to use (Lefley, 1996).

Also related to imperfect information are a variety of agency problems that can inhibit the adoption of superior technology. The agency problem can be either external or internal to organizations. An example of an external agency problem would be a landlord/tenant relationship, in which a tenant pays for utilities but the landlord makes decisions regarding which appliances to purchase, or vice versa. Internal agency problems can arise in organizations where the individual or department responsible for equipment purchase or maintenance differs from the individual or department whose budget covers utility costs. DeCanio (1998) explores the significance of organizational factors in explaining firms' perceived returns to installation of energy-efficient lighting.

Uncertainty is another factor that may limit the adoption of new technology (Geroski, 2000). Uncertainty can be inherent in the technology itself, in the sense that its newness means that users are not sure how it will be perform (Mansfield, 1968). For resource-saving technology, there is the additional uncertainty that the economic value of such savings depends on future resource prices, which are themselves uncertain. This uncertainty about future returns means that there is an "option value" associated with postponing the adoption of new technology (Hassett and Metcalf, 1995, 1996; Pindyck, 1991).

Closely related to the issue of uncertainty is the issue of the discount rate or investment hurdle rate used by purchasers in evaluating the desirability of new technology, particularly resource-conserving technology. A large body of research demonstrates that purchasers appear to use relatively high discount rates in evaluating energy-efficiency investments (Hausman, 1979; Ross, 1990; Ruderman et al., 1987). The implicit or explicit use of relatively high discount rates for energy savings does not represent a market failure in itself; it is rather the manifestation of underlying aspects of the decision process including those just discussed. At least some portion of the discount rate premium is likely to be related to uncertainty, although the extent to which the premium can be explained by uncertainty and option 
value is subject to debate (Hassett and Metcalf, 1995, 1996; Sanstad et al., 1995). Capital market failures that make it difficult to secure external financing for these investments may also play a role.

Finally, the presence of increasing returns in the form of learning effects, network externalities, or other positive adoption externalities presents the possibility that market outcomes for technologies exhibiting these features, including those with environmental consequences, may be inefficient. For example, the idea that we are "locked into" a fossil-fuel-based energy system is a recurring theme in policy discussions regarding climate change and other energy-related environmental problems. At a more aggregate level, there has been much discussion of the question of whether it is possible for developing countries to take less environmentally damaging paths of development than have currently industrialized countries, for example, by relying less on fossil fuels. In a theoretical study, Mulder et al. (2003) use a vintage model to consider the adoption of energy-efficiency technologies. They assume complementarities among technologies, so that there are returns to using technologies from a mix of vintages. This complementarity allows old technologies to persist, offering a possible explanation for the energy-efficiency paradox. As complementarities increase, adoption levels of technology decrease. Finally, they introduce learning by doing into the model. This further reduces the adoption level of new technologies, as firms lose their expertise on past vintages when choosing a new technology.

While the empirical literature is quite thin, some studies have explored the issue of increasing returns and technology lock-in for competing technologies within the energy and environment arenas, including analysis of renewable energy and fossil fuels (Cowan and Kline, 1996), the internal combustion engine and alternatively fueled vehicles (Cowan and Hulten, 1996), pesticides and integrated pest management (Cowan and Gunby, 1996), technologies for electricity generation (Islas, 1997), nuclear power reactor designs (Cowan, 1990), and the transition from hydrocarbon-based fuels (Kemp, 1997).

\subsubsection{What can technological change economists contribute?}

Much of the discussion on the energy paradox focuses on whether or not there are market failures that slow adoption. One area in which technological change economists could contribute is to move beyond the focus on market failures. For example, a micro and behavioral understanding of the decision to adopt could result from a marriage of the economics of technological change with the new "behavioral economics." Such work would contribute to our understanding of why adoption of energy-efficiency technologies is slow, and would better inform policy makers attempts to increase adoption of energy efficient technologies.

\subsection{Diffusion across countries}

While international technology transfer has received much attention in the broader economic literature, few applications focus specifically on environmental technologies. ${ }^{12}$ Nearly all of the papers cited so far focus on highly developed economies. This is not surprising, as these countries were the first to enact environmental protections and most R\&D expenditures occur in these countries. In 2006, global R\&D expenditures were about $\$ 960$ billion, with $85 \%$ of this R\&D occurring in the OECD, and half in the United States and Japan alone (Newell, 2008a; OECD, 2008).

12 For a general review of the literature on international technology transfer, see Keller (2004). 
Nonetheless, diffusion of environmental technologies, particularly to developing countries, is currently one of the most pressing environmental concerns. Much of this concern stems from the need to address climate change while allowing for economic development. Rapid economic growth in countries such as China and India not only increases current carbon emissions from these countries, but results in high emission growth rates from these countries as well. In 1990, China and India accounted for $13 \%$ of world $\mathrm{CO}_{2}$ emissions. By 2004, that figure had risen to $22 \%$, and it is projected to rise to $31 \%$ by 2030 (Energy Information Administration, 2007). Given these concerns, designing policy that encourages the transfer of clean technologies to developing countries has been a major discussion point in climate negotiations. Currently, the Kyoto agreement includes the Clean Development Mechanism (CDM), which allows polluters in industrialized countries with emission constraints to receive credit for financing projects that reduce emissions in developing countries, which do not face emission constraints under the Kyoto Protocol. ${ }^{13}$ Because carbon emissions are a global public good, CDM can help developed countries reach emission targets at a lower total cost, by allowing developed country firms to substitute cheaper emissions reductions in developing countries for more expensive reductions in the home country. For developing countries, technology transfer and diffusion of clean technologies may be an additional benefit from CDM.

Dechezleprêtre et al. (2008) study this question, asking how many CDM projects transfer "hardware," such as equipment or machinery, as opposed to "software," which they consider to be knowledge, skills, or know-how. That is, how often do CDM projects transfer knowledge and skills that not only allow a developed country investor to meet emission reduction credits, but also enable the recipient developing country to make continual improvements to their own emission levels? Dechezleprêtre et al. look at 644 CDM projects registered by the Executive Board of the UNFCCC. They find that 279 projects, or $43 \%$, involve technology transfer. ${ }^{14}$ Of these, 57 transfer equipment, 101 transfer knowledge, and 121 transfer both equipment and knowledge. A project is more likely to include technology transfer if it is larger, if the project developer is a subsidiary of a company in a developed country, and if the project includes one or more carbon credit buyers. Before credits for a project can be sold, the emission reductions must be certified. Because they have an interest in obtaining emission credits, credit buyers help to facilitate this process.

Most economic applications of environmental technology transfer have been more general. In the broadest sense, environmental technological change is addressed in literature on trade and the environment. There, economists decompose the effect of international trade on environmental quality in developing countries into three components. First, scale effects account for increased pollution levels due to the greater wealth and increased economic activity that follows international trade. Second, composition effects refer to reductions in pollution resulting from a preference for cleaner goods that develops as countries become richer. Third, technique effects refer to emission reductions that occur because trade expands access to cleaner technologies (Copeland and Taylor, 2003; Esty, 2001). Attempts to identify this technique effect can be seen as examples of technology transfer.

Fisher-Vanden and Ho (2006) consider the interaction of scale and technique effects in a simulation of increased science and technology ( $\&$ T) capabilities and energy use in China. They note that

13 Lecocq and Ambrosi (2007) provide a description of the Clean Development Mechanism.

${ }^{14}$ However, these projects are among the most significant CDM projects, as they account for $84 \%$ of the expected emissions reductions from registered CDM projects. 
improving S\&T capabilities have two offsetting effects. While technological development can lead to the use of cleaner technologies (the technique effect), increases in S\&T also lead to larger energy intensive industries (the scale effect). Their paper simulates the effect of S\&T growth in China, with R\&D intensity reaching $2.5 \%$ by 2020 , as stated in China's long-term policy goals. They note that China's R\&D intensity has already increased from $0.6 \%$ in 1996 to $1.3 \%$ in 2003. Calibrating their model based on econometric results from 1500 industrial enterprises, they find that the S\&T takeoff should have an energy-saving bias, resulting in lower energy prices. However, this leads to more economic growth and greater energy consumption by households, so that the net effect of the S\&T takeoff is greater energy use and more carbon emissions. Fisher-Vanden and Sue Wing (2008) develop an analytical model that finds similar results.

Khanna and Zilberman (2001) illustrate the importance of trade to diffusion in a study of the adoption of energy efficient technologies at electric power plants in India. As is typical in adoption models, variations in the adoption of these technologies occur due to differences across heterogeneous plants. Emissions could be reduced by the adoption of high quality coal. However, such coal would need to be imported. In an effort to protect the domestic coal industry, such imports were virtually banned by the Indian government. Khanna and Zilberman find that while an emissions tax is necessary to achieve optimal levels of abatement, simply removing domestic and trade policy distortions would increase adoption of energy efficient technology and potentially decrease carbon emissions.

Focusing more directly on the invention and diffusion of environmental technologies, Lanjouw and Mody (1996) use patent data from the United States, Japan, Germany, and 14 low- and middle-income countries to study technological change for a variety of environmentally friendly technologies. They find that environmentally friendly innovation increases as pollution abatement cost expenditures in the country increase. For the United States, Japan, and Germany, the majority of these patents are typically domestic patents. For the developing countries, the majority of these patents come from foreign countries, highlighting the importance of diffusion. This is especially true of air pollution-control technologies, which are typically complex. In contrast, while air pollution patents in developing countries go primarily to developed country inventors, water pollution-control technologies are more frequently local innovations, as local conditions affect the potential benefits of such technologies. However, these innovations are less likely to be patented elsewhere. Lanjouw and Mody also find that policies in one nation may affect innovation of technologies in a second nation. For example, they note that the majority of vehicle air emissions patents granted in the US are from foreign nations, even though the United States was the first country to adopt strict emissions standards.

Popp (2006b) addresses the links between regulations and innovations across countries, using patent data to study innovation on air pollution-control technologies for coal-fired power plants in the United States, Japan, and Germany. He finds that inventors respond primarily to domestic regulatory incentives. In each country, the largest increase in domestic patent applications occurs after the country passes regulations affecting power plants. Moreover, Popp finds evidence of innovation even in countries that adopt regulations late, suggesting that these countries do not simply take advantage of technologies "off the shelf" that have been developed elsewhere. Instead, adaptive R\&D seems to be necessary to suit the technology to the local market, as these later patents are more likely to cite earlier foreign than domestic inventions. Thus, the foreign knowledge serves as blueprints for further improvements, rather than as a direct source of technology. 
One reason why foreign markets may have little influence on innovation is that electricity is not a traded commodity, and the bulk of emissions control equipment used in these countries comes from domestic suppliers. Note, for example, that this result contrasts with the findings of Lanjouw and Mody (1996), who find that US automotive emission regulations in the 1970s lead to increased innovation from Japanese and German firms. Similarly, Popp et al. (2008) show that pulp and paper manufacturers respond to the demands of consumers in key export markets when adopting cleaner paper bleaching techniques. Finally, Medhi (2008) finds that Korean automotive manufacturers first incorporated advanced emission controls into their vehicles to satisfy regulatory requirements in US and Japanese markets. It was only after fitting these technologies into their vehicles that the Korean government passed their own regulations requiring advanced emission controls.

Because most pollution-control technologies are first developed in industrialized countries, and because environmental regulations are needed to provide incentives to adopt these technologies, Lovely and Popp (2008) focus on the adoption of environmental regulation as the first step in the international diffusion of environmental technologies. They study the adoption of regulations limiting emissions of sulfur dioxide and nitrogen oxides at coal-fired power plants in 39 countries. Their sample includes both developed and developing countries. While the adoption of pollution-control technologies within a country responds quickly to environmental regulation, they find that adoption of the regulations themselves follows the typical S-shaped pattern noted in studies of technology diffusion. In their work, they focus on access to technology as an important factor influencing regulatory adoption. As pollutioncontrol technologies improve, the costs of abatement, and thus the costs of adopting environmental regulation, fall. As such, they find that, over time, countries adopt environmental regulation at lower levels of per capita income. Moreover, they find that openness to international trade is important for providing access to these technologies, providing support for the technique effect discussed earlier.

Hilton (2001) finds that late adopters of regulation can learn from early adopters. Using data on 48 nations, he looks at the time it took each country to eliminate lead from fuel. This time is measured from the time that each country first began phasing out lead in fuel to the time in which the country achieved lead levels at or below $0.5 \mathrm{~g}$ of lead per gallon. Countries that began the process after 1979 completed the lead phase-out 5 years faster, on average, than those beginning before 1979. Moreover, among those countries that did not completely phase out lead, countries that begin the phase-out process earlier achieve greater reductions. Hilton concludes with evidence that late adopters are able to move more quickly because they benefit from lessons learnt by early adopters.

Finally, in developing country settings, factors inducing adoption of environmentally friendly technology may differ from factors that are important in developed countries. Blackman and Kildegaard (2003) study the adoption of three clean leather tanning technologies in Mexico. They use original survey data on a cluster of small- and medium-scale leather tanneries in León, Guanajuato, noting that small- and medium-scale enterprises often dominate pollution intensive industries in developing countries. To explain the adoption of each tanning technique, they estimate a system of multivariate probit models. They find that a firm's human capital and stock of technical information influence adoption. They also find that private-sector trade associations and input suppliers are important sources of technical information about clean technologies. In contrast to results typically found in developed countries, neither firm size nor regulatory pressure are correlated with adoption.

In contrast to pollution-control technologies, energy-efficiency technologies will diffuse even without environmental policy in place, as they offer users the opportunity of cost savings. Fisher-Vanden 
et al. (2006) use a panel of 22,000 Chinese large and medium enterprises to study improvements in energy efficiency. Between 1997 and 1999, total energy use fell by 17\%. Fifty-four percent of this decline can be explained by price changes. Technological change, measured by firm-level R\&D, accounts for $17 \%$ of this change, and changes in ownership account for another $12 \%$. Looking more closely at the role of technological change, they find that imported technology saves labor and energy, whereas internal R\&D from Chinese firms saves capital and energy. They explain this difference by noting that technological change responds to the resource scarcities in the country supplying the technology. They also find that a firm's in-house technological activities are important for creating absorptive capacity needed for successful diffusion of imported technology.

Fisher-Vanden (2003) studies the diffusion of continuous casting technology for steel production at 75 Chinese steel firms. The use of continuous casting has important energy implications, as it uses $70 \%$ less energy than ingot casting. Fisher-Vanden finds that while centrally managed firms are the first to acquire new technology, locally managed firms complete integration of the technology throughout the firm more rapidly.

Finally, several papers have looked at the intersection of politics and technology transfer. Fredriksson and Wollscheid (2008) study the adoption of cleaner steel production technologies across countries, measured by the percentage of steel produced using electric arc furnaces. While stricter environmental policy does encourage greater adoption of cleaner techniques, they surprisingly find that adoption of cleaner technologies is greater in countries with more corruption. They argue that firms in honest countries underinvest in technology in order to convince regulators to keep environmental standards weak. In corrupt countries, firms can invest in better technologies, and instead use bribes to weaken environmental regulations.

Rosendahl (2004) considers the role of learning on optimal environmental taxes across countries. When the benefits of learning extend beyond the firm, optimal environmental taxes should be higher, so as to give incentives for providing the positive learning externality. Because environmental technologies are first developed in industrialized countries, he argues that optimal environmental taxes should be higher in developed countries than developing countries, so as to create incentives for learning in developed countries that can then benefit late adopters in developing countries.

Barrett (2006) asks whether a climate change agreement focusing on the development and adoption of new technologies could perform better than an agreement focusing on emissions reduction. In general, the answer is no. However, one exception is when R\&D leads to breakthrough technologies with increasing returns to scale. In such a case, the benefits of adopting the new technology would be great enough that the treaty would be self-enforcing. Similarly, de Coninck et al. (2008) examine the conceptual arguments and specific options for technology-oriented climate agreements aimed at knowledge sharing and coordination, $\mathrm{R} \& \mathrm{D}$, demonstration, and deployment. They find that technology-oriented climate agreements could increase the overall efficiency and effectiveness of international climate cooperation, but are only likely to be successful as a complement to, rather than substitute for, flexible emissions-based policies.

Golombek and Hoel (2004) raise the possibility that induced technological change could help alleviate the problem of incomplete participation in climate treaties. The standard presumption is that when only some countries commit to reducing carbon emissions, high-carbon industries will migrate to nonparticipating countries, resulting in carbon leakage. Golombek and Hoel note that, in the countries committed to carbon reductions, induced technological change will lower abatement costs. In some 
cases, these cost reductions will be sufficient to encourage nonparticipating countries to reduce carbon emissions as well. In Golombek and Hoel's model, R\&D is chosen by a central planner. Di Maria and van der Werf (2008) perform a similar analysis, but allow technological change to be truly endogenous, as it is performed by profit-maximizing firms. They show that induced technological change always reduces the rate of carbon leakage, although the results depend on assumptions about key elasticities, particularly the elasticity of energy supply. Others have also investigated how the nature of global environmental problems, technological diffusion, and international trade can provide arguments for issues linkage where more countries may participate and comply with international agreements on environmental policy and technology policy if they are linked than if they are treated separately (see, e.g., Carraro and Egenhofer, 2002; Folmer and van Mouche, 1993; Kemfert, 2004).

Finally, Newell (2008b) considers opportunities for improved and expanded international development and transfer of climate technologies. He clarifies the importance of options for inducing technology market demand through domestic GHG pricing, international trade, and international development assistance, and then turns to upstream innovation strategies, including international coordination and funding of climate technology R\&D, and knowledge transfer through intellectual property. Newell concludes that a successful international effort to accelerate and then sustain the rate of development and transfer of GHG mitigation technologies must harness a diverse set of markets and institutions beyond those explicitly related to climate, to include those for energy, trade, development, and intellectual property.

\subsubsection{What can technological change economists contribute?}

International diffusion of environmental technologies is an area where much work remains to be done. While there is a broad, more general literature on international technology diffusion, specific applications to the environment are few. However, the lessons from this literature, such as documenting links between trade and diffusion, are just beginning to filter into environmental economics. Among the questions waiting to be addressed include the role of absorptive capacity. What must be in place for developing countries to be able to adopt cutting edge environmental technologies? To what extent will developing countries need to adapt these innovations to local market conditions? Disentangling the role of embodied and disembodied technological change, such as in the work by Fisher-Vanden et al. (2006) is also important. To what extent will improvements in developing countries come from imports of advanced technology, as opposed to innovations made in developing countries? At what speed do these international technology transfers occur? Answers to questions such as these would be very useful for economists wishing to model the role of technological change for sustainable development.

\section{Technological change in aggregate energy-environment models}

As noted in the introduction, the potential environmental impacts of technological change play an important role in the long-term sustainability of economic growth. This is particularly true in the realm of climate policy, for which most impacts will not be felt for years to come, and for which current technologies are not sufficient to meet many of the emissions targets advocated at politically acceptable cost. To assess the role of technological change on long-term environmental and economic well-being, economists have developed aggregate economic models that integrate economic growth, technological 
change, and environmental impacts. These models demonstrate both the potential for new technologies to limit the environmental impact of economic growth, and the challenges of accurately forecasting long-term technological trends.

Indeed, one of the most difficult questions remaining in aggregate energy-economic modeling is the appropriate treatment of technological change-particularly for analyzing long-term environmental and resource problems. The approach to modeling technological change is widely considered to be one of the most important determinants of the results of climate policy analyses; that is, the level of emissions abatement that can be achieved at a given cost. However, the detailed microeconomic analyses of the previous two sections suggest complex mechanisms by which these processes work. These mechanisms are not captured easily in modeling frameworks, creating significant difficulties for modelers attempting to determine the effects of policies that inevitably are intertwined with technological change in energy supply and demand technologies. Gillingham et al. (2008)_from which this section draws considerably_provide an in-depth review of this issue. ${ }^{15}$ Our focus here is on the techniques used to include technological change in these models, as well as the implications of these modeling choices.

The most widespread method of treating technological change in environmental policy modeling is to consider it an exogenous variable-simply an autonomous function of time. The fundamental distinction between exogenous technological change and endogenous technological change is that with exogenous technological change production possibilities depend only on time, whereas with endogenous technological change, these possibilities can depend in a variety of ways on past, present, and/or future expected prices and policy. Thus, with endogenous technological change current technological possibilities for producing output with various combinations of capital, labor, and emission limits depend on past activities. In turn, there is a dependence of future technological possibilities on current actions.

Given the large number of other reviews of the endogenous modeling literature, as applied to climate modeling, we focus on select papers that illustrate key concepts and provide insight into the theoretical basis for this modeling methodology. With only a few exceptions most studies find that the ramifications and insights elucidated by incorporating endogenous technological change are important quantitatively.

\subsection{Exogenous technological change}

There are several different ways that climate policy modelers have incorporated technological change even when it is only a function of time. The simplest approach to technological change is to assume that a Hicks-neutral productivity gain governs the overall progress of the economy. However, this approach does not capture the potential for technological change to proceed in an energy (and carbon)-saving (or energy-using) manner. An easy modification that reflects an energy-saving direction to productivity improvements — within either the economy as a whole, or an individual sector—is to include a so-called autonomous energy-efficiency improvement (AEEI) parameter, which increases the energy efficiency

\footnotetext{
15 For surveys of the literature and other overviews of modeling methodology, see the references given in Gillingham et al. (2008), including Loschel (2002), Clarke and Weyant (2002), Grubb et al. (2002), Goulder (2004), Smulders (2005), Vollebergh and Kemfert (2007), Edenhofer et al. (2006), Köhler et al. (2006), Sue Wing (2006), and Edmonds et al. (2000).
} 
of the economy by some exogenous amount each year. The use of an AEEI parameter is particularly common in more aggregated models (e.g., MacCracken et al., 1999; Nordhaus, 1994).

In more disaggregated models, overall energy-saving progress can also be implemented by Hicksneutral productivity gains in a more energy-efficient sector or technology, or by adding a new energyefficient technology to the menu of available technologies at a given point in time. AEEI has the primary advantage of simplicity and transparency, and in addition reduces the risk of model nonlinearities, multiple equilibria, and permits ready sensitivity analysis with different AEEI values.

In a similar vein, the incorporation of "backstop technologies" into models can also be thought of as a form of exogenous technological change. Backstop technologies are typically carbon-free energy sources that may be already known, but are not yet commercialized widely. It often is assumed that such a backstop technology is available in a virtually unlimited supply at a constant, but relatively high, marginal cost (e.g., advanced solar power, nuclear fusion). If the price of energy inclusive of carbon policy becomes high enough, the backstop technology will penetrate the market and prevent the price of energy from rising further. Modelers often assume that the cost of the backstop technology is decreasing with time at its own autonomous rate-effectively implying that if the backstop comes into effect, then technology is improving solely as a function of time.

Finally, in some econometric models with flexible functional forms there may be multiple trends determining the overall level and direction of technological change. For example, Jorgenson and Wilcoxen (1993) include five parameters describing technological change-two describing the overall level and three describing the direction (i.e., the vector of factor biases).

\subsection{Endogenous technological change}

While modeling technological change exogenously simplifies the modeling of technological change, there is a wide literature acknowledging that technological change is a complex process that is dependent on more than just the passage of time. This implies, among other things, that the cost function depends not just on time and current prices, but also on historic indicators of prices and activity. This view has motivated considerable modeling work on the processes by which historic prices (and policies) influence today's production possibilities. ${ }^{16}$ In particular, some of these studies criticize the use of AEEI as neglecting the causes that affect the evolution of technologies, leading to distorted and inappropriate model results. ${ }^{17}$ Table 6 presents some of the key papers in this rapidly growing literature.

One approach is to summarize the influence of historic prices and activity in terms of an unobserved "knowledge stock" that governs overall level and direction (i.e., input-bias) of technological change. The difficulty lies in determining exactly how this stock accumulates and affects future energy use and emissions. As the empirical evidence in Section 3 suggests, prices, $R \& D$, and learning through past

\footnotetext{
16 This extensive literature of endogenous technological change includes an edited book (Grübler et al., 2002), and four special journal issues (Resource and Energy Economics, 2003, vol. 25; Energy Economics, 2004, vol. 26; Ecological Economics, 2005, vol. 54; and The Energy Journal, Special issue 2006)

17 This is related to the Lucas (1976) critique in that AEEI is not a "deep" structural parameter and it is unlikely to remain stable as policymakers change their behavior.
} 
Table 6

Technology in climate change models

\begin{tabular}{|c|c|c|c|}
\hline Article & Model type $^{a}$ & $\begin{array}{l}\text { Technological } \\
\text { change }^{b}\end{array}$ & Key results \\
\hline Jakeman et al. (2004) & CGE & PI & PI technological change lead to decrease in abatement costs \\
\hline Popp (2004) & IAM & $R \& D$ & $\begin{array}{l}\text { Induced innovation increases welfare by } 9 \% \text {. Partial crowding out of other R\&D } \\
\text { assumed }\end{array}$ \\
\hline Buonanno et al. (2003) & IAM & $\mathrm{R} \& \mathrm{D}$ & $\begin{array}{l}\text { Induced innovation plays larger role. Climate } R \& D \text { does not crowd out other } \\
R \& D\end{array}$ \\
\hline Gerlagh (2008) & ME & $R \& D$ & $\begin{array}{l}\text { Models clean, dirty, and neutral R\&D. Policy-induced clean R\&D crowds out } \\
\text { dirty R\&D, enhancing the benefits of induced } R \& D\end{array}$ \\
\hline Smulders and de Nooij (2003) & CGE & $R \& D$ & $\begin{array}{l}\text { Endogenous technological change lowers costs of energy conservation policy, } \\
\text { but crowd out non-energy R\&D resulting in no increase in total R\&D. Energy } \\
\text { conservation policy reduces net per capita income levels }\end{array}$ \\
\hline van Zon and Yetkiner (2003) & ME & $R \& D$ & $\begin{array}{l}\text { Energy tax recycled as R\&D subsidy promotes long-term growth by induced } \\
\text { technological change }\end{array}$ \\
\hline Sue Wing (2006) & CGE & $\mathrm{R} \& \mathrm{D}$ & $\begin{array}{l}\text { Effect on R\&D depends on substitutability between clean and dirty inputs. The } \\
\text { stringency of environmental tax affects the dirty } R \& D \text { activities. With low taxes, } \\
\text { dirty R\&D may increase. The higher the tax, cleaner the R\&D }\end{array}$ \\
\hline Goulder and Schneider (1999) & CGE & $\mathrm{R} \& \mathrm{D}$ & $\begin{array}{l}\text { Endogenous technological change lowers costs of achieving a given target, but } \\
\text { leads to higher gross costs of a carbon tax }\end{array}$ \\
\hline Nordhaus (2002) & IAM & $R \& D$ & $\begin{array}{l}\text { Substitution more important than innovation. Assumes climate R\&D crowds out } \\
\text { other R\&D }\end{array}$ \\
\hline Sue Wing (2003) & CGE & $\mathrm{R} \& \mathrm{D}$ & Carbon tax reduces overall growth by slowing down technological change \\
\hline Grübler and Messner (1998) & ES & LBD & $\begin{array}{l}\text { Abatement activity is optimized with large abatement in earlier period and small } \\
\text { abatement in later period }\end{array}$ \\
\hline Manne and Richels (2004) & CGE/IAM & LBD & $\begin{array}{l}\text { Optimal abatement activity includes small abatement in earlier period and large } \\
\text { abatement in later period }\end{array}$ \\
\hline Goulder and Mathai (2000) & $\mathrm{CF}$ & $\mathrm{LBD} / \mathrm{R} \& \mathrm{D}$ & LBD does not significantly affect optimizing abatement profile \\
\hline
\end{tabular}

${ }^{a}$ CGE, computable general-equilibrium model; ME, macroeconometric model; IAM, integrated assessment model; ES, disaggregated energy technology and system model; CF, cost-function model; IAM, integrated assessment model.

${ }^{b}$ PI, price-induced; LBD, learning-by-doing; R\&D, research and development. 
experience all play some role in the accumulation of this stock, yet there is no single structural theory that addresses exactly how this occurs, and hence, how each influences future production possibilities.

An important element of incorporating endogenous technological change is whether one assumes the "base case" behavior of technological change-in the absence of climate policy—is roughly optimal. One line of reasoning is that exogenous technological change represents a constraint that, when relaxed, yields lower costs for reducing emissions. A number of studies find this result when endogenous technological change is coupled with the possibility that technological change is undersupplied due to innovation market imperfections (Grubb et al., 2002). In contrast, other studies implicitly or explicitly assume that technological change in the base case is (roughly) optimal; therefore, allowing it to change in response to policy changes may not affect mitigation costs very much (e.g., Goulder and Mathai, 2000; Goulder and Schneider, 1999; Nordhaus, 2002; Smulders and de Nooij, 2003; Sue Wing, 2003). These implicit assumptions about the optimality of technological change in the base case often confound comparisons of the implications of different approaches for endogenizing technological change. Another factor that can influence results across models is whether other technological change parameters are adjusted once endogenous technological change is added, in order to allow for evenhanded comparisons (Fischer and Newell, 2008; Gerlagh, 2007).

Although difficult to categorize neatly, the most commonly used approaches model endogenous technological change in one of three ways: direct price-induced, R\&D-induced, and learning-induced. Direct price-induced technological change implies that changes in relative prices can spur innovation to reduce the use of the more expensive input (e.g., energy) in accordance with the Hicks-induced innovation hypothesis. R\&D-induced technological change allows for $R \& D$ investment to influence the rate and direction of technological change. It often involves an explicit knowledge capital stock. Finally, learning-induced technological change allows for the unit cost of a particular technology to be a decreasing function of the experience with that technology. LBD is the most commonly employed method used in this approach, where the unit cost of a technology is typically modeled as a decreasing function of its cumulative output (see Section 5.2.3).

\subsubsection{Direct price-induced technological change}

Direct price-induced technological change is a relatively straightforward method of endogenizing technological change, with conceptual roots dating back to Hicks (1932). In the context of climate policy modeling, if the price of energy rises, price-induced technological change will lead to greater energy efficiency, often through a productivity parameter that is tied to historic prices (or whose change is tied to current prices) or through earlier diffusion of energy-efficient technologies. The exact pathway through which this occurs depends greatly on the model structure. There are only a few examples of direct price-induced technological change used in climate policy models due to the somewhat ad hoc, reduced-form nature of specifying the relationship between price and technological change. In particular, there is no accounting for the cost of achieving these changes, which may involve R\&D investments (see Section 5.2.2). It is most common for models that use price-induced technological change to use an AEEI parameter or an LBD approach.

Perhaps the most faithful representation of price-induced technological change is Jakeman et al. (2004), who assume a fixed amount of technological change in each region and time period, which is allocated across inputs to all industries according to the relative prices of the inputs. In this case, 
including price-induced technological change reduces the cost of meeting carbon mitigation targets. Other examples in energy-economic modeling include Dowlatabadi (1998) and the US Energy Information Administration's NEMS model (Energy Information Administration, 2003). The empirical evidence presented in Section 3.1 suggests that the price-inducement form of technological change has merit as a partial explanation; higher energy prices clearly are associated with faster improvements in energy efficiency. However, the reduced-form approach largely has been passed over for the R\&D- or learning-induced technological change methodologies.

\subsection{2. $R \& D$-induced technological change}

R\&D-induced technological change is one of the most common approaches used to endogenize technological change, and a variety of models have been developed along these lines. R\&D-based technological change has a long-running theoretical foundation beginning with the early work by Kennedy (1964), Kamien and Schwartz (1968), and Binswanger and Ruttan (1978) in developing the innovation possibility frontier (IPF) and the theory behind induced technological change. More recent work by Acemoglu (2002) addresses how the trade-off between innovation in different directions inherent in the IPF results endogenously from a firm's dynamic optimization. This approach parallels the endogenous-growth literature (e.g., Acemoglu, 1998; Aghion and Howitt, 1998; Grossman and Helpman, 1994; Kily, 1999; Kortum and Eaton, 2008; Lucas, 1988; Romer, 1990) in including a stock of "knowledge capital" when modeling economic growth. Recently, the concept of induced innovation has enjoyed a renaissance in economics through Acemoglu's work on directed technological change.

Climate policy modelers have introduced a knowledge stock in a variety of different ways. While the theoretical basis for relative prices inducing technological change in a particular direction is quite welldeveloped, exactly how the knowledge stock accumulates and influences production possibilities is not completely settled in the literature. In some models, the concept of the knowledge stock is made more concrete by using an IPF to govern how investments in R\&D increase the knowledge stock. Popp (2004) develops one such model and discusses the use of empirical evidence to parameterize the IPF. Model structures vary in terms of whether they permit embedding the IPF within a perpetual inventory framework for the knowledge stock, analogous to inventory methods for standard capital stocks.

Several themes resonate throughout the R\&D model literature. Two key points are whether R\&Dinduced technological change is associated with an innovation market imperfection due to spillovers, and whether carbon-saving $R \& D$ crowds out $R \& D$ in other sectors. There clearly exists a tension between spillovers and crowding out, with the former tending to point to greater cost savings when endogenous technological change is included and the latter dampening or even overturning that effect. In many models, the degree to which spillovers and crowding out arise is a complex interaction among underlying assumptions about model structure and distortions in the R\&D market. Yet, these assumptions have important ramifications for the total cost of a climate policy as well as the conclusions drawn about the degree to which estimates based on exogenous technology assumptions are biased. There is only a small empirical and conceptual literature to guide assumptions of the degree of crowding out, primarily on the elasticity of the science and engineering workforce in relation to greater $R \& D$ incentives (David and Hall, 2000; Goolsbee, 1998; Wolff, 2008).

A third point is whether there is a substitutability, as in most papers, or complementarity between the generation of output (i.e., conventional production) and the generation of new knowledge 
(i.e., innovation). Most approaches have some mechanism where the generation of output substitutes for the generation of knowledge, implying a larger role for crowding out and less opportunity for gains from endogenous technological change. Related to this issue is the important difference among models in the elasticity of the supply, or opportunity cost, of additional R\&D. If there is a relatively inelastic supply of $R \& D$ (e.g., capable engineers and scientists), more effort on climate mitigation $R \& D$ reduces the ability of other firms or sectors to perform $R \& D$, effectively crowding out $R \& D$ activity. This implies that the cost of a carbon constraint could be more or less costly with the inclusion of endogenous technological change (vs. presumptively leading to lower costs).

Theoretical models of $R \& D$-induced technological change Including a knowledge stock in the production function does not on its own imply a pathway for inducing carbon-saving technological change. In the simple formulation of a knowledge stock that is most true to the endogenous growth literature, the knowledge stock increases the productivity of all inputs equally. For example, Buonanno et al. (2003) extend the Nordhaus and Yang (1996) RICE model to implement such a knowledge stock in the endogenous technological change-RICE numerical model. This simple methodology for endogenizing technological change may be useful to capture important aggregate dynamics, but it does not provide a pathway for relative prices to influence energy-saving or carbon-saving innovation.

Smulders and de Nooij (2003) and van Zon and Yetkiner (2003) both build on the endogenous growth literature that includes a continuum of intermediate goods (e.g., Romer, 1990) and apply a variation of this modeling approach to an economy that includes energy as an input to production. In Smulders and de Nooij, endogenous technological change is achieved by improvements in the quality of the continuum of intermediate goods through investment in $\mathrm{R} \& \mathrm{D}$, while van Zon and Yetkiner achieve endogenous technological change through increases in the variety of the continuum of intermediate goods through R\&D investment. Both papers demonstrate the important theoretical point that profit maximization by innovating intermediate goods producers can give rise to a change in the direction of technological change toward energy-saving technological change based on increasing energy prices or constrained energy quantities.

Smulders and de Nooij's modeling framework allows for policy analysis examining the short- and long-run growth implications of energy conservation policies but does not address questions of economic welfare. They find that energy-conservation policy will lead to reduced net per capita income levels due to the direct costs of the policy outweighing the offsetting effect of induced innovation. Nonetheless, the endogenous technological change framework does reduce the cost of a policy, although nonenergy R\&D activities may be crowded out, with no increase in total R\&D. In fact, a theoretical result based on this model structure is that the gains from induced innovation will never offset the initial policy-induced decline in per capita income levels, obviating the possibility of "win-win" situations. As a general proposition, endogenous technological change should induce higher long-run output only if spillovers are relatively high in carbon-saving innovation compared to other areas that would otherwise receive R\&D effort. This appears not to be the case in Smulders and de Nooij's model. The same messages arise in Goulder and Schneider (1999) and Gerlagh (2008).

In contrast, van Zon and Yetkiner use a blueprint framework to find that an energy tax that is recycled in the form of an R\&D subsidy may increase long-run growth, through R\&D-induced technological change. This result stems from two different market imperfections in the R\&D market: (1) firms do not consider the effect that current $R \& D$ has on increasing the productivity of future $R \& D$ investment 
because it is not captured appropriately in the price of the blueprints, and (2) a market imperfection in the supply of intermediates that leads to too low of a demand for those intermediates relative to the social optimum. Effectively, these market imperfections imply an intertemporal spillover for each firm, rather than a spillover from the research of one firm to other firms. Crowding out also plays a less prominent role in the van Zon and Yetkiner model than in Smulders and de Nooij.

Sue Wing (2006) develops this theory in the context of climate change policy by adding externalities and environmental taxation to Acemoglu's (2002) model. Sue Wing shows that an environmental tax always biases production away from the dirty good toward the clean good. However, this does not necessarily mean that the environmental tax also biases innovation toward research on the clean good. Rather, this depends on the substitutability between clean and dirty inputs. If the clean input is not readily substitutable for the more expensive dirty input, the absolute quantity of dirty R\&D exhibits a hump-shaped profile, so that it increases under small environmental taxes, but declines under higher environmental taxes. That is, a low environmental tax encourages research to make the dirty input more productive, so as to get more output from each unit of the dirty input.

Numerical models of $R \& D$-induced technological change Unfortunately, theoretical models with continuous intermediate goods and abstract representations of blueprints are not well suited to match technological change up to measurable real-world variables or technologies that most numerical models attempt to represent. However, the more general notion of including a Hicks-neutral knowledge stock, as shown above in Buonanno et al. (2003) or factor-augmenting knowledge stock, as in Smulders and de Nooij (2003), is a common choice for numerical models that include an economy-wide production function. Popp (2004) provides a good example of this approach in an economy-wide production function. Gerlagh and Lise (2005), Hart (2008), and Gerlagh (2008) also employ simple calibrated R\&D models within an assessment of climate policy-induced innovation.

In the DICE model (Nordhaus, 1994), one of the best known models of climate policy, carbon intensity (i.e., carbon per unit of GDP) is affected by the substitution of capital and labor for carbon energy. This is modified in the R\&DICE model in Nordhaus (2002), so that carbon intensity is determined by an IPF, which is a function of R\&D inputs into the carbon-energy sector. The cost of investing in knowledge through $\mathrm{R} \& \mathrm{D}$ is subtracted from consumption in the DICE model's output balance equation, analogous to conventional investment. In the case of $R \& D$ investment, however, the cost of research is multiplied by four to reflect a generic innovation market imperfection; that is, that the social opportunity cost of R\&D exceeds its private cost due to crowding out.

Nordhaus (2002) compares this endogenous technological change specification with the specification in DICE (where carbon intensity only is affected by mitigation efforts substituting abatement for consumption). His primary conclusion is that induced innovation is likely to be less powerful of a factor in reducing emissions than substitution. This result is related directly to the calibration that assumes the returns to R\&D equal the opportunity costs, allowing crowding out to have an important effect. Buonanno et al. (2003) provide a different variation on Nordhaus' approach by making emission intensity a function of a knowledge stock that accumulates one-to-one with R\&D investment and depreciates at an exogenous rate; however, there is no potential for climate-friendly R\&D to compete with or crowd out other R\&D. As such, they find a much larger role for induced innovation. Using the ENTICE model, Popp (2004) investigates the importance of R\&D crowding out more carefully. The base case of ENTICE assumes that one-half of new energy R\&D crowds out other R\&D. In this case, 
induced innovation increases welfare by $9 \%$. Assuming no crowding out increases the welfare gains from induced innovation to as much as $45 \%$. Similarly, assuming full crowding of R\&D reduces welfare gains to as little as $2 \%$. Finally, Gerlagh (2008) extends this work by separately modeling the choice of carbon-energy-producing $R \& D$, carbon-energy-saving $R \& D$, and neutral $R \& D$. In such a case, it is carbon-producing $R \& D$, rather than neutral $R \& D$, that is crowded out by induced carbon-energy-saving $\mathrm{R} \& \mathrm{D}$. As a result, the impact of induced technological change is larger, with optimal carbon taxes falling by a factor of 2 .

Multisector general equilibrium models differ from the previous approaches in that the economy is disaggregated into distinct sectors and the economic activity within and between sectors is modeled. ${ }^{18}$ The strength of the approach is that it may provide additional insights on the effects of interactions between sectors, such as spillovers - or crowding out - from R\&D. The cost is that general equilibrium models tend to be data intensive and computationally demanding. Just as in several of the models discussed above, some general equilibrium models explicitly endogenize technological change through the inclusion of knowledge capital in the production function, albeit at a sectoral level, rather than economy-wide.

One notable example is Goulder and Schneider (1999). Goulder and Schneider develop a partial equilibrium analytical framework and then implement some of the resulting insights in a numerical general equilibrium model that endogenizes technological change, with a particular emphasis on spillover effects. Specifically, in their general equilibrium model, Goulder and Schneider divide the knowledge stock into appropriable knowledge and nonexcludable knowledge. The nonexcludable knowledge represents the spillover knowledge enjoyed by all firms in each industry (but not across industries). A scaling factor is then used to determine the effect of spillovers on output in a CES production function for a representative firm in each industry. R\&D thus influences output both through the firm's input of appropriable knowledge and the spillovers from nonexcludable knowledge generated in the industry. Goulder and Schneider find that the presence of endogenous technological change in their model leads to lower costs of achieving a given abatement target, but higher gross costs of a given carbon tax (i.e., costs before netting out climate benefits). In fact, both costs and benefits of a given carbon tax are higher relative to their model with only exogenous technological change, due to more extensive carbon abatement, for the economy responds more elastically to price shocks from the policy. With environmental benefits included, Goulder and Schneider find greater net benefits of this higher abatement level for a given carbon tax when endogenous technological change is present. This outcome can be reinforced or muted if there are prior distortions in R\&D markets, depending on the type of distortions.

One important feature underlying these results is a crowding out effect where expansion of knowledge generation in one sector comes at a cost to other sectors due to the limited pool of knowledgegenerating resources (i.e., there is a positive and increasing opportunity cost to $R \& D$ in one sector). A carbon-tax policy serves to spur $R \& D$ in the alternative energy sector, but discourages $R \& D$ in non-energy and conventional energy sectors due both to slower growth of output in those industries and the limited pool of knowledge-generating resources. On the other hand, the knowledge spillover effects, whereby policy-induced $R \& D$ has social returns above private returns, provide additional benefits from a climate policy above the environmental benefits. However, the presence of endogenous technological change with spillovers does not imply the possibility of zero-cost carbon abatement, unless the spillovers overwhelm the crowding out effect, a largely empirical question.

18 Others have taken a macroeconometric approaches (e.g., Carraro and Galeotti, 1997). 
Sue Wing (2003) incorporates endogenous technological change into a detailed general equilibrium model, building on several of the concepts in Goulder and Schneider (1999) and others. At the core of Sue Wing's model is a recursive, dynamic general equilibrium model in which a representative agent maximizes welfare. A major difference between Sue Wing's model and previous models is that Sue Wing further distinguishes several of the factors influencing innovation to gain insight into the general equilibrium effects of inducing innovation in one sector and its consequences for the cost of carbon policies. Conceptually, Sue Wing describes his approach in terms of two commodities: a "clean" commodity and a "dirty" commodity. Sue Wing (2003) finds that a carbon tax reduces aggregate $\mathrm{R} \& \mathrm{D}$, slowing the rate of technological change and the growth in output. Given the fixed-saving rule and absence of knowledge spillovers in the model, this follows from having a smaller economy due to the carbon tax. However, the relative price effects of a carbon tax lead to considerable reallocation of knowledge services, enabling the economy to adjust to the carbon tax in a more elastic manner, reducing the total costs of the carbon tax.

\subsubsection{Learning-induced technological change}

Learning-induced technological change approaches tend to be quite different than R\&D-induced approaches. These models use the concept of LBD described in Section 3.2.2, in which costs to manufacturers decrease as a function of cumulative output, or "learning-by-using," in which the decrease in costs (and/or increase in benefits) to consumers comes as a function of the use of a technology (Arrow, 1962; Rosenberg, 1982). The primary disadvantage to the incorporation of learning-induced technological change into aggregate economic modeling is its reduced-form nature. LBD can be inserted mechanically into many models, but it is difficult to identify the mechanisms behind LBD_or even be confident about the causality. The ease with which learning curves can be estimated may give a false sense of comfort and precision that may belie the $R \& D$ or other resources that went into the technology development (Clarke and Weyant, 2002). For instance, it may be that the part of the underlying force driving learning curves is $\mathrm{R} \& \mathrm{D}$, which tends to be roughly proportional to sales. In fact, some have used learning curve estimates to calibrate an R\&D-based model (Gerlagh and Lise, 2005).

Despite its disadvantages, the tractability of learning curves has led to the use of learning-induced technological change throughout the literature, particularly in disaggregated or so-called "bottom-up" models. Disaggregated models are well suited for incorporating learning because of their rich technology specificity, which easily lends itself to a learning curve for each technology. Some more aggregated models also use learning, but it is not as common.

A common result of including endogenous technological change through LBD is that the carbon tax needed to attain a specific $\mathrm{CO}_{2}$ concentration target tends to be lower than in models without LBD. This result is intuitive-with LBD modeled as described above, no R\&D expenditure is needed and any additional capacity of carbon-free energy technologies will lower the costs of that technology in the future, leading to more emissions reductions per dollar of further investment. Another commonly observed result of incorporating LBD in climate policy models is that the optimal abatement path to reach a given concentration target involves increased near-term abatement and less abatement later (Grübler and Messner, 1998). This result occurs because increased near-term abatement encourages earlier LBD in low-carbon technologies, which lowers the long-term costs of abatement. Van der Zwaan et al. (2002) also find a strong effect of LBD on the timing of abatement, showing that earlier abatement 
is desirable when LBD is included in climate models, and that the carbon taxes needed to achieve these reductions are lower, due to the cost savings resulting from LBD.

Other studies suggest that there are actually two competing effects. On one hand, there is the added value to near-term technology investment due to LBD, as just mentioned. On the other hand, LBD also leads to lower costs of future abatement, which implies that abatement should be delayed. The net result of the two opposing effects may be theoretically ambiguous, but numerical simulations by Manne and Richels (2004) suggest that the slope of the abatement curve over time actually may be steeper with LBD included, contrary to previous findings, such as those of Grübler and Messner (1998) described above.

Goulder and Mathai (2000) look at optimal carbon abatement policy in a dynamic setting, considering not only the optimal overall amount of abatement but also its timing. They consider separately cases in which innovation comes through R\&D and in which innovation comes via LBD. In the R\&D model, there are two effects of induced innovation on optimal abatement: it reduces marginal abatement costs, which increases the optimal amount of abatement. But it also increases the cost of abatement today relative to the future, because of lower abatement costs in the future. The combination of these effects implies that with R\&D-induced innovation, optimal abatement is lower in early years and higher in later years than it would otherwise be. In contrast, in the LBD model, there is a third effect: abatement today lowers the cost of abatement in the future. This reinforces the tendency for cumulative optimal abatement to be higher in the presence of induced innovation, but makes the effect on optimal nearterm abatement ambiguous. Bramoullé and Olson (2005) formalize the relationship between learning and policy, noting that if technology improves by learning by doing, abatement across time should be allocated so that marginal abatement costs are equal across time, with an adjustment for the cumulative marginal savings that current abatement provides for future costs.

\subsection{What can technological change economists contribute?}

Given the considerable variety of approaches used to include endogenous technological change in economic models for analyzing climate policy, it is clear that there is no agreement in the literature regarding a single best approach. All of the approaches have their limitations and all are approximations that miss some important phenomena underlying the complex nature of technological change, with important effects on the results of climate policy models. Perhaps more importantly, all struggle with an inherent lack of empirical data to calibrate model parameters convincingly. Thus, while exceptionally promising, there is a sense that our ability to conceptually model technological change has outstripped our ability to validate the models empirically, making this an area for high-value research and where policymakers and other normative users need to be particularly careful.

Looking forward, there are several promising areas for continued research on the modeling of induced technological change in energy-economic models. Most models simulate policy through a simple emissions constraint or by using carbon taxes to impose a price on emissions. In contrast, real-world climate policy often makes use of a variety of smaller policies, such as subsidies for technology adoption, R\&D funding and tax incentives, information programs, renewable portfolio standards, and energy-efficiency standards. Improving the ability of climate policy models to assess the effects of both price and nonprice technology policies would be a valuable contribution. This may require relaxing assumptions that the only relevant market failure is that related to the climate externality. The current 
generation of models addresses diffusion only to the extent that improperly priced pollution makes adoption of clean technologies less likely. However, as discussed in Section 4.1.2.2, empirical evidence suggests that diffusion is slow for other reasons. In this regard, greater attention to knowledge spillovers, adjustment costs, and informational market failures may be necessary. For instance, Schwoon and Tol (2006) use adjustment costs to develop a climate model with slower penetration of new technology. Given the lack of consensus as to why energy-efficient technologies are underutilized, it is not clear that one "correct" representation of gradual diffusion exists. Developing alternative means for modeling the gradual diffusion process, such as incorporating higher discount rates for potential adopters, could enable a comparison of diffusion mandates across a range of assumptions about why diffusion is gradual.

Another potential role for technological change economists is critical assessment, synthesis, and extension of the existing empirical literature on learning curves in energy technologies. This includes improving the ability of assessment models to incorporate learning effects in an economically coherent manner, as well as new empirical research avoiding the pitfalls of previous studies and that can potentially be incorporated into computational models. Assessment models would also benefit from improved treatment of technology spillovers and the opportunity cost of R\&D directed toward carbon mitigation technology. Finally, given the long-term nature of the climate problem, empirical, analytical, and numerical research on the treatment of long-term discounting in assessment models and its influence on technological change would be beneficial.

\section{Conclusions}

Technological change plays an important role in environmental policy. While new technologies can make cleaner production and more efficient resource use possible, markets are unlikely to provide proper incentives for the development of clean technologies, absent public policy. As in other areas of technological change, knowledge spillovers lead to underinvestment in R\&D by private firms. However, even if all knowledge market failures were addressed, firms would still underinvest in environmental R\&D, as many of the benefits to providing a cleaner environmental are external. By addressing the externality problem, environmental policy increases incentives for environmental R\&D.

Much of the research described in this chapter addresses the links between environmental policy and innovation. While any environmental policy should provide some additional incentive for environmentally oriented R\&D, environmental economists have focused much research on how the proper design of policy will lead to greater innovation. In particular, flexible policy instruments that provide rewards for continual environmental improvement and cost reduction tend to have better dynamic efficiency properties than policies that mandate a specific behavior.

Measuring the effects of environmental technological change is equally if not more challenging. There are three main challenges here. Because policy is needed to encourage adoption of environmental technology, one needs to separately identify the effects of both environmental policy and innovation to ascertain the gains from environmental technological change. Moreover, while innovation on alternative energy sources has increased in recent years, diffusion is still slow, as these technologies still are not cost competitive with fossil fuels without policy intervention. As a result, while there are good data on the cost of traditional energy sources, due to thorough market penetration, quality data on the cost savings accruing from early research on alternative energy sources is lacking, as such technologies have 
yet to become well-established in the market place. The data that do exist are often aggregate in nature, making identifying the various effects of $\mathrm{R} \& \mathrm{D}$, experience, and policy difficult, as in our discussion of learning curves in Section 3.2.2.

A third challenge for estimating the effects of environmental technological change is the role of government $R \& D$, particularly with respect to environmentally-friendly energy R\&D. Government $\mathrm{R} \& \mathrm{D}$ is particularly important for energy, where many technologies are still years from being commercially viable. The combination of long-term payoffs and high uncertainty make government R\&D a popular policy choice. However, there is little research evaluating the effectiveness of these programs, making this a fruitful topic for technological change scholars interested in doing research on environmental topics.

As with environmental innovation, studies on the diffusion of environmental technologies also find that regulation is necessary for diffusion to occur. One notable difference is between environmental technologies (e.g., pollution control) and energy-efficiency technologies. Without environmental regulation, there is little private benefit to pollution control. Thus, as expected, regulation is necessary for diffusion to occur. Individual consumers or firms can benefit from choosing energy efficient technologies, as adopters benefit from lower energy bills. However, research on the adoption of energyefficiency technologies suggests that decision making by both firms and consumers is potentially subject to market and behavioral failures (Gillingham et al., 2009). Both environment and technological change have, in the last several decades, benefitted greatly from an increased attention to the micro over the macro, and to empirical measurement over pure theory. To address questions such as the "energy paradox," one might expand the scope of microempirical analysis to include a wider array of factors affecting people's decisions-what could be termed as a Behavioral Economics of Environmental Technology Innovation and Diffusion.

In recent years, environmental economists have begun to investigate the role of international technology diffusion for environmental technologies. International diffusion is particularly important for problems such as climate change, as carbon emissions are growing faster in developing nations than in the developed world. Recent research suggests that these developing countries can take advantage of clean technologies developed in high income countries, but that both environmental and trade policy will affect the pace and quality of international technology diffusion. Compared to the more general literature on international technology transfer, applications pertaining to the environment are scarce, and are another area where technological change scholars could have a significant impact.

Aggregate economic models combining economic growth, technological change, and environmental policy demonstrate the important long-term benefits that can come from environmentally friendly technological change. Unchecked by environmental policy, increased economic growth is likely to come with increased environmental impacts. While the costs of mitigating these impacts could lower future growth, technological change offers the opportunity to offset increasing environmental compliance costs. Still, just as the modeling of technological change itself in macroeconomics is still evolving, there is much work to be done on aggregate economic representations of environmental technological change. Moreover, both technological change and environmental policy are areas where the usual presumption of efficiency of competitive markets is reversed-the presumption is of market failure. Yet recommendations regarding good policy still depend on important empirical magnitudes that are often not well measured.

One key question is estimating baseline technological change. Even without policy changes, some environmentally technologies will develop. This is particularly important for climate change, as energy 
efficiency has historically improved over time. Rates of future technological change have a large impact on projections of future carbon emissions. As policy evolves to reduce future carbon emissions, baseline projections help determine how stringent climate policies must be in order to attain certain environmental goals, and in turn what the economic cost of these constraints may be. Also important here is integrating the microeconomic foundations of technological change into macroeconomic representations of climate policy. Many models still overlook basic features of knowledge markets, such as the role of knowledge spillovers. As shown in Section 5, the assumptions about technological change used in these models can greatly influence projections about future policy costs.

We conclude by considering challenges that may be unique to environmental technological change. One question is how the dual market failures of environmental externalities and knowledge spillovers interact. Is simply combining environmental policy to address externalities with general technology policy to address spillovers sufficient, or do these two market failures interact in ways that necessitate specific technology policies for the environment?

Uncertainty may provide one interaction causing first-order policies to be insufficient. In "pure" environment issues, uncertainty is about the behavior of natural systems. In technological change this "natural" uncertainty is exacerbated by uncertainty about the behavior of human and social systems. For example, the huge uncertainties surrounding the future impacts of climate change, the magnitude of the policy response, and thus the likely returns to $R \& D$ investment, would seem to exacerbate the challenge of encouraging private environmental investment. What the future will look like will be determined, to a very significant extent, by the rate and direction of technological change between now and then. But it is also true that what happens today with respect to the investments that will determine that rate and direction is highly dependent on people's beliefs about what will happen in the future. For instance, given the need for environmental policy to encourage environmental innovation, policy makers need to both provide current incentives and signal the future costs of pollution to inventors. Are current policy instruments and institutions sufficient to address the uncertainties and long time frames often observed with environmental problems? This is a major challenge for environmental policy makers, perhaps the single greatest challenge. We hope that research on such questions can provide a framework for future work linking policy and environmental technological change.

\section{Acknowledgments}

In preparing this chapter, the authors draw heavily on earlier joint work with Robert Stavins, William Pizer, and Kenneth Gillingham. We thank them for those contributions and for all that we have learned from them. Thanks to Jung Eun Kim and Kelly Bogart for their assistance preparing this manuscript. Finally, we thank Bronwyn Hall, Reyer Gerlagh, and Nick Johnstone for helpful comments on an earlier version of this chapter.

\section{References}

Acemoglu, D. (1998). "Why do new technologies complement skills? Directed technical change and wage inequality". Quarterly Journal of Economics 113, 1055-1089.

Acemoglu, D. (2002). "Directed technical change". Review of Economic Studies 69, 781-809. Aghion, P., Howitt, P. (1998). Endogenous Growth Theory. MIT Press, Cambridge, MA. 
Anderson, S.T., Newell, R.G. (2004). "Information programs for technology adoption: The case of energy-efficiency audits". Resource and Energy Economics 26 (1), 27-50.

Arrow, K.J. (1962). "The economic implications of learning by doing”. Review of Economic Studies 29, 155-173.

Bahn, O., Kypreos, S. (2003). "Incorporating different endogenous learning formulations in MERGE". International Journal of Global Energy Issues 19 (4), 333-358.

Baker, E., Adu-Bonnah, K. (2008). "Investment in risky R\&D programs in the face of climate uncertainty". Energy Economics 30 (2), 465-486.

Barrett, S. (2006). "Climate treaties and 'breakthrough' technologies". American Economic Review 96 (2), $22-25$.

Bauman, Y., Lee, M., Seeley, K. (2008). "Does technological innovation really reduce marginal abatement costs? Some theory, algebraic evidence, and policy implications". Environmental and Resource Economics 40, 507-527.

Bellas, A.S. (1998). "Empirical evidence of advances in scrubber technology". Resource and Energy Economics 20, $327-343$.

Berndt, E.R., Kolstad, C.D., Lee, J. (1993). "Measuring the energy efficiency and productivity impacts of embodied technical change". The Energy Journal 14, 33-55.

Berry, S., Kortum, S., Pakes, A. (1996). "Environmental change and hedonic cost functions for automobiles". Proceedings of the National Academy of Sciences United States of America 93, 12731-12738.

Biglaiser, G., Horowitz, J.K., Quiggin, J. (1995). “Dynamic pollution regulation”. Journal of Regulatory Economics 8, $33-44$.

Binswanger, H., Ruttan, V. (1978). Induced Innovation: Technology Institutions and Development. Johns Hopkins University Press, Baltimore, MD.

Blackman, A., Bannister, G.J. (1998). "Community pressure and clean technology in the informal sector: An econometric analysis of the adoption of propane by traditional Mexican brickmakers". Journal of Environmental Economics and Management 35 (1), 1-21.

Blackman, A., Kildegaard, A. (2003). "Clean Technological Change in Developing-Country Industrial Clusters: Mexican Leather Tanning”. Resources for the Future Discussion Paper 03-12.

Boyd, G.A., Karlson, S.H. (1993). "The impact of energy prices on technology choice in the United States steel industry". The Energy Journal 14 (2), 47-56.

Bramoullé, Y., Olson, L.J. (2005). “Allocation of pollution abatement under learning by doing”. Journal of Public Economics 89 , $1935-1960$

Bresnahan, T.J., Trajtenberg, M. (1995). “General purpose technologies: 'Engines of growth'?” Journal of Econometrics 95, 83-108.

Brunneimer, S., Cohen, M. (2003). "Determinants of environmental innovation in US manufacturing industries". Journal of Environmental Economics and Management 45, 278-293.

Buonanno, P., Carraro, C., Galeotti, M. (2003). "Endogenous induced technical change and the costs of Kyoto". Resource and Energy Economics 25 (1), 11-34.

Cadot, O., Sinclair-Desgagne, B. (1996). "Innovation under the threat of stricter environmental standards". In: Carraro, C. et al. (Ed.), Environmental Policy and Market Structure. Kluwer Academic Publishers, Dordrecht, pp. 131-141.

Carlson, C., Burtraw, D., Cropper, M., Palmer, K. (2000). "Sulfur dioxide control by electric utilities: What are the gains from trade?" Journal of Political Economy 108, 1292-1326.

Carraro, C., Egenhofer, C. (2002). Firms, Governments, and Climate Policy: Incentive-Based Policies for Long-Term Climate Change. Edward Elgar, Cheltenham.

Carraro, C., Galeotti, M. (1997). "Economic growth, international competitiveness and environmental protection: R\&D and innovation strategies with the WARM model". Energy Economics 19 (1), 2-28.

Carraro, C., Siniscalaco, D. (1994). "Environmental policy reconsidered: The role of technology innovation”. European Economic Review 38, 545-555.

Carraro, C., Soubeyran, A. (1996). "Environmental policy and the choice of production technology”. In: Carraro, C. et al. (Ed.), Environmental Policy and Market Structure. Kluwer Academic Publishers, Dordrecht, pp. 151-180.

Clarke, L., Weyant, J. (2002). "Modeling induced technological change: An overview". In: Grübler, A., Nakicenovic, N., Nordhaus, W. (Eds.), Technological Change and the Environment. Resources for the Future Press, Washington, DC.

Cohen, L.R., Noll, R.G. (1991). The Technology Pork Barrel. Brookings, Washington, DC.

Copeland, B.R., Taylor, M.S. (2003). Trade and the Environment: Theory and Evidence. Princeton University Press, Princeton, NJ.

Cowan, R. (1990). “Nuclear power reactors: A study in technological lock-in”. Journal of Economic History 50, 541-567. 
Cowan, R., Gunby, P. (1996). "Sprayed to death: Path dependence, lock-in and pest control strategies". Economic Journal 106, 521-542.

Cowan, R., Hulten, S. (1996). "Escaping lock-in: The case of the electric vehicle". Technological Forecasting and Social Change 53, 61-79.

Cowan, R., Kline, D. (1996). The Implications Of Potential 'Lock-In' in Markets for Renewable Energy. National Renewable Energy Laboratory, Golden, CO.

David, P. (1997). “A contribution to the theory of diffusion”. In: David, P. (Ed.), Behind the Diffusion Curve. Westview Press, Boulder, CO.

David, P.A., Hall, B.H. (2000). "Heart of darkness: Modeling public-private funding interactions inside the R\&D black box". Research Policy 29, 1165-1183.

de Coninck, H., Fisher, C., Newell, R.G., Ueno, T. (2008). "International technology-oriented agreements to address climate change". Energy Policy 36, 335-356.

DeCanio, S.J. (1998). "The efficiency paradox: Bureaucratic and organizational barriers to profitable energy-saving investments". Energy Policy 26, 441-454.

Dechezleprêtre, A., Glachant, M., Ménière, Y. (2008). "The clean development mechanism and the international diffusion of technologies: An empirical study”. Energy Policy 36, 1273-1283.

Denicolo, V. (1999). "Pollution-reducing innovations under taxes or permits". Oxford Economic Papers 51, $184-199$.

Di Maria, C., van der Werf, E. (2008). "Carbon leakage revisited: Unilateral climate policy with directed technological change”. Environmental and Resource Economics 39 (1), 55-74.

Dowlatabadi, H. (1998). "Sensitivity of climate change mitigation estimates to assumptions about technical change". Energy Economics 20 (5-6), 473-493.

Downing, P.B., White, L.J. (1986). “Innovation in pollution control”. Journal of Environmental Economics and Management 13, $18-29$.

Edenhofer, O., Lessmann, K., Kemfert, K.C., Grubb, M., Kohler, J. (2006). "Induced technological change: Exploring its implications for the economics of atmospheric stabilization: Synthesis report from the innovation modelling comparison project". The Energy Journal Endogenous Technological Change and the Economics of Atmospheric Stabilisation (special issue).

Edmonds, J., Roop, J., Scott, M. (2000). Technology and the Economics of Climate Change Policy. Pew Center on Global Climate Change, Arlington, VA.

Energy Information Administration. (2003). National Energy Modeling System: An Overview 2003. U.S. Department of Energy, Washington, DC, DOE/EIA-0581.

Energy Information Administration. (2007). International Energy Outlook: 2007. U.S. Department of Energy, Washington, DC.

Esty, D.C. (2001). "Bridging the trade-environment divide". Journal of Economic Perspectives 15 (3), 113-130.

Evenson, R., Putnam, E., Kortum, J. (1991). "Estimating patent counts by industry using the Yale-Canada concordance". Final Report to the National Science Foundation.

Fischer, C. (2008). "Emissions pricing, spillovers, and public investment in environmentally friendly technologies". Energy Economics 30 (2), 487-502.

Fischer, C., Newell, R. (2008). "Environmental and technology policies for climate mitigation”. Journal of Environmental Economics and Management 55 (2), 142-162.

Fischer, C., Parry, I.W.H., Pizer, W.A. (2003). "Instrument choice for environmental protection when technological innovation is endogenous". Journal of Environmental Economics and Management 45 (3), 523-545.

Fisher-Vanden, K. (2003). "Management structure and technology diffusion in Chinese state-owned enterprises". Energy Policy 31 (3), 247-257.

Fisher-Vanden, Karen, Ho, M.S. (2006). “Technology, development, and the environment”. Working Paper, Dartmouth College.

Fisher-Vanden, K., Sue Wing, I. (2008). “Accounting for quality: Issues with modeling the impact of R\&D on economic growth and carbon emissions in developing countries". Energy Economics 30 (6), 2771-2784.

Fisher-Vanden, K., Jefferson, G., Ma, J., Xu, J. (2006). "Technology development and energy productivity in China”. Energy Economics 28 (5/6), 690-705.

Folmer, H., van Mouche, P. (1993). "Interconnected games and international environmental problems". Environmental and Resource Economics 3, 313-335. 
Fowlie, M. (2007). "Emissions Trading, Electricity Industry Restructuring, and Investment in Pollution Abatement". Working Paper, University of Michigan, forthcoming in American Economic Review.

Fredriksson, P.G., Wollscheid, J.R. (2008). "The political economy of investment: The case of pollution control technology". European Journal of Political Economy 24 (1), 53-72.

Freeman, A.M., Haveman, R.H. (1972). "Clean rhetoric and dirty water". Public Interest 28, 51-65.

Frondel, M., Horbach, J., Rennings, K. (2007). "End-of-pipe or cleaner production? An empirical comparison of environmental innovation decisions across OECD countries". Business Strategy and the Environment 16, 571-584.

Gerlagh, R. (2007). "Measuring the value of induced technical change". Energy Policy 35, 5287-5297.

Gerlagh, R. (2008). "A climate-change policy induced shift from innovations in carbon-energy production to carbon-energy savings”. Energy Economics 30, 425-448.

Gerlagh, R., Lise, W. (2005). "Carbon taxes: a drop in the ocean, or a drop that erodes the stone? The effect of carbon taxes on technological change". Ecological Economics 54, 241-260.

Gerlagh, R., van der Zwaan, R. (2006). "Options and instruments for a deep cut in CO2 emissions: Carbon dioxide capture or renewables, taxes or subsidies?" The Energy Journal 27 (3), 25-48.

Geroski, P.A. (2000). "Models of technology diffusion”. Research Policy 29, 603-626.

Gillingham, K., Newell, R.G., Palmer, K. (2006). "Energy efficiency policies: A retrospective examination”. Annual Review of Environment and Resources 31, 162-192.

Gillingham, K., Newell, R.G., Pizer, W.A. (2008). "Modeling endogenous technological change for climate policy analysis". Energy Economics 30 (6), 2734-2753.

Gillingham, K., Newell, R.G., Palmer, K. (2009). "Energy efficiency economics and policy". Annual Review of Resource Economics (in preparation).

Goldberg, P.K. (1998). "The effects of the corporate average fuel efficiency standards in the US". Journal of Industrial Economics 46, 1-33.

Gollop, F.M., Roberts, M.J. (1983). "Environmental regulations and productivity growth: The case of fossil-fueled electric power generation". Journal of Political Economy 91, 654-674.

Golombek, R., Hoel, M. (2004). "Unilateral emission reductions and cross-country technology spillovers". Advances in Economic Analysis and Policy 4 (2), Article 3. http://www.bepress.com/bejeap/advances/vol4/iss2/art3 Available at:

Goolsbee, A. (1998). "Does government R\&D policy mainly benefit scientists and engineers?". American Economic Review Papers and Proceedings 88 (2), 298-302.

Goulder, L.H. (2004). Induced Technological Change and Climate Policy. Pew Center on Global Climate Change, Washington, DC.

Goulder, L.H., Mathai, K. (2000). "Optimal CO2 abatement in the presence of induced technological change". Journal of Environmental Economics and Management 39, 1-38.

Goulder, L.H., Schneider, S. (1999). "Induced technological change and the attractiveness of $\mathrm{CO}_{2}$ abatement policies". Resource and Energy Economics 21, 211-253.

Greaker, M., Pade, L. (2008). Optimal $\mathrm{CO}_{2}$ Abatement and Technological Change: Should Emission Taxes Start High in Order to Spur R\&D?. Discussion Papers No. 548, Statistics Norway, Research Department.

Greene, D.L. (1990). "CAFE or price? An analysis of the effects of federal fuel economy regulations and gasoline price on new car MPG, 1978-89”. The Energy Journal 11 (3), 37-57.

Griliches, Z. (1957). "Hybrid corn: An exploration in the economics of technical change". Econometrica 48, 501-522.

Grossman, G., Helpman, E. (1994). "Endogenous innovation in the theory of growth". Journal of Economic Perspectives $8,23-44$.

Grubb, M., Köhler, J., Anderson, D. (2002). "Induced technical change in energy and environmental modeling”. Annual Review of Energy and the Environment 27, 271-308.

Grübler, A., Messner, S. (1998). "Technological change and the timing of mitigation measures". Energy Economics 20, 495-512.

Grübler, A., Nakicenovic, N., Nordhaus, W. (Eds.), (2002). Technological Change and the Environment. Resources for the Future Press, Washington, DC.

Hahn, R.W., Stavins, R.N. (1991). "Incentive-based environmental regulation: A new era from an old idea?" Ecology Law Quarterly 18, 1-42. 
Hall, B.H. (1996). "The private and social returns to research and development". In: Smith, B.H., Barfield, B.H. (Eds.), Technology, R\&D and the Economy. The Brookings Institution and American Enterprise Institute, Washington, DC, pp. 140-162.

Hamamoto, M. (2006). "Environmental regulation and the productivity of Japanese manufacturing industries". Resource and Energy Economics 28, 299-312.

Harrington, W., Morgenstern, R.D., Nelson, P. (2000). "On the accuracy of regulatory cost estimates”. Journal of Policy Analysis and Management 19 (2), 297-322.

Hart, R. (2008). "The timing of taxes on $\mathrm{CO}_{2}$ emissions when technological change is endogenous". Journal of Environmental Economics and Management 55 (2), 194-212.

Hascic, I., Johnstone, N., Michel, C. (2008). "Environmental policy stringency and technological innovation: Evidence from patent counts". Paper presented at the European Association of Environmental and Resource Economists 16th Annual Conference, Gothenburg, Sweden, June 26.

Hassett, K.A., Metcalf, G.E. (1995). "Energy tax credits and residential conservation investment: Evidence form panel data". Journal of Public Economics 57, 201-217.

Hassett, K.A., Metcalf, G.E. (1996). "Can irreversibility explain the slow diffusion of energy saving technologies?" Energy Policy $24,7-8$.

Hausman, J.A. (1979). "Individual discount rates and the purchase and utilization of energy-using durables". Bell Journal of Economics 10, 33.

Helpman, E. (Ed.), (1998). General Purpose Technologies and Economic Growth. MIT Press, Cambridge, MA.

Hicks, J. (1932). The Theory of Wages. Macmillan, London.

Hilton, F.H. (2001). "Later abatement, faster abatement: Evidence and explanations from the global phaseout of leaded gasoline". Journal of Environment and Development 10 (3), 246-265.

Howarth, R.B., Haddad, B.M., Paton, B. (2000). "The economics of energy efficiency: Insights from voluntary participation programs". Energy Policy 28, 477-486.

Innes, R., Bial, J.J. (2002). "Inducing innovation in the environmental technology of oligopolistic firms". Journal of Industrial Economics 50 (3), 265-287.

IPCC. (2007). "Climate change 2007: Mitigation”. In: Metz, B., Davidson, O.R., Bosch, P.R., Dave, R., Meyer, L.A. (Eds.), Contribution of Working Group III to the Fourth Assessment Report of the Intergovernmental Panel on Climate Change. Cambridge University Press, Cambridge, UK and New York, NY.

Irwin, D.A., Klenow, P.W. (1994). "Learning-by-doing spillovers in the semiconductor industry". Journal of Political Economy $102,1200-1227$.

Islas, J. (1997). "Getting round the lock-in in electricity generating systems: The example of the gas turbine". Research Policy 26, 49-66.

Jaffe, A.B. (1986). "Technological opportunity and spillovers of R\&D: Evidence from firms' patents, profits and market value". American Economic Review 76, 984-1001.

Jaffe, A.B., Lerner, J. (2001). "Reinventing public R\&D: Patent policy and the commercialization of national laboratory technologies". RAND Journal of Economics 32 (1), 167-198.

Jaffe, A.B., Palmer, K. (1997). "Environmental regulation and innovation: A panel data study". Review of Economics and Statistics 79, 610-619.

Jaffe, A.B., Stavins, R.N. (1994). "The energy paradox and the diffusion of conservation technology". Resource and Energy Economics 16, 91-122.

Jaffe, A.B., Stavins, R.N. (1995). "Dynamic incentives of environmental regulations: The effects of alternative policy instruments on technology diffusion". Journal of Environmental Economics and Management 29, S43-S63.

Jaffe, A.B., Peterson, S., Portney, P., Stavins, R.N. (1995). "Environmental regulation and the competitiveness of U.S. manufacturing: What does the evidence tell us?" Journal of Economic Literature 33, 132-163.

Jaffe, A.B., Newell, R.G., Stavins, R.N. (2003). “Technological change and the environment”. In: Mäler, K.-G., Vincent, J. (Eds.), Handbook of Environmental Economics. Handbooks in Economics Series (Arrow, K.J., Intriligator, M.D., Series Eds.), vol. 1. North-Holland/Elsevier, Amsterdam, pp. 461-516.

Jakeman, G., Hanslow, K., Hinchy, M., Fisher, B., Woffenden, K. (2004). "Induced innovations and climate change policy". Energy Economics 26 (6), 937-960. 
Jaffe, A.B., Newell, R.G., Stavins, R.N. (2005). "A tale of two market failures: Technology and environmental policy”. Ecological Economics 54, 164-174.

Johnstone, N., Hascic, I. (2008). “Environmental policy design and the fragmentation of markets for innovation”. Paper presented at the Venice Summer Institute 2008 Workshop on "Reforming Rules and Regulations_-Laws, Institutions and Implementation" Venice, Italy, July 19, 2008.

Johnstone, N., Hascic, I., Popp, D. (2010). "Renewable energy policies and technological innovation: Evidence based on patent counts". Environmental and Resource Economics 45 (1), 133-155.

Jones, C., Williams, J. (1998). "Measuring the social return to R\&D”. Quarterly Journal of Economics 113, 1119-1135.

Jorgenson, D.W., Fraumeni, B.M. (1981). "Relative prices on technical change”. In: Field, B.C., Berndt, E.R. (Eds.), Modeling and Measuring Natural Resource Substitution. MIT Press, Cambridge, MA, pp. 17-47.

Jorgenson, D., Wilcoxen, P. (1993). "Reducing US carbon emissions: An econometric general equilibrium assessment". Resource and Energy Economics 15, 7-25.

Jung, C.H., Krutilla, K., Boyd, R. (1996). "Incentives for advanced pollution abatement technology at the industry level: An evaluation of policy alternatives". Journal of Environmental Economics and Management 30, 95-111.

Kamien, M.I., Schwartz, N.L. (1968). “Optimal induced technical change”. Econometrica 36, 1-17.

Katsoulacos, Y., Xepapadeas, A. (1996). "Environmental innovation, spillovers and optimal policy rules”. In: Carraro, C., et al. (Ed.), Environmental Policy and Market Structure. Kluwer Academic Publishers, Dordrecht, pp. 143-150.

Keller, W. (2004). "International technology diffusion”. Journal of Economic Literature 42, 752-782.

Kemfert, C. (2004). "International climate coalitions and trade: Assessment of cooperation incentives by issue linkage”. Energy Policy 32, 455-465.

Kemp, R. (1997). Environmental Policy and Technical Change. Edward Elgar, Cheltenham.

Kemp, R. (1998). "The diffusion of biological waste-water treatment plants in the Dutch food and beverage industry". Environmental and Resource Economics 12, 113-136.

Kennedy, C. (1964). "Induced bias in innovation and the theory of distribution". Economic Journal 74 (295), $541-547$.

Kennedy, P.W., Laplante, B. (1999). "Environmental policy and time consistency: Emissions taxes and emissions trading”. In: Petrakis, E., Sarzetakis, E., Xepapadeas, A. (Eds.), Environmental Regulation and Market Power: Competition, Time Consistency and International. Trade Edward Elgar Publishing, Northampton, MA.

Keohane, N.O. (2007). "Cost savings from allowance trading in the 1990 Clean Air Act: Estimates from a choice-based model". In: Kolstad, Charles E., Freeman, Jody (Eds.), Moving to Markets in Environmental Regulation: Lessons from Twenty Years of Experience. Oxford University Press, New York.

Kerr, S., Newell, R.G. (2003). "Policy-induced technology adoption: Evidence from the U.S. lead phasedown". Journal of Industrial Economics 51 (3), 317-343.

Khanna, M., Zilberman, D. (2001). “Adoption of energy efficient technologies and carbon abatement: The electricity generating sector in India”. Energy Economics 23, 637-658.

Kily, M.T. (1999). “The supply of skilled labor and skill-biased technological progress”. Economic Journal 109, 708-724.

Klaassen, G., Miketa, S., Larsen, K., Sundqvist, T. (2005). "The impact of R\&D on innovation for wind energy in Denmark, Germany and the United Kingdom”. Ecological Economics 54, 227-240.

Köhler, J., Grubb, M., Popp, D., Edenhoffer, O. (2006). "The transition to endogenous technical change in climate-energy models: A technical overview to the innovation modeling comparison project". The Energy Journal 17-55, Endogenous Technological Change and the Economics of Atmospheric Stabilization (special issue).

Kortum, S., Eaton, J. (2008). "Endogenous innovation and growth theory”. In: Hall, B.H., Rosenberg, N. (Eds.), Handbook of Economics of Technological Change. (this volume).

Kortum, S., Putnam, J. (1989). "Estimating Patents by Industry: Part I and II”. Unpublished manuscript, Yale University.

Kortum, S., Putnam, J. (1997). “Assigning patents by industry: Tests of the Yale Technology Concordance”. Economic Systems Research 9, 161-175.

Laffont, J., Tirole, J. (1996). "Pollution permits and compliance strategies". Journal of Public Economics 62, 85-125.

Lange, I., Bellas, A. (2005). "Technological change for sulfur dioxide scrubbers under market-based regulation”. Land Economics $81(4), 546-556$.

Lanjouw, J.O., Mody, A. (1996). "Innovation and the international diffusion of environmentally responsive technology". Research Policy 25, 549-571. 
Lanoie, P., Laurent-Lucchetti, J., Johnstone, N., Ambec, S. (2007). Environmental Policy, Innovation and Performance: New insights. Working Paper 2007-07, GAEL.

Lecocq, F., Ambrosi, P. (2007). "The clean development mechanism: History, status, and prospects". Review of Environmental Economics and Policy 1 (1), 134-151.

Lefley, F. (1996). "The payback method of investment appraisal: A review and synthesis". Journal of Production Economics 44, 207-224.

Linn, J. (2008). "Energy prices and the adoption of energy-saving technology". Economic Journal 118 (533), $1986-2012$.

Loschel, A. (2002). "Technological change in economic models of environmental policy: A survey". Ecological Economics 43 (2-3), 105-126.

Lovely, M., Popp, D. (2008). Trade, Technology and the Environment: Why Do Poorer Countries Regulate Sooner? NBER, Cambridge, MA, Working Paper No. 14286.

Lucas, R. (1976). "Econometric policy evaluation: A critique”. Carnegie-Rochester Conference Series on Public Policy 1, $19-46$.

Lucas, R. (1988). "On the mechanics of economic development”. Journal of Monetary Economics 100, $223-251$.

MacCracken, C., Edmonds, J., Kim, S., Sands, R. (1999). “The economics of the Kyoto Protocol”. The Energy Journal 25-72 (special issue).

Magat, W.A. (1978). "Pollution control and technological advance: A dynamic model of the firm". Journal of Environmental Economics and Management 5, 1-25.

Magat, W.A. (1979). "The effects of environmental regulation on innovation". Law and Contemporary Problems 43, 3-25.

Mäler, K., Vincent, J., Arrow, K.J., Intriligator, M.D. (Eds.), (2005). Handbook of Environmental Economics: Valuing Environmental Changes. Elsevier, North-Holland, Amsterdam.

Maloney, M.T., Brady, G.L. (1988). "Capital turnover and marketable Pollution rights”. Journal of Law and Economics 31, 203-226.

Manne, A., Richels, R. (2004). "The impact of learning-by-doing on the timing and costs of $\mathrm{CO}_{2}$ abatement". Energy Economics 26, 603-619.

Mansfield, E. (1968). Industrial Research and Technological Innovation. Norton, New York.

Mansfield, E. (1977). "Social and private rates of return from industrial innovations". Quarterly Journal of Economics 91, 221-240.

Mansfield, E. (1996). Estimating Social and Private Returns from Innovations Based on the Advanced Technology Program: Problems and Opportunities. National Institute of Standards and Technology, Gaithersburg, MD, NIST GCR 99-780.

Marin, A. (1991). "Firm incentives to promote technological change in pollution control: Comment". Journal of Environmental Economics and Management 21, 297-300.

McCubbins, M.D., Noll, R.G., Weingast, B.R. (1989). "Structure and process, politics and policy: Administrative arrangements and the political control of agencies". Virginia Law Review 75, 431-482.

McDonald, A., Schrattenholzer, L. (2000). "Learning rates for energy technologies". Energy Policy 29, $255-261$.

Medhi, N. (2008). "Regulatory Matters: What Factors Matter in Regulating the Environment?” Working Paper, Syracuse University.

Metcalf, G.E., Hassett, K.A. (1999). "Measuring the energy savings from home improvement investments: Evidence from monthly billing data". The Review of Economics and Statistics 81, 516-528.

Milliman, S.R., Prince, R. (1989). "Firm incentives to promote technological change in pollution control". Journal of Environmental Economics and Management 17, 247-265.

Milliman, S.R., Prince, R. (1992). "Firm incentives to promote technological change in pollution control: Reply". Journal of Environmental Economics and Management 22, 292-296.

Montero, J.P. (2002). "Market structure and environmental innovation,”. Journal of Applied Economics 5 (2), $293-325$.

Montgomery, W.D., Smith, A.E. (2007). "Price, quantity and technology strategies for climate change policy". Human-Induced Climate Change: An Interdisciplinary Assessment. Cambridge University Press, Cambridge.

Mountain, D.C., Stipdonk, B.P., Warren, C.J. (1989). "Technological innovation and a changing energy mix-A parametric and flexible approach to modeling Ontario manufacturing". The Energy Journal 10, 139-158.

Mulder, P., de Groot, H.L.F., Hofkes, M.W. (2003). "Explaining slow diffusion of energy-saving technologies; a vintage model with returns to diversity and learning-by-using". Resource and Energy Economics 25 (1), 105-126.

National Research Council. (2001). Energy Research at DOE: Was it Worth It? National Academy Press, Washington, DC.

National Science Board. (2006). Science and Engineering Indicators 2006. National Science Foundation, Arlington, VA Chapter 4: Research and Development: Funds and Technology Linkages. 
Nelson, R., Tietenberg, T., Donihue, M. (1993). "Differential environmental regulation: Effects on electric utility capital turnover and emissions". Review of Economics and Statistics 75, 368-373.

Nemet, G.F. (2006). "Beyond the learning curve: Factors influencing cost reductions in photovoltaics". Energy Policy 34 (17), 3218-3232.

Newell, R.G. (2008a). A U.S. Innovation Strategy for Climate Change Mitigation. Brookings Institution, Washington, DC Hamilton Project Discussion Paper 2008-15.

"International climate technology strategies". Discussion Paper 08-12, Harvard Project on International Climate Agreements, Cambridge, MA.

Newell, R., Jaffe, A., Stavins, R. (1999). "The induced innovation hypothesis and energy-saving technological change". The Quarterly Journal of Economics 114 (3), 941-975.

Newell, R.G., Jaffe, A.B., Stavins, R.N. (2004). “The economics of energy efficiency”. In: Cleveland, C. (Ed.), Encyclopedia of Energy, vol. 2. Elsevier, Amsterdam, pp. 79-90.

Nijkamp, P., Rodenburg, C.A., Verhoef, E.T. (2001). "The adoption and diffusion of environmentally friendly technologies among firms". International Journal of Environmental Technology and Management 1 (1/2), 87-103.

Nordhaus, W.D. (1994). Managing the Global Commons: The Economics of Climate Change. MIT Press, Cambridge, MA.

Nordhaus, W.D. (2002). "Modeling induced innovation in climate change policy". In: Grubler, A., Nakicenovic, N., Nordhaus, W. (Eds.), Technological Change and the Environment. Resources for the Future Press, Washington, DC.

Nordhaus, W.D., Yang, Z. (1996). "A regional dynamic general-equilibrium model of alternative climate-change strategies". American Economic Review 86 (4), 741-765.

Organisation of Economic Co-operation and Development (OECD). (2008). Main Science and Technology Indicators, Volume 2008/1. OECD, Paris.

Pakes, A. (1985). "On patents, R\&D, and the stock market rate of return". Journal of Political Economy 93 (2), $390-409$.

Pakes, A., Berry, S., Levinsohn, J.A. (1993). "Applications and limitations of some recent advances in empirical industrial organization: Prices indexes and the analysis of environmental change”. American Economic Review 83, 240-246.

Parry, I.W.H. (1998). "Pollution regulation and the efficiency gains from technological innovation". Journal of Regulatory Economics 14, 229-254.

Pegram, W.M. (1991). “The photovoltaics commercialization program”. In: Cohen, L., Noll, R. (Eds.), The Technology Pork Barrel. Brookings Institution, Washington, DC.

Pindyck, R. (1991). "Irreversibility, uncertainty, and investment". Journal of Economic Literature 29, 1110-1152.

Pizer, W.A., Harrington, W., Kopp, R.J., Morgenstern, R.D., Shih, J. (2001). Technology Adoption and Aggregate Energy Efficiency. Resources for the Future, Washington, DC Discussion Paper 01-21.

Popp, D. (2001). "The effect of new technology on energy consumption”. Resource and Energy Economics 23 (3), $215-239$.

Popp, D. (2002). "Induced innovation and energy prices". American Economic Review 92 (1), 160-180.

Popp, D. (2003). "Pollution control innovations and the clean air act of 1990". Journal of Policy Analysis and Management 22, 641-660.

Popp, D. (2004). "ENTICE: Endogenous technological change in the DICE model of global warming”. Journal of Environmental Economics and Management 48, 742-768.

Popp, D. (2006a). "R\&D subsidies and climate policy: Is there a 'free lunch'?” Climatic Change 77 (3-4), 311-341.

Popp, D. (2006b). "International innovation and diffusion of air pollution control technologies: The effects of $\mathrm{NO}_{X}$ and $\mathrm{SO}_{2}$ regulation in the U.S., Japan, and Germany". Journal of Environmental Economics and Management 51 (1), 46-71.

Popp, D. (2006c). "They don't invent them like they used to: An examination of energy patent citations over time". Economics of Innovation and New Technology 15 (8), 753-776.

Popp, D. (2006d). Exploring the Links Between Innovation and Diffusion: Adoption of $\mathrm{NO}_{X}$ Control Technologies at U.S. CoalFired Power Plants. NBER, Cambridge, MA Working Paper No. 12119, forthcoming in Environmental and Resource Economics.

Popp, D., Hafner, T., Johnstone, N. (2008). Policy vs. Consumer Pressure: Innovation and Diffusion of Alternative Bleaching Technologies in the Pulp Industry. NBER, Cambridge, MA Working Paper No. 13439.

Purvis, A., Outlaw, J. (1995). "What we know about technological innovation to achieve environmental compliance: Policy issues for an industrializing animal agriculture sector". American Journal of Agricultural Economics 77, 1237-1243.

Rapping, L. (1965). "Learning and World War II production functions". Review of Economics and Statistics 47 (1), 81-86. 
Reppelin-Hill, V. (1999). "Trade and environment: An empirical analysis of the technology effect in the steel industry". Journal of Environmental Economics and Management 38, 283-301.

Requate, T. (1998). "Incentives to innovate under emission taxes and tradeable permits". European Journal of Political Economy 14, 139-165.

Requate, T. (2005). "Timing and commitment of environmental policy, adoption of new technology, and repercussions on R\&D”. Environmental and Resource Economics 31, 175-199.

Romer, P. (1990). "Endogenous technological change”. Journal of Political Economy 98 (5), S71-S102.

Rose, N., Joskow, P. (1990). "The diffusion of new technologies: Evidence from the electric utility industry". Rand Journal of Economics 21, 354-373.

Rosenberg, N. (1982). Inside the Black Box: Technology and Economics. Cambridge University Press, Cambridge, UK.

Rosendahl, K.E. (2004). "Cost-effective environmental policy: Implications of induced technological change". Journal of Environmental Economics and Management 48 (3), 1099-1121.

Ross, M. (1990). "Capital budgeting practices of twelve large manufacturers". In: Cooley, P. (Ed.), Advances in Business Financial Management. Dryden Press, Chicago, pp. 157-170.

Ruderman, H., Levine, M.D., McMahon, J.E. (1987). "The behavior of the market for energy efficiency in residential appliances including heating and cooling equipment". The Energy Journal 8, 101-123.

Sanstad, A., Blumstein, C., Stoft, S. (1995). "How high are option values in energy-efficiency investments". Energy Policy 23, 739-743.

Sanyal, P. (2007). "The effect of deregulation on environmental research by electric utilities". Journal of Regulatory Economics $31,335-353$.

Scherer, F., Harhoff, D., Kukies, J. (2000). "Uncertainty and the size distribution of rewards from technological innovation". Journal of Evolutionary Economics 10, 175-200.

Schneider, S., Goulder, L. (1997). "Commentary: Achieving low-cost emissions targets". Nature 389, 13-14 (September).

Schwoon, M., Tol, R. (2006). "Optimal $\mathrm{CO}_{2}$-abatement with socio-economic inertia and induced technological change". The Energy Journal 27 (4), 25-59.

Shama, A. (1983). "Energy conservation in U.S. buildings, solving the high potential/low adoption paradox from a behavioral perspective". Energy Policy 11, 148-168.

Smulders, S. (2005). "Endogenous technological change, natural resources, and growth". In: Simpson, R.D., Toman, M.A., Ayres, R.U. (Eds.), Scarcity and Growth Revisited. Resources for the Future, Washington, DC.

Smulders, S., de Nooij, M. (2003). "The impact of energy conservation on technology and economic growth". Resource and Energy Economics 25 (1), 59-79.

Snyder, L.D., Miller, N.H., Stavins, R.N. (2003). "The effects of environmental regulation on technology diffusion: The case of chlorine manufacturing". American Economic Review 93 (2), 431-435.

Söderholm, P., Klaassen, G. (2007). "Wind power in Europe: A simultaneous innovation-diffusion model”. Environmental and Resource Economics 36, 163-190.

Söderholm, P., Sundqvist, T. (2007). "Empirical challenges in the use of learning curves for assessing the economic prospects of renewable energy technologies". Renewable Energy 32, 2559-2578.

Sterner, T. (1990). "Energy efficiency and capital embodied technical change: The case of Mexican cement manufacturing". The Energy Journal 11, 155-167.

Stewart, R.B. (1981). "Regulation, innovation, and administrative law: A conceptual framework". California Law Review 69, 1256-1270.

Stoneman, P., Battisti, G. (2010). "Modeling diffusion”. In: Hall, B.H., Rosenberg, N. (Eds.), Handbook of Economics of Technological Change. (this volume).

Sue Wing, I. (2003). Induced Technical Change and the Cost of Climate Policy. Massachusetts Institute of Technology, Cambridge, MA Joint Program on the Science and Policy of Global Change Report no. 112.

Sue Wing, I. (2006). Induced Technological Change: Firm Innovatory Responses to Environmental Regulation. Boston University, Boston, MA, Working Paper.

Sue Wing, I. (2008). "Explaining the declining energy intensity of the U.S. economy”. Resource and Energy Economics 30 (1), 21-49.

Taylor, M.R. (2008). Cap-and-Trade Programs and Innovation for Climate Safety. University of California, Berkeley, CA, Working Paper. 
Taylor, M.R., Rubin, E.S., Hounshell, D.H. (2003). "Effect of government actions on technological innovation for $\mathrm{SO}_{2}$ control". Environmental Science and Technology 37, 4527-4534.

Thirtle, C.G., Ruttan, V.W. (1987). "The role of demand and supply in the generation and diffusion of technical change". Fundamentals of Pure and Applied Economics. vol 21. Harwood Academic Publishers, New York.

Ulph, D. (1998). "Environmental policy and technological innovation”. In: Carraro, C., Siniscalaco, D. (Eds.), Frontiers of Environmental Economics. Edward Elgar, Cheltenhsam.

van Zon, A., Yetkiner, I.H. (2003). “An endogenous growth model with embodied energy-saving technical change". Resource and Energy Economics 25 (1), 81-103.

Van der Zwaan, B.C.C., Gerlagh, R., Klaassen, G., Schrattenholzer, L. (2002). "Endogenous technological change in climate change modelling". Energy Economics 24, 1-19.

Vollebergh, H. (2007). "Differential Impact of Environmental Policy Instruments on Technological Change: A Review of the Empirical Literature". Tinbergen Institute Discussion Paper TI 2007-042/3.

Weitzman, M.L. (1974). "Prices vs. quantities". Review of Economic Studies 41, 477-491.

Wolfram, C., Bushnell, J.B. (2008). Enforcement of Vintage Differentiated Regulations: The Case of New Source Review. University of California, California Working Paper.

Wolff, G.B. (2008). "The effectiveness of subsidies revisited: Accounting for wage and employment effects in business R\&D". Research Policy 37, 1403-1412.

Wright, T.P. (1936). "Factors affecting the costs of airplanes". Journal of Aeronautical Sciences 3, 122-128.

Zerbe, R.O. (1970). "Theoretical efficiency in pollution control”. Western Economic Journal 8, 364-376. 